\title{
Pretreating Underutilized Woody Biomass for Value-Added Biofuels and Bioproducts
}

Amy K. Falcon

Follow this and additional works at: https://researchrepository.wvu.edu/etd

\section{Recommended Citation}

Falcon, Amy K., "Pretreating Underutilized Woody Biomass for Value-Added Biofuels and Bioproducts" (2016). Graduate Theses, Dissertations, and Problem Reports. 5566.

https://researchrepository.wvu.edu/etd/5566

This Dissertation is protected by copyright and/or related rights. It has been brought to you by the The Research Repository @ WVU with permission from the rights-holder(s). You are free to use this Dissertation in any way that is permitted by the copyright and related rights legislation that applies to your use. For other uses you must obtain permission from the rights-holder(s) directly, unless additional rights are indicated by a Creative Commons license in the record and/ or on the work itself. This Dissertation has been accepted for inclusion in WVU Graduate Theses, Dissertations, and Problem Reports collection by an authorized administrator of The Research Repository @ WVU.

For more information, please contact researchrepository@mail.wvu.edu. 


\title{
Pretreating Underutilized Woody Biomass for Value-Added Biofuels and Bioproducts
}

\author{
Amy K. Falcon \\ Dissertation submitted \\ to the Davis College of Agriculture, Natural Resources and Design \\ at West Virginia University \\ in partial fulfillment of the requirements for the degree of \\ Doctor of Philosophy in \\ Forest Resources Science
}

\author{
Jingxin Wang, Ph.D., Chair \\ Benjamin Dawson-Andoh, Ph.D. \\ David DeVallance, Ph.D. \\ Ping Wang, Ph.D. \\ Xinfeng Xie, Ph.D. \\ John Zondlo, Ph.D.
}

Division of Forestry and Natural Resources

\author{
Morgantown, West Virginia \\ 2016
}

Keywords: pretreatment, urea concentration, sugar extraction, biochemical Copyright 2016 Amy Falcon 


\begin{abstract}
Pretreating Underutilized Woody Biomass for Value-Added

\author{
Biofuels and Bioproducts
}

\author{
Amy K. Falcon
}

Biomass pretreatment is a key techno-economic factor affecting the yield and economics of bioenergy or bioproduct production. The cost of pretreatment significantly increases if the sugars cannot be efficiently recovered once they are removed from the complex wood structure. Separation of the liquid extract from the solid particulates is important, especially in cellulose and hemicellulose recovery. A urea pretreatment of woody biomass was studied in this paper due to the ability of urea to decompose into ammonia molecules and carbon dioxide. Glucose separation from woody biomass was analyzed as an indication of pretreatment efficiency using three separation techniques: Whatman 113 filter paper, centrifugation, and a stainless steel mesh screen. The solid residues consist mainly of decrystallized cellulose, hemicellulose and lignin. The liquid extract, however, contains partial carbohydrate removal, thus inefficient separation techniques could potentially result in the loss of these soluble sugars. The stainless steel mesh screen provided the most reproducible method of sugar recovery, measurable in grams of glucose per gram of biomass $(\mathrm{g} / \mathrm{g})$, measuring $0.624 \mathrm{~g} / \mathrm{g} \pm 0.015$ on average for the solid residue. The filter paper was capable of recovering $0.710 \mathrm{~g} / \mathrm{g} \pm 0.017$, and the centrifuge recovered $0.820 \mathrm{~g} / \mathrm{g}$ \pm 0.055 . Filter paper and stainless steel mesh screen filtration methods are not significantly different from each other at low urea concentrations. Centrifugation has the largest variation in its ability to efficiently recover sugars.

Among many characteristics, an effective pretreatment of woody biomass should be able to consistently overcome the lignocellulosic recalcitrance, produce high yields of sugars, and be cost effective. To this end, urea is a promising additive to a hot water extraction of woody biomass because when one molecule of urea is hydrolyzed, two molecules of ammonia are produced. This characteristic, when applied in a hot water treatment of woody biomass, can react with lignin and decrystallize cellulose. Pretreated red oak biomass was tested and analyzed for sugar content according to the National Renewable Energy Laboratory (NREL) Analytical Procedures to determine the structural carbohydrates and lignin. Glucose is used as an indicator for total sugar content, and response surface modelling was employed to optimize the urea 
concentration for maximum sugar yield with consideration of temperature, holding time, and urea concentration. It was found that temperature and holding time were insignificant in the recovery of glucose, and urea concentration was the major significant factor in maximizing the quantity of glucose recovered. Of the factors analyzed, the optimal extraction factors were determined to be: temperature at $170^{\circ} \mathrm{C}$, holding time of 60 minutes, and a urea concentration ranging between $12 \%-15 \%(\mathrm{w} / \mathrm{w})$. These conditions produced a maximum glucose yield of 1.05 grams glucose per gram biomass.

Hybrid willow is a short rotation wood crop (SWRC) that can be used for the extraction of sugars for biofuels or bioproducts. In the extraction of sugars from the woody biomass feedstock, the pretreatment process is the most critical and costly step. Chemical pretreatments can partially destroy this recalcitrance of biomass and make it accessible for further conversion agents. A 2 x 4 factorial design was applied to analyze the use of urea as a chemical additive to a hot-water extraction process for the recovery of glucose from two cultivars of hybrid shrub willow: Belleville SV1 and Belleville Owasco. A reaction temperature of $170^{\circ} \mathrm{C}$ with a holding time of 60 minutes and varying urea concentration level were employed. A urea concentration of $13.27 \%$ produced the 0.37 grams of glucose per gram of biomass, recovered from hybrid shrub willow cultivar SV1 while 0.41 grams glucose per gram biomass were recovered from cultivar Owasco. There was no significant difference in the quantity of total lignin determined in cultivars SV1 (37.9\%) and Owasco (44.7\%).

Densified biomass, such as pellets, could be an ideal feedstock for the production of biofuels and bioproducts due to their advantages of long-term storage, resistance to degradation, and transportation. This study compared and tested whether pelletized biomass could produce the same quantity and quality of sugars as non-pelletized biomass using two cultivars of hybrid willow biomass: Belleville SV1 and Belleville Owasco. Biomass was pretreated with hot water and urea, filtered, and a Nelson-Somogyi assay was used to determine the reducing sugar content of the liquid fraction of the biomass as an indication of total sugar content. The National Renewable Energy Laboratory, Laboratory Analytical Procedure (LAP) for the determination of structural carbohydrates and lignin was performed on the solid fraction, and the extracted sugars were quantified. The results of this study showed that no significant difference in the sugar yield existed between pelletized and non-pelletized biomass for cultivar SV1. However, there was a significant difference in the quantity of glucose extracted based on cultivar, regardless of pelletization. Pelleted cultivar SV1 yielded the greatest quantity of glucose, measurable in grams of glucose per gram of biomass $(\mathrm{g} / \mathrm{g})$, at $0.49 \mathrm{~g} / \mathrm{g}$, while pelleted cultivar Owasco contained 0.16 g/g. Non-pelleted SV1 contained $0.48 \mathrm{~g} / \mathrm{g}$, while non-pelleted Owasco contained $0.38 \mathrm{~g} / \mathrm{g}$. 


\section{Acknowledgements}

I would first like to thank my major professor Dr. Jingxin Wang for providing me with this opportunity and the guidance he provided throughout my time at West Virginia University. Second, I would like to thank the Bowbly family for providing a portion of my funding throughout my research. I would also like to thank my committee members: Dr. Ben DawsonAndoh, Dr. David DeVallance, Dr. Ping Wang, Dr. Xinfeng Xie, and Dr. John Zondlo for their time, comments and advice.

Additionally, I would like to thank my family, friends, and colleagues for the support that they have given. Especially my husband, Zeke, for putting up with my stress and moods when self-imposed deadlines started looming, and his constant support. 


\section{Table of Contents}

List of Tables ............................................................................................................ vii

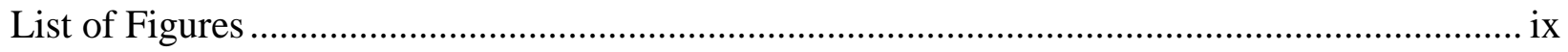

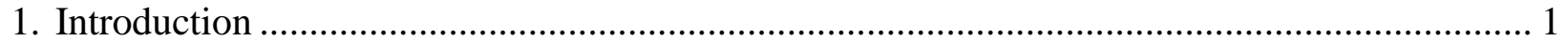

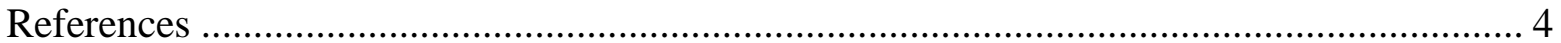

2. Analysis of Separation Techniques on Urea Pretreated Woody Biomass for Biofuels and

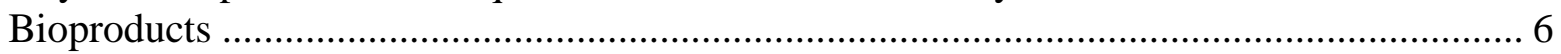

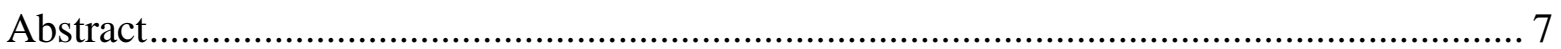

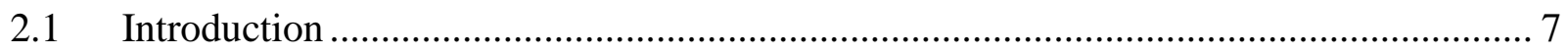

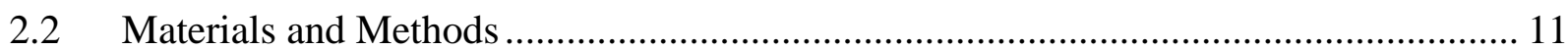

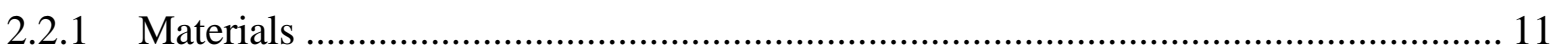

2.2.2 Experimental Design and Analysis .................................................................... 12

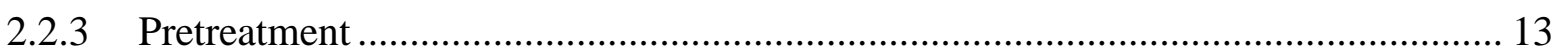

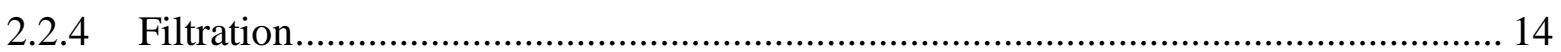

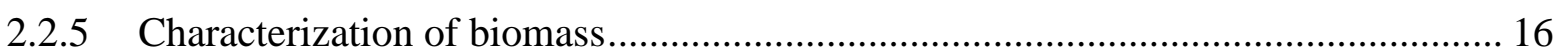

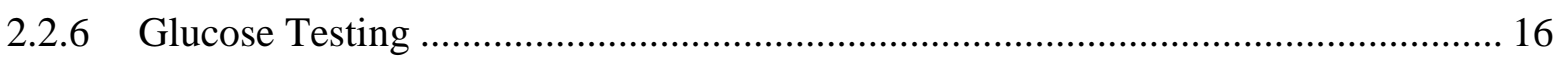

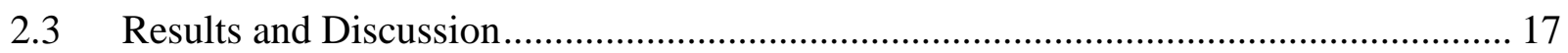

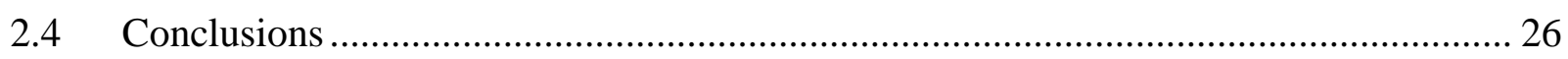

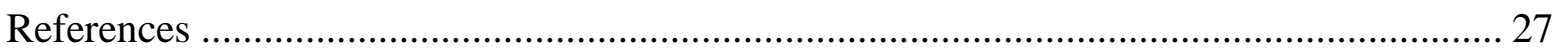

3. Analysis of Urea as an Additive to the Hot-Water Extraction of Red Oak Biomass ................ 30

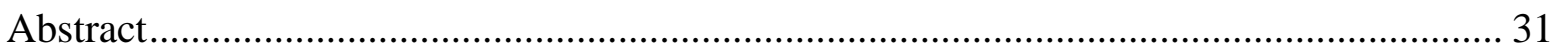

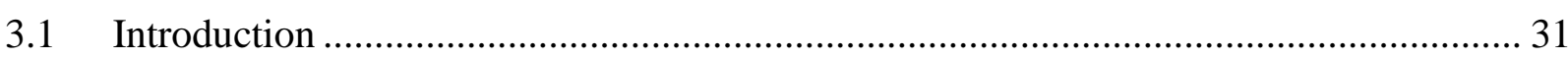

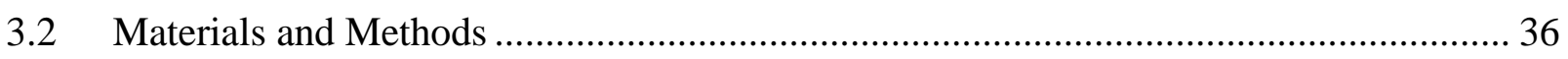

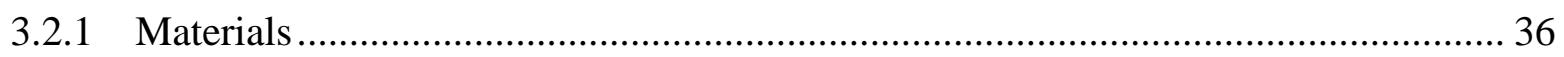

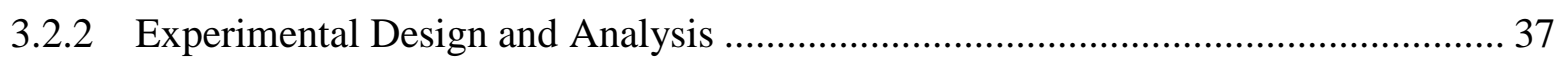

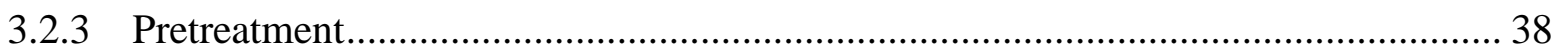

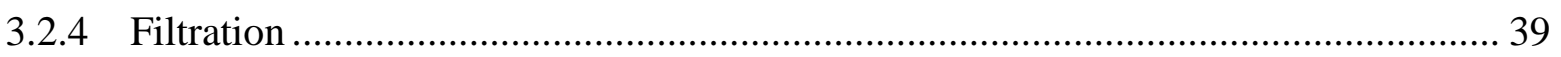

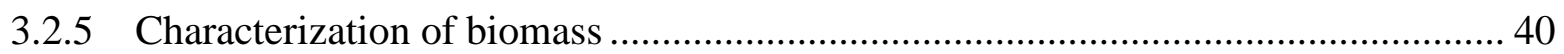

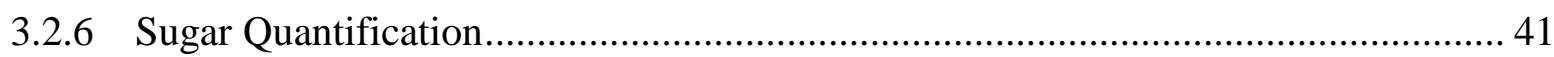

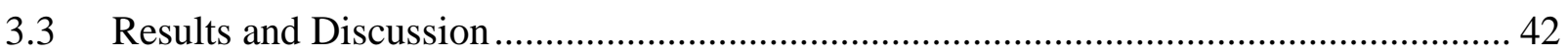

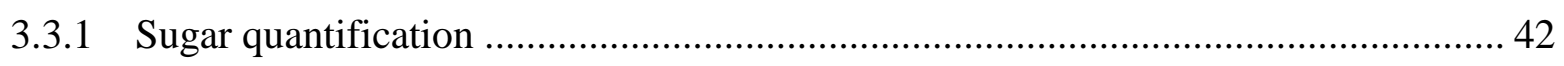

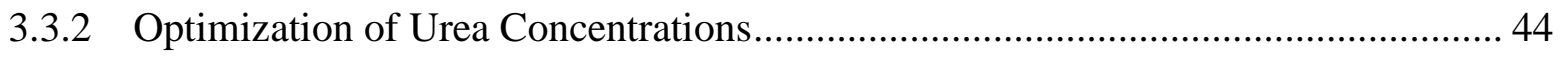

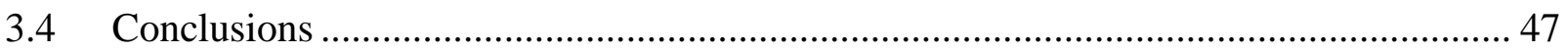

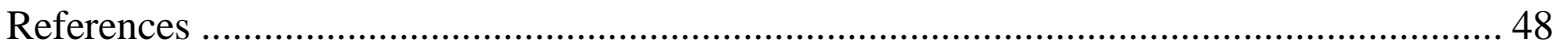


4. Urea Catalyzed Hot-Water Pretreatment of Hybrid Willow Biomass ....................................... 51

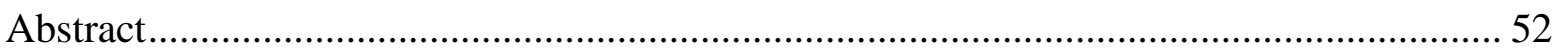

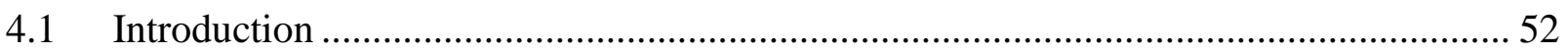

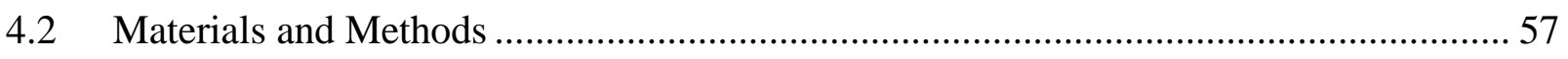

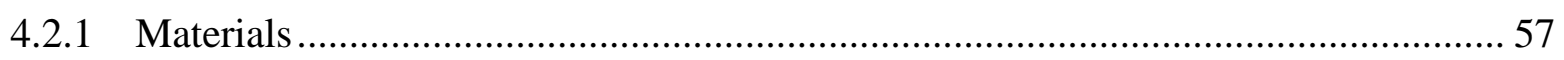

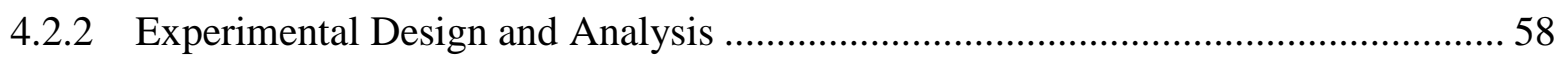

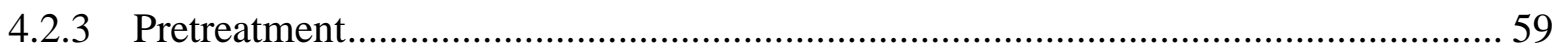

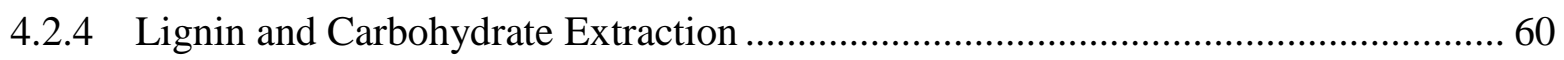

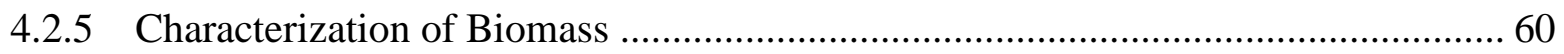

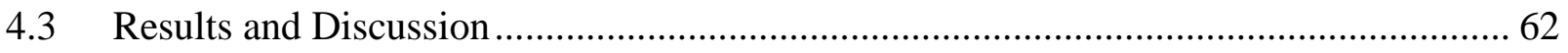

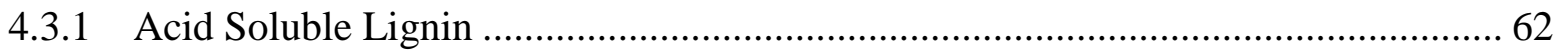

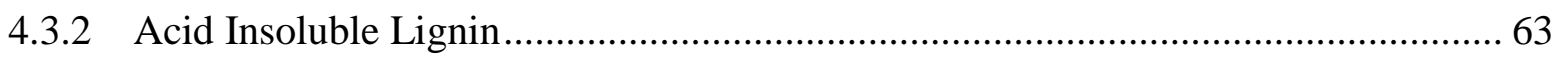

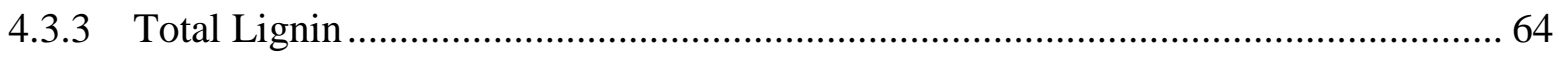

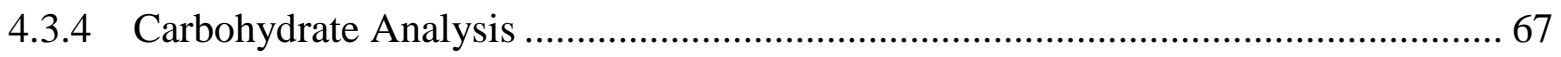

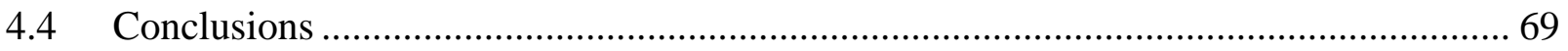

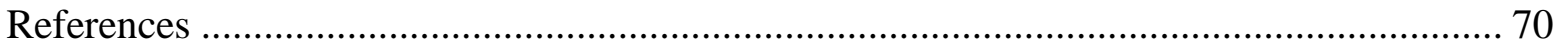

5. A Comparative Analysis of Pelletization Effects on Lignocellulosic Sugar Extraction from

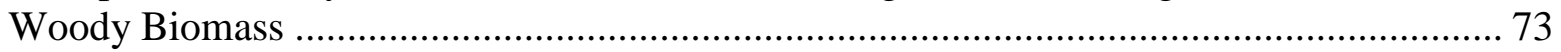

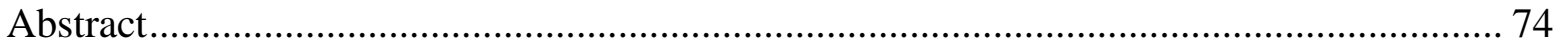

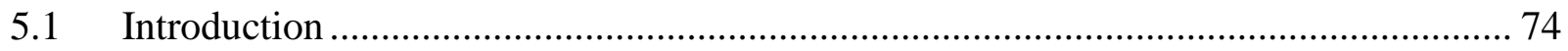

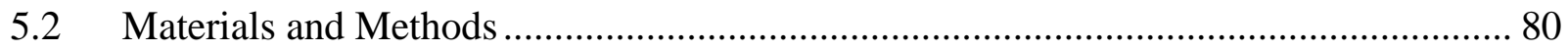

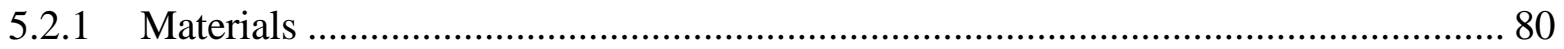

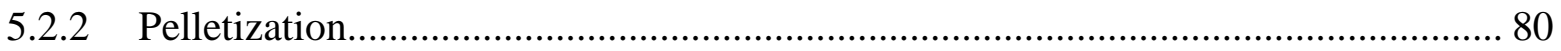

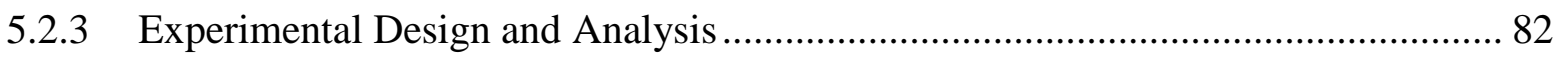

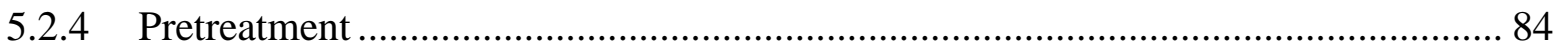

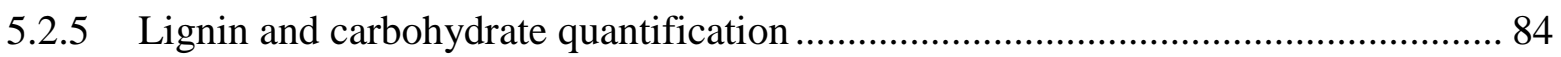

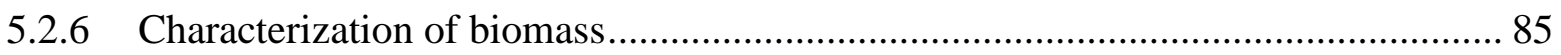

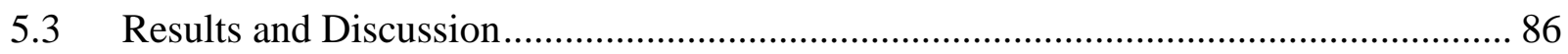

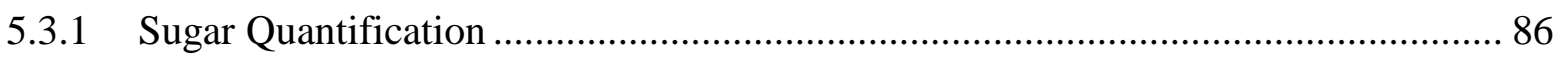

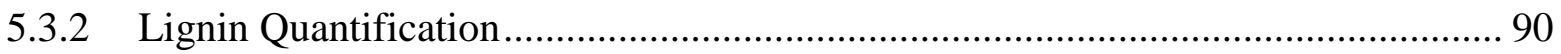

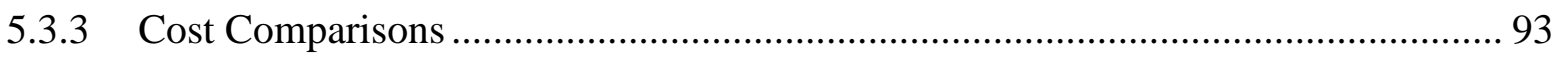

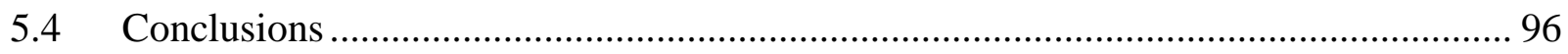

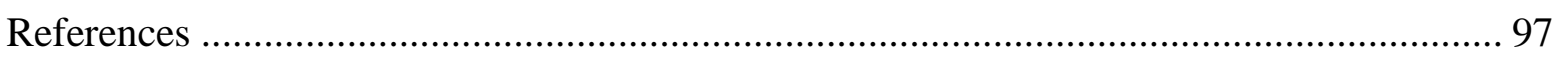

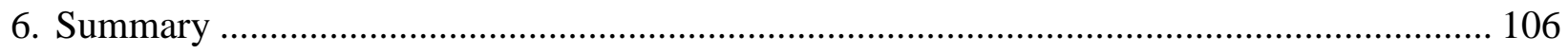




\section{LIST OF TABLES}

Table 2.1. Testing conditions for $3 \times 3$ factorial design. 13

Table 2.2. Glucose concentrations \pm standard deviation following a DNS assay. Calculated from equation 2.2 .......

Table 2.3. Elemental analysis (carbon, hydrogen, nitrogen, and sulfur content) of urea pretreated red oak biomass.

Table 2.4. Proximate analysis (moisture, ash, volatile, and fixed carbon (\% d.b.) of urea pretreated red oak biomass.

Table 2.5. Sugar concentrations (grams of sugar per gram of biomass) extracted from red oak biomass, determined by HPLC performed by the Forest Products Laboratory in Madison, WI. Sugars were extracted using the NREL procedure for the determination of structural carbohydrates and lignin. Sample key: $\mathrm{C}=$ centrifuge, $\mathrm{FP}=$ filter paper, $\mathrm{MS}=$ stainless steel mesh screen; and urea concentration $0 \%, 10 \%, 20 \%$. 24

Table 3.1. Comparison of major pretreatment methods. 34

Table 3.2. Initial pretreatment conditions.

Table 3.3. Proximate analysis (moisture, ash, volatile, and fixed carbon (\% d.b.) of urea pretreated red oak biomass (mean \pm standard deviation)...... 40

Table 3.4. Elemental analysis (carbon, hydrogen, nitrogen, and sulfur content) of red oak biomass (mean \pm standard deviation).

Table 3.5. Glucose concentrations (grams of glucose per gram of wood) of initial testing conditions (mean \pm standard deviation).

Table 3.6. Amount of recovered glucose (gram glucose per gram biomass) based on urea concentration (mean \pm standard deviation).

Table 4.1. Testing conditions for shrub willow hybrids. 58 
Table 4.2. Approximate percent concentrations of cellulose, hemicellulose, and lignin of hybrid willow cultivars SV1 and Owasco (Serapiglia et al., 2013). Numbers in parentheses are the least significant differences from Tukey's studentized range test (Serapiglia et al., 2013) ... 61

Table 4.3. Proximate analysis (moisture, ash, volatile, and fixed carbon (\% d.b.) of urea pretreated red oak biomass

Table 4.4. Percent acid soluble lignin (ASL) in willow biomass at varying urea extraction concentrations (mean \pm standard deviation).

Table 4.5. Percent acid insoluble lignin (AIL) in willow biomass at varying urea concentrations.

Table 4.6. Total lignin (\%) found in willow biomass at varying urea concentrations 65

Table 4.7. Sugar concentrations (g sugar/g biomass) determined by HPLC. Sugars separated using "Determination of Structural Carbohydrates and Lignin" procedure, and converted from $\mathrm{mg} / \mathrm{L}$ to gram sugar/gram biomass

Table 5.1. Production parameters to make pellets for the extraction of sugars. 81

Table 5.2. Urea concentration for willow cultivars. 83

Table 5.3. Proximate analysis (moisture, ash, volatile, and fixed carbon (\% d.b.) of urea pretreated hybrid willow biomass, both pelleted and non-pelleted. 86

Table 5.4. HPLC analysis of sugars performed by Penn State University. Values obtained were reported in $\mathrm{mg} / \mathrm{L}$ and converted to grams sugar per gram biomass using equations found in NREL-LAP (Sluiter et al., 2012).

Table 5.5. Means and significance levels of percent acid soluble lignin (ASL) and acid insoluble lignin (AIL) between pelletized and non-pelletized hybrid willow cultivars by urea concentrations. 91

Table 5.6. Cost comparisons of wood pellets and willow wood chips in terms of major logistical processes. A transportation distance of 50 miles is assumed. 95 


\section{LIST OF FigURES}

Figure 2.1 Experimental results from Sahu et al. study on urea to ammonia conversion: (a) Effect of temperature on conversion at different initial urea concentrations (b) Effect of urea concentration on conversion at different temperatures 10

Figure 2.2. Glucose standard curve in grams per liter. Equivalent to 0, 5, 10, 15, 20, 30 percent glucose concentrations.

Figure 2.3 Major sugar concentrations: (a) glucose, (b) xylose, (c) mannose; represented as a percentage of total sugars $(\mathrm{CHO})$ available, based on filtration method and urea concentration. Data labels indicate percent at each urea level.

Figure 3.1. Glucose Standard Curve, representing percent glucose concentrations vs absorbance recorded at $540 \mathrm{~nm}$. 43

Figure 3.2. Plot of the theoretical glucose concentration vs. urea concentration, as determined by Equation 3.5.

Figure 4.1. Total lignin available in cultivars of shrub willow according to urea pretreatment concentrations.

Figure 5.1. Diagram of a flat die for a pellet mill with top and side views. Die hole and length labelled for the press ratio.

Figure 5.2. Glucose concentrations (g/g) recovered from willow biomass, based on urea concentration, cultivar, and material type (mean \pm standard deviation)

Figure 5.3. Total lignin as a composite of acid insoluble lignin (AIL) and acid soluble lignin (ASL) by species (Owasco, SV1), treatment (pellet, ground) and urea concentration $(0 \%$, $13.27 \%, 15 \%)$. 


\section{INTRODUCTION}

There is a growing demand in the U.S. for bioenergy to reduce the nation's dependency on fossil fuels. Currently, a total of 4.31 quadrillion BTU's of energy from biomass alone were consumed in 2014 by the United States, with 1.988 quadrillion BTU's of that total coming from wood and wood derived fuels alone (EIA, 2015). Of that original 4.31 quadrillion BTU's, 1.935 quadrillion BTU's are made into biofuels including ethanol and biodiesel (EIA, 2015). In order for a material, such as the low value hardwood biomass, to be viable as a substitute for a fossil fuel, the alternative fuel should have environmental benefits over the fossil fuel it displaces. The alternative fuel should also be economically competitive, and be producible in sufficient quantities to have a meaningful impact on energy demand (Hill et al., 2006). Biomass is unique because it provides the only renewable source of fixed carbon, and is considered the renewable energy source with the highest potential to contribute to the energy needs of modern society (Bridgwater, 2006). Biomass is also considered carbon neutral, thus fixing as much carbon as it releases into the environment. The Energy Independence and Security Act in 2007 mandated that 36 billion gallons of renewable fuel must be produced by 2022. Of that 36 billion gallons, 21 billion gallons are required from cellulosic ethanol and other advanced biofuels (Sissine, 2007). With the demand for alternative fuels increasing to an estimated 107 quadrillion Btu's with $14 \%$ coming from renewables, it is necessary to find a solution that will not take away from the food base necessary for human survival (EIA, 2012).

Before ethanol, biodiesel, or other biofuels can be made, there must be a steady supply of sugars available for conversion into these second generation biofuels. Chemically, woody biomass has a high lignin content as compared to conventional sources like agricultural biomass (Zhu and Pan, 2010), thus, more energy is required to overcome the recalcitrance of the woody 
biomass structure. The high lignin content increases the energy density of the material, and when combined with a greater quantity of 6-carbon sugars as opposed to 5-carbon sugars, provides strong advantages of using woody biomass for cellulosic ethanol production if the structure of the wood can be overcome (Zhu and Pan, 2010). To overcome the rigid structure of woody biomass, the most investigated pretreatment processes include dilute acid, steam explosion, and organosolv processes (Zhu et al., 2010).

The development of technologies for effectively converting the less costly forest residues to fermentable sugars offers outstanding potential to the national interest of the United States. Some of these benefits include: improved strategic security, decreased trade deficits, healthier rural economies, improved environmental quality, technology exports, and a sustainable energy resource supply (Zhang et al., 2006). Low quality hardwood material, such as logging residues and poorly formed trees, is an ideal candidate to be used for the extraction of sugars because it is plentiful and competitive markets have not been introduced for this material. This type of biomass is commonly left behind after a harvest, and the low quality hardwood residue is plentiful in the Appalachian region. These residues, such as slash or deformed pulpwood trees are normally abandoned as uneconomical to extract from the forest, but with new technologies being developed, loggers and foresters may see the benefits of removing this material from the forest.

Studies have been conducted on the separation of cellulose from woody biomass to produce ethanol, but have not been commercialized due to existing technical, economic and commercial barriers (Huang et al., 2008). There are currently three major pathways of extracting the cellulose, hemicellulose and lignin from woody biomass: chemical pretreatment, enzymatic hydrolysis and thermochemical conversion, but more efficient and cost effective methods of 
separating cellulose, hemicellulose, and lignin must be confirmed. Liquid hot water extraction can completely recover hemicellulose from hardwoods and herbaceous materials without significant degradation (Huang et al., 2008), but only dissolves about half of the total woody biomass (Kumar et al., 2009). Ammonia Fiber Explosion (AFEX) treatment also yields optimal hydrolysis rates for pretreated lignocellulosic materials with the ammonia reacting primarily with the lignin and the decrystallization of cellulose (Mosier et al., 2005), but the price of ammonia and ammonia recovery significantly increases the costs. The use of urea is an ideal substitute for the use of ammonia due to its stability and it is considered nontoxic. The extraction of sugars from woody biomass is desirable for the production of bioproducts, and the ability to use biomass from low value and underutilized timber stands could redefine the forest industry creating less waste as well as a higher utilization and product yield from harvested stands.

This dissertation is separated into four major papers, focused on a chemical pretreatment and was designed to address the following objectives: (1) Analyze the efficiency of filtration techniques on woody biomass pretreated with hot water and urea, (2) Evaluate the effects of temperature, holding time, and urea concentration on the extraction of sugars from red oak biomass (Quercus rubra) to produce ideal conditions for the maximization of sugar recovery, (3) Evaluate the ability to use a urea pretreatment on hybrid willow biomass (Salix spp.) for the recovery of glucose, and (4) Analyze the effects of pelletization on the extraction of lignocellulosic sugars in willow biomass. 


\section{REFERENCES}

Bridgwater T. 2006. Biomass for energy. Journal of the Science of Food and Agriculture $86: 1755-1768$.

EIA. 2012. Annual Energy Outlook 2012 with Projections to 2035. In: Catalogue No. DOE/EIA-0383ER Washington D.C.

EIA. 2015. February 2015 Monthly Energy Review. Washington, DC.

Hill J, Nelson E, Tilman D, Polasky S, Tiffany D. 2006. Environmental, economic, and energetic costs and benefits of biodiesel and ethanol biofuels. Proceedings of the National Academy of Sciences of the United States of America 103:11206-11210.

Huang H-J, Ramaswamy S, Tschirner UW, Ramarao BV. 2008. A review of separation technologies in current and future biorefineries. Separation and Purification Technology 62:1-21.

Kumar P, Barrett DM, Delwiche MJ, Stroeve P. 2009. Methods for Pretreatment of Lignocellulosic Biomass for Efficient Hydrolysis and Biofuel Production. Industrial \& Engineering Chemistry Research 48:3713-3729.

Mosier N, et al. 2005. Features of promising technologies for pretreatment of lignocellulosic biomass. Bioresource Technology 96:673-686.

Sissine F. 2007. Energy Independence and Security Act of 2007: a summary of major provisions: DTIC Document

Zhang Y-HP, Himmel ME, Mielenz JR. 2006. Outlook for cellulase improvement: screening and selection strategies. Biotechnology advances 24:452-481. 
Zhu JY, Pan X, Zalesny RS, Jr. 2010. Pretreatment of woody biomass for biofuel production: energy efficiency, technologies, and recalcitrance. Applied microbiology and biotechnology 87:847-857.

Zhu JY, Pan XJ. 2010. Woody biomass pretreatment for cellulosic ethanol production: Technology and energy consumption evaluation. Bioresource Technology 101:49925002. 


\section{ANALYSIS OF SEPARATION TECHNIQUES ON UREA \\ PreTreated WoOdy BIOMASS FOR BIOFUELS AND BIOPRODUCTS}




\section{AbSTRACT}

Biomass pretreatment is a key techno-economic factor affecting the yield and economics of bioenergy or bioproduct production. The cost of pretreatment significantly increases if the sugars cannot be efficiently recovered once they are removed from the complex wood structure. Separation of the liquid extract from the solid particulates is important, especially in cellulose and hemicellulose recovery. In this paper, a urea pretreatment of red oak biomass was studied due to the ability of urea to decompose into ammonia and carbon dioxide. Glucose separation from woody biomass was analyzed as an indication of pretreatment efficiency using three separation techniques: a) a vacuum method using Whatman 113 filter paper, b) a vacuum method using a stainless steel mesh screen, and c) centrifugation. The solid residues consist mainly of decrystallized cellulose, hemicellulose and lignin. The liquid extract, however, contains partial carbohydrate extraction from hemicellulose, thus inefficient separation techniques could potentially result in the loss of these soluble sugars. At the baseline urea concentration $(0 \%)$, glucose comprised $87 \%-90 \%$ of the total sugars, xylose was $8 \%-10 \%$, and mannose was $2 \%-3 \%$ of the total sugars. As the urea concentration increased, the glucose concentration decreased to $71 \%-72 \%$ of the total sugars found, while xylose increased to $24 \%$ of the total sugars, and mannose was consistent at 2\%-3\% of the total sugars available.

\subsection{INTRODUCTION}

Using biomass as a renewable energy source for the production of sugars for liquid fuels is a challenge due to its recalcitrant structure that resists efficient separation techniques. The optimum conditions required for pretreatment strictly depend on the characteristics of the raw material, as well as the final purpose of the process itself. Several pretreatments have been developed and are classified into different categories: physical, physicochemical, chemical, and 
biological (Galletti and Antonetti, 2012). An effective pretreatment should meet the following requirements: overcome lignocellulosic recalcitrance, afford high yields of sugars/chemicals, avoid sugar degradation, avoid formation of inhibitory byproducts, allow for lignin recovery and exploitation, and be cost effective (Alvira et al., 2010). Currently, several chemical pretreatment methods such as acid, alkali, organic solvent and ionic liquids have been reported to have significant effect on the structure of lignocellulosic biomass (Agbor et al., 2011). A pretreatment review by Kumar et al. (2009) described some promising cost-effective chemical pretreatment technologies for lignocellulosic biomass including dilute acid, hot water, and alkaline materials. Dilute acid pretreatment is one promising approach because of its lower costs and higher hemicellulose yields of up to 90\% (Mosier et al., 2005). Liquid hot water extraction can completely recover hemicellulose from hardwoods and herbaceous materials without significant degradation of xylose into various byproducts (Huang et al., 2008).

Ammonia Fiber Explosion (AFEX), an alkaline pretreatment, also yields optimal hydrolysis rates for pretreated lignocellulosic materials with the ammonia reacting primarily with the lignin and the decrystallization of cellulose (Mosier et al., 2005). Ammonia pretreatment of biomass in the Ammonia Fiber Explosion (AFEX) process aims to hydrolyze both cellulose and hemicellulose for enzymatic digestion, while ammonia in the Ammonia Recycle Percolation (ARP) process aims to depolymerize lignin and cleave lignin carbohydrate linkages. Additionally, ammonia pretreatments such as these, have not been shown to produce inhibitors in downstream biological processes (Kumar et al., 2009). Ammonia used in industrial and agricultural purposes is often delivered either in the form of anhydrous or aqueous ammonia. Both forms have been shown to be extremely hazardous, toxic, and volatile, and both can exhibit deadly characteristics in the case of a spill (Sahu et al., 2008). 
A urea-to-ammonia conversion is ideally suited to replace anhydrous or aqueous ammonia because the derived ammonia is stored in a non-toxic compound and presents little danger to its surroundings. The conversion of urea to ammonia occurs in two steps: ammonia hydrolyzes in water to form ammonium carbamate, which then further breaks down to ammonia and carbon dioxide. According to an equilibrium and kinetics study by Sahu et al. (2008), the decomposition of urea begins slowly around $110^{\circ} \mathrm{C}$ and, for a $10 \%$ urea solution, the conversion increases exponentially from $110^{\circ} \mathrm{C}$ to $180^{\circ} \mathrm{C}$ (Figure $2.1 \mathrm{a}$ ). The same trend occurs with $20 \%$ and $30 \%$ urea concentrations. Sahu's study determined that as the initial concentrations of urea increased from $10 \%$ to $30 \%$, the conversion of urea to ammonia decreases slightly; at $180^{\circ} \mathrm{C}$, the conversion of urea to ammonia decreased from $17.07 \%$ when $10 \%$ urea was used, while the conversion of $30 \%$ urea was only $9.58 \%$ (Figure $2.1 \mathrm{~b}$ ). 
a)

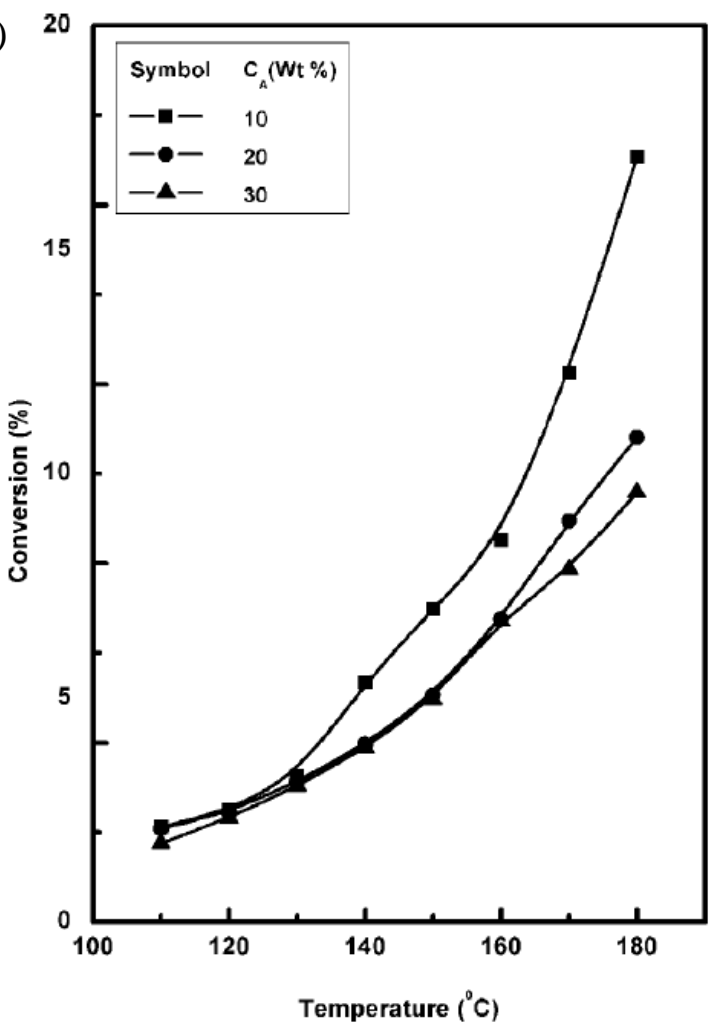

b)

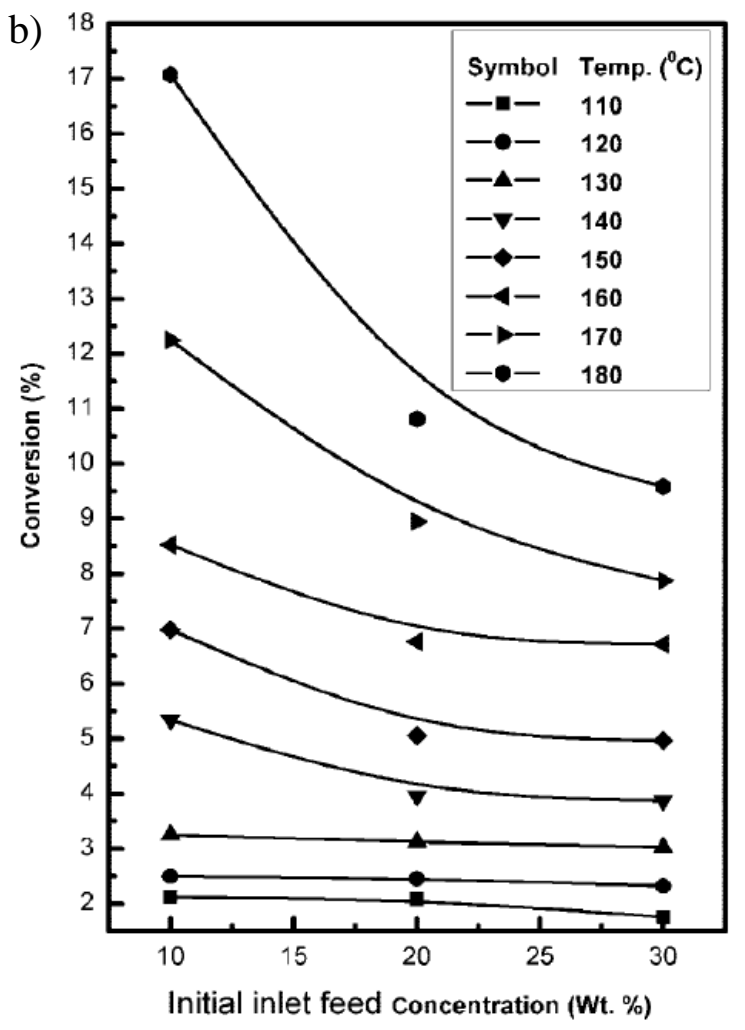

Figure 2.1 Experimental results from Sahu et al. study on urea to ammonia conversion: (a) Effect of temperature on conversion at different initial urea concentrations (b) Effect of urea concentration on conversion at different temperatures

The reason for the decrease in conversion is suggested to be that higher urea concentrations have less excess water to react with, thereby reducing the rate of reaction (Sahu et al., 2008). It was also found that the conversion of urea to ammonia increased with time, and the rate of the forward reaction behaves as a first order reaction with respect to urea (Sahu et al., 2008).

Studies have been conducted on the separation of cellulose from wood, but they have not been commercialized due to existing technical, economic and commercial barriers (Brodeur et 
al., 2011; Huang et al., 2008). Therefore, further exploration of more efficient and cost effective separations of cellulose, hemicellulose, and lignin is necessary to make woody biomass a more promising alternative feedstock for biofuels and bioproducts. The objectives of this study are to (1) examine three filtration methods of separating urea pretreated biomass; and (2) quantify the amount of glucose removed from treated woody biomass to evaluate the efficiency of each filtration method.

\subsection{MATERIALS AND METHODS}

\subsubsection{Materials}

Red oak (Quercus rubra) biomass was obtained from West Virginia University's Research Forest, a mixed hardwood forest of 3,042 ha, located approximately at $39.66^{\circ} \mathrm{N}, 79.78^{\circ}$ near Morgantown, West Virginia, USA. Red oak biomass was selected because it is a commonly harvested species in the Appalachian region, thus comprises a large portion of the unutilized slash left behind after a timber harvest (Grushecky et al., 2007). Material was air dried and milled using a power cutting mill (Model: Pulverisette 25, Fritsch GmbH, Germany) with a 1

$\mathrm{mm}$ screen. After the material was milled through the $1 \mathrm{~mm}$ screen, the ground material was sieved into two groups of particle sizes: $<0.25 \mathrm{~mm}$ and $>0.25 \mathrm{~mm}$. The material in this research were the particles $>0.25 \mathrm{~mm}$, while the material $<0.25 \mathrm{~mm}$ was considered a waste byproduct. The dust is not used in order to ensure sufficient wetting of the material. Initial moisture content was determined to be $6 \%$. Urea pellets were purchased from Fisher Scientific (CAS 57-13-6, $>98 \%$ purity). 


\subsubsection{Experimental Design and Analysis}

A $3 \times 3$ factorial design with three replicates was used to determine the optimal solidliquid separation process for urea pretreated woody biomass (Table 2.1). The factors tested included three separation methods: a stainless steel mesh screen, filter paper, and centrifugation; and three urea concentrations. The first separation method was chosen based on the typical medium used for the filtration of coarse materials: a woven wire mesh; in which particulate will be retained on the surface of the screen (Rushton et al., 2008). Alternative medium rate separation techniques include centrifugation and vacuum filtration. Vacuum filtration can apply to both a wire mesh as well as a paper filtration; as the particle size decreases, membrane with a smaller and smaller pore size are required (Rushton et al., 2008). Analysis of variance (ANOVA) was performed to determine significance among testing conditions at a significance level of $\alpha=0.05$.

The ANOVA model for glucose concentration is expressed as:

$$
\begin{gathered}
S G_{i j k}=\mu+F T_{i}+U C_{j}+F T_{i}\left(U C_{j}\right)+\varepsilon_{i j k} \\
\mathrm{i}=1,2,3 \\
\mathrm{j}=1,2,3 \\
\mathrm{k}=1,2, \ldots, \mathrm{n}
\end{gathered}
$$

Where $\mathrm{SG}_{\mathrm{ijk}}$ represents the $k^{\text {th }}$ observation of glucose sugar concentration; $\mu$ is the mean of each response variable; $F T_{i}$ is the effect of the $i^{\text {th }}$ filtration method; $U C_{j}$ is the effect of the $j^{\text {th }}$ urea 
concentration; $\varepsilon_{i j k}$ is an error component that represents uncontrolled variability; and $k$ is the number of observations within each treatment.

Table 2.1. Testing conditions for $3 \times 3$ factorial design.

\begin{tabular}{lc}
\hline Filtration method & Urea Concentration (\%) \\
\hline Mesh Screen & 0 \\
Mesh Screen & 10 \\
Mesh Screen & 20 \\
Centrifuge & 0 \\
Centrifuge & 10 \\
Centrifuge & 20 \\
Filter paper & 0 \\
Filter paper & 10 \\
Filter paper & 20 \\
\hline
\end{tabular}

\subsubsection{Pretreatment}

A urea pretreatment was performed in a stirred Parr batch reactor, equipped with a $1 \mathrm{~L}$ vessel and the stirring speed set between 160-170 rpm. Deionized water and wood particles are combined in the $1 \mathrm{~L}$ vessel, with urea concentrations as found in Table 2.1. Pretreatment conditions include: temperature held at $170^{\circ} \mathrm{C}$, a soak time of 60 minutes with urea concentrations including $0 \%, 10 \%$ and $20 \%(\mathrm{w} / \mathrm{w})$. The maximum concentration of $20 \%$ urea was chosen based on the equilibrium and kinetic studies of the hydrolysis of urea performed by Sahu and Malik, 2008. This study used 10, 20 and 30\% urea concentrations and analyzed the conversion rates due to the effects of temperature, initial concentration and time. They determined that the rate of conversion of urea into ammonia did not significantly change between $20 \%$ and $30 \%$ urea concentrations with increasing temperature. This allowed for the use of $20 \%$ urea without concern, instead of $30 \%$. This also allows for a reduction in the quantity of urea 
required, as well as the costs associated with its use. Ten percent urea was chosen as a midpoint concentration. Sahu and Malik's study, 2008, also supplied the conditions for temperature and holding time. As the temperature was increased in the equilibrium study, higher conversions were achieved in a shorter amount of time. The reactor was allowed to increase internal pressure as needed to maintain set temperatures. Once the reactor reached $170^{\circ} \mathrm{C}$, the temperature was held there for 60 minutes. After the 60 minute soak time, the reactor is allowed to cool to room temperature before filtration. The material is then subjected to a specific filtration procedure, as explained in the next sub-sections.

\subsubsection{Filtration}

Filtration is used to separate the soluble sugars from the pretreated biomass, but when urea is used to pretreat the biomass it was found that the hydrolyzed polymers were still too large to easily pass through a $30 \mu \mathrm{m}$ filter paper. This hinders the ability to separate the sugar oligomers from the solid fraction. Three methods of filtration were compared to examine the separation efficiency of the liquid extraction from the solid residues. The filtration methods tested: filter paper with a pore size of $30 \mu \mathrm{m}$, a centrifuge separation, and a 304 stainless steel mesh screen with a pore size of $72 \mu \mathrm{m}$. Filter paper and stainless steel mesh screen filtrations were assisted with a vacuum. Thirty micron filter paper was used because it contains an ultrahigh loading capacity and the fastest flow rate of the qualitative grades. It is also ideal for use with coarse precipitates (Sigma-Aldrich, 2016). 304 stainless steel woven wire mesh at $72 \mu \mathrm{m}$ was used because 304 is the most common stainless steel grade used in wire cloth, and this mesh is extensively used in the chemical, food, and pharmaceutical industries (Boegger, 2016). The filtration efficiency was measured by the amount of glucose recovered after pretreatment. 
Filter Paper: Whatman 113 filter paper with a pore size of $30 \mu \mathrm{m}$ was used for the initial filtration. The extracted mixture of water, urea and wood was poured over the $30 \mu \mathrm{m}$ paper and the liquid pulled through via a vacuum pump. The solids remaining on the paper were then rinsed with $350 \mathrm{~mL}$ of deionized water. Once the solids were washed, the liquid extract plus rinsing liquid were weighed and the solids oven-dried. Excess deionized water was used to capture all solid particles onto the filter paper and remove soluble ions clinging to the solid particles before drying.

Centrifugation: An Accuspin 3000 was used to separate the solid and liquid fractions of the reacted biomass. The reacted material was transferred to the centrifuge containers and spun for 40 minutes at $4000 \mathrm{rpm}$. Once a cycle was completed, a pipette was used to decant the liquid from the top of the containers. The solid was then rinsed with deionized water and spun for an additional $40 \mathrm{~min}$ at $4000 \mathrm{rpm}$ until $350 \mathrm{~mL}$ had been used to rinse the solids. The liquid portions for each of these runs were added to the initial liquid extract and weighed. Excess deionized water was rinsed into each of the centrifuge containers and spun at the same conditions to capture all particulate matter and remove soluble ions from the solid particles. The solid was then poured over a piece of $30 \mu \mathrm{m}$ filter paper to remove the remaining liquid from the centrifuge containers. Excess deionized water was also used to remove the remaining particulate matter from the centrifuge containers. The solid fraction with the filter paper was then ovendried and the mass was recorded.

Mesh Screen: A 304 stainless steel mesh sheet with a pore size of $72 \mu \mathrm{m}$ was used as the third filtration technique. The extracted mixture of water, urea and wood is poured over the 72 $\mu \mathrm{m}$ mesh screen and a vacuum pump was used to pull the liquid through the screen and separate it from the solid fraction. The solids remaining on the mesh screen were then washed with 350 
$\mathrm{mL}$ of deionized water. Once the solids had been washed, the liquid extract plus $350 \mathrm{~mL}$ rinse were combined and weighed while the solids were oven-dried. Excess deionized water was used to capture all solid particles onto the mesh screen and remove soluble ions clinging to the solid particles.

\subsubsection{Characterization of biomass}

The red oak biomass used in the present study was characterized using proximate and ultimate analyses. The proximate analysis (moisture, volatile matter, fixed carbon, and ash) was performed using a thermogravimetric analyzer (Model: LECO TGA 701, LECO Corporation, St. Joseph, MI. USA). Samples were run in triplicates to ensure accuracy. The ultimate (elemental) analysis was performed using CHNS analysis (Model: Series II CHNS/O Analyzer 2400, PerkinElmer, Waltham, MA. USA).

\subsubsection{Glucose Testing}

Once the filtrations were performed, a dinitrosalicylic acid (DNS) assay was carried out on the liquid fraction to test for the presence of reducing sugars, i.e. glucose, as a representation of the quantity of cellulose degraded by the urea pretreatment. A glucose standard curve was developed to calculate the concentration of glucose found in each extraction. This procedure was used directly on the liquid extract, while further treatment must occur on the remaining solids to determine the reducing sugar content. The solid material was subjected to the NRELLAP (National Renewable Energy Laboratory-Laboratory Analytical Procedure) for the determination of structural carbohydrates (Sluiter et al., 2012), with sugar analysis samples sent to the Forest Products laboratory for quantification and qualification using HPLC. 


\subsection{RESULTS AND DISCUSSION}

A glucose standard curve (Figure 2.1) was created based on known concentrations of Dglucose subjected to the DNS assay developed by the University of Maryland (Wang, 2005) from the original work of Gail Miller (Miller, 1959). Glucose concentrations were tested in triplicates to ensure accurate readings and a linear regression model was also developed and used for the unknown sample concentration calculations. Serial dilutions were performed to bring the absorbance readings into the acceptable range of 0 to 1, according to Beer's Law (King and Garner, 1947) and the sensitivity of the equipment. Absorbance values were determined with an ultraviolet (UV) spectrometer. The corrected absorbance was determined by subtracting the absorbance found in the blank (deionized water) from the absorbance of the unknown solutions. The y-intercept and slope are determined from the equation of the linear relationship of the glucose standards found in Figure 2.1, and the dilution is the number of times the unknown was diluted until an absorbance between 0 and 1 is measured (King and Garner, 1947). Unknown glucose concentrations were determined by the following equation (Caymon_Chemical_Company, 2015):

$$
\text { Glucose }\left(\frac{g}{L}\right)=(\text { slope } * \text { corrected absorbance }+y \text { intercept }) * \text { dilution }
$$




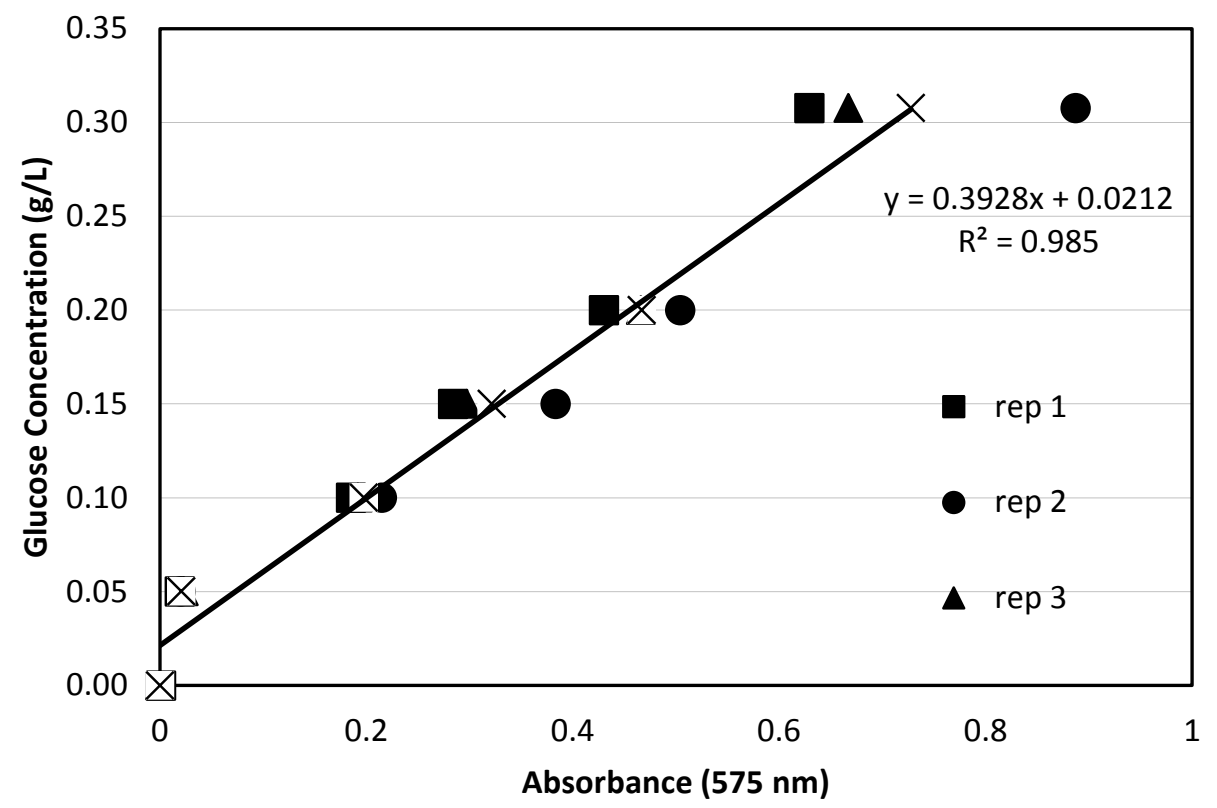

Figure 2.2. Glucose standard curve in grams per liter. Equivalent to 0, 5, 10, 15, 20, 30 percent glucose concentrations.

After the urea treatment has been performed, the initial liquid filtrate is subjected to a DNS assay. Testing was performed in triplicates, and glucose concentrations determined from the DNS assay can be found in Table 2.2. It is noted that the general trend of glucose concentrations decreased as the urea concentration increased, and that on average, filtration with a stainless steel mesh screen was able to recover the greatest quantity of glucose. The only condition that did not follow this trend was the glucose determined from the mesh screen filtration at $20 \%$ urea concentration. This could be due to the efficiency of the stainless steel mesh screen and its ability to separate solid and liquid fractions, in that the mesh screen was not affected by the quantity of urea used for pretreatment. This indicates that the stainless steel mesh screen may be the most efficient at filtering urea pretreated material. The concentrations of 
glucose extracted during the mesh screen filtration are relatively consistent, while centrifugation and the filter paper methods have significantly higher glucose concentrations when extracted at the baseline level: $0 \%$ urea, i.e. a hot water extraction.

The quantity of glucose capable of being recovered from the liquid filtrate was very low, measurable in milligrams per milliliter. This supports our claim that urea is capable of disrupting the structure of wood but does not hydrolyze the sugars, thus the majority of sugar after pretreatment remains in the solid fraction of the biomass.

Table 2.2. Glucose concentrations \pm standard deviation following a DNS assay. Calculated from equation 2.2.

\begin{tabular}{lc}
\hline Sample ID & Glucose $(\mathrm{mg} / \mathrm{mL})$ \\
\hline C-0 & $1.92 \pm 0.13$ \\
C-10 & $0.67 \pm 0.04$ \\
C-20 & $0.62 \pm 0.11$ \\
FP-0 & $1.54 \pm 0.22$ \\
FP-10 & $0.94 \pm 0.04$ \\
FP-20 & $0.86 \pm 0.16$ \\
MS-0 & $1.63 \pm 0.49$ \\
MS-10 & $1.09 \pm 0.43$ \\
MS-20 & $1.14 \pm 0.03$ \\
\hline
\end{tabular}

As the filter paper extraction was performed, the rate at which the liquid was separated from the solid fraction decreased as the quantity of urea increased. At a $0 \%$ urea concentration, there was no significant difference between filtration methods in the quantity of glucose found in the liquid extract $(\mathrm{p}=0.373)$. It is only when the urea concentration begins to increase that a difference in filtration methods comes to light. 
Ten percent urea concentration was not high enough to demonstrate any significant difference in glucose concentration between the vacuum methods of filter paper and a stainless steel mesh screen $(\mathrm{p}=0.570)$. There was also no significant difference in the quantity of glucose found between the filter paper and centrifuge filtrations $(\mathrm{p}=0.348)$. However, a significant difference in sugar concentration existed between the centrifuge and the mesh screen $(\mathrm{p}=$ 0.0003). When separating liquids from solids using a centrifuge, it is necessary to be careful when decanting the liquid from the top of the solid portion. There is a zone where the solid is completely saturated with the liquid and the particulates have a tendency to be transferred with the soluble molecules. This is undesirable because the yield of solubilized sugars is being determined and the particulate increases the weight of the liquid fraction, thereby reducing the calculated concentration of sugar in the liquid extract.

When the urea concentration increased to $20 \%$ (w/w), there was a significant difference in glucose concentration in the liquid among all three filtration methods. Centrifugation showed the least amount of glucose available and was significantly different from both the filter paper ( $\mathrm{p}$ $=0.023)$ and the mesh screen $(\mathrm{p}=0.010)$. The amount of glucose available in the liquid extract between the filter paper and mesh screen also differed significantly $(\mathrm{p}=0.043)$. Centrifugation provided the lowest glucose concentration at $0.62 \mathrm{mg} / \mathrm{mL}$, followed by the filter paper at 0.86 $\mathrm{mg} / \mathrm{mL}$, while the greatest concentration of glucose found with the mesh screen filtration at 1.14 $\mathrm{mg} / \mathrm{mL}$.

When the urea treated material was poured over the filter paper to separate the liquid extract from the solid biomass, it was found that the liquid pooled on top of the paper and struggled to pass through the pores. The cause of this is thought to be either a reaction between the residual ammonia in the sugar solution ( $\mathrm{pH}$ between 9 and 10) and the filter paper, or due to 
surface tension forces. Liquid ammonia causes swelling in cellulose fibers, thus penetrating its crystalline structure and reacting with the hydroxyl groups after breaking hydrogen bonds to yield a cellulose-ammonia complex (Barry et al., 1936; Mittal et al., 2011). This same principle seems to apply to aqueous ammonia, i.e. ammonia is dissolved in water, such as the case in this experiment. Whatman 113 filter paper is a cellulose based paper, thus when the residual ammonia attempted to interact with the cellulose in these fibers, it caused swelling to occur, and therefore restricted the pore opening in which the hydrolyzed sugar attempted to pass through.

The solid residue was next analyzed, and elemental and proximate analyses of the red oak biomass were performed, as well as sugar quantification. No substantial differences were observed for carbon, hydrogen, nitrogen, and sulfur contents among filtration methods (Table 2.3). The average carbon content was $45 \%-46 \%$, hydrogen content was $6 \%$, nitrogen content was $1.2 \%-1.7 \%$, and sulfur content was $0.5 \%$. Nitrogen content was high when compared to accepted values determined by Jin et al. 2013 for red oak biomass, whose research determined a nitrogen content ranging from $0.07 \%$ to $0.56 \%$ for red oak, depending on the type of sample used: heartwood, sapwood, or bark (Jin et al., 2013). The increase in nitrogen determined in this research was due to the urea used to pretreat the material.

Table 2.3. Elemental analysis (carbon, hydrogen, nitrogen, and sulfur content) of urea pretreated red oak biomass

\begin{tabular}{lcccc}
\hline & $\mathrm{C}(\%)$ & $\mathrm{H}(\%)$ & $\mathrm{N}(\%)$ & $\mathrm{S}(\%)$ \\
\hline Mesh Screen & $46.6 \pm 0.22$ & $5.9 \pm 0.13$ & $1.2 \pm 0.08$ & $0.5 \pm 0.02$ \\
Centrifuge & $46.3 \pm 0.28$ & $5.9 \pm 0.11$ & $1.2 \pm 0.13$ & $0.5 \pm 0.07$ \\
Filter Paper & $45.1 \pm 1.46$ & $6.0 \pm 0.16$ & $1.7 \pm 0.27$ & $0.4 \pm 0.17$ \\
\hline
\end{tabular}


In the proximate analysis, the average fixed carbon and volatile matter contents were around $17 \%$ and $83 \%$, respectively (Table 2.4 ). This agrees with the previous study of red oak biomass conducted by Jin et al. 2013. The ash content was extremely low, $<0.1 \%$, and the moisture content was determined to be consistently between $4 \%-5 \%$.

Table 2.4. Proximate analysis (moisture, ash, volatile, and fixed carbon (\% d.b.) of urea pretreated red oak biomass.

\begin{tabular}{lcccc}
\hline & Moisture $(\%)$ & Ash $(\%)$ & Volatile $(\%)$ & Fixed Carbon $(\%)$ \\
\hline Centrifuge & $4.58 \pm 0.39$ & $0.01 \pm 0.06$ & $82.34 \pm 0.50$ & $17.68 \pm 0.50$ \\
Filter Paper & $4.78 \pm 0.60$ & $0.10 \pm 0.08$ & $83.43 \pm 0.41$ & $16.67 \pm 0.37$ \\
Mesh Screen & $4.43 \pm 0.39$ & $0.05 \pm 0.13$ & $83.34 \pm 0.70$ & $16.61 \pm 0.67$ \\
\hline
\end{tabular}

The solid biomass, after the filtration method is applied, is subsequently tested for sugars as well following a protocol developed by the National Renewable Energy Laboratory (NREL) for the determination of structural carbohydrates and lignin. After polymeric sugars were cleaved into their individual monomers, samples were sent to the Forest Products Laboratory in Madison, WI for a sugar analysis using high performance liquid chromatography (Table 2.5). Results obtained from the Forest Products Laboratory were obtained in $\mathrm{mg} / \mathrm{mL}$, and converted to a weight basis using the conversion equations determined in the NREL procedure (Sluiter et al., 2012). The quantity of arabinose and galactose determined is negligible in the total sugar quantity and mannose recovery was consistent between both filtration methods and urea concentrations. The xylose, mainly from hemicellulose, and the glucose, mainly from cellulose, comprise the majority of sugars available from the red oak biomass. 
It was found that there was a significant difference in both the quantity of glucose recovered between filtration methods $(\mathrm{p}=0.0017)$, and the quantity of glucose recovered between urea concentrations $(\mathrm{p}=0.0021)$. As the urea concentration increased, regardless of filtration method, the quantity of glucose recovered decreased, but also the quantity of total sugars recovered decreased as well. The stainless steel mesh screen contained the least amount of variance for the total amount of sugar recovered (grams of total sugars per gram biomass), recovering $0.641 \mathrm{~g} / \mathrm{g}$ at $0 \%$ urea, to $0.616 \mathrm{~g} / \mathrm{g}$ at the $20 \%$ urea level. The filter paper method recovered $0.722 \mathrm{~g} / \mathrm{g}$ to $0.691 \mathrm{~g} / \mathrm{g}$ of total sugars from $0 \%$ to $20 \%$ urea, and finally centrifugation contained the greatest amount of variation in total sugars recovered among all urea concentrations, ranging from $0.805 \mathrm{~g} / \mathrm{g}$ to $0.774 \mathrm{~g} / \mathrm{g}$ of total sugars. This shows that centrifugation has the greatest capacity for error in the recovery of sugars, followed by filter paper, and the stainless steel mesh screen displaying the most consistent ability to recover sugars.

The sugar analysis provided by the Forest Products Laboratory supports the use of glucose as an indicator for the total concentration of sugars, since the amount of glucose capable of being recovered ranged from $70-90 \%$ of the total sugars found in the solid sample. Xylose was the second most abundant sugar and represented $7-25 \%$ of the total sugars available. Mannose represented 2-3\% of the total sugars, while galactose and arabinose represented $\leq 1 \%$ of the total sugars (Table 2.5 and Figure 2.3). 
Table 2.5. Sugar concentrations (grams of sugar per gram of biomass) extracted from red oak biomass, determined by HPLC performed by the Forest Products Laboratory in Madison, WI. Sugars were extracted using the NREL procedure for the determination of structural carbohydrates and lignin. Sample key: $\mathrm{C}=$ centrifuge, $\mathrm{FP}=$ filter paper, $\mathrm{MS}=$ stainless steel mesh screen; and urea concentration $0 \%, 10 \%, 20 \%$.

\begin{tabular}{lcccccc}
\hline Sample ID & $\begin{array}{c}\text { Arabinose } \\
(\mathrm{g} / \mathrm{g})\end{array}$ & $\begin{array}{c}\text { Galactose } \\
(\mathrm{g} / \mathrm{g})\end{array}$ & $\begin{array}{c}\text { Glucose } \\
(\mathrm{g} / \mathrm{g})\end{array}$ & $\begin{array}{c}\text { Xylose } \\
(\mathrm{g} / \mathrm{g})\end{array}$ & $\begin{array}{c}\text { Mannose } \\
(\mathrm{g} / \mathrm{g})\end{array}$ & $\begin{array}{c}\text { Total } \\
(\mathrm{g} / \mathrm{g})\end{array}$ \\
\hline C-0 & ND & ND & 0.729 & 0.061 & 0.016 & 0.805 \\
C-10 & 0.003 & 0.010 & 0.663 & 0.188 & 0.016 & 0.880 \\
C-20 & 0.003 & 0.008 & 0.557 & 0.186 & 0.021 & 0.774 \\
FP-0 & ND & ND & 0.627 & 0.074 & 0.021 & 0.722 \\
FP-10 & 0.008 & 0.008 & 0.533 & 0.155 & 0.013 & 0.717 \\
FP-20 & 0.003 & 0.008 & 0.497 & 0.165 & 0.018 & 0.691 \\
MS-0 & ND & ND & 0.575 & 0.053 & 0.013 & 0.641 \\
MS-10 & ND & ND & 0.479 & 0.137 & ND & 0.616 \\
MS-20 & 0.003 & 0.008 & 0.437 & 0.150 & 0.018 & 0.616 \\
\hline
\end{tabular}

As the percentage of urea used in pretreatment increased, the percentage of glucose recovered decreased. Centrifugation recovered the greatest percentage of glucose at each urea concentration level, with $90 \%-72 \%$ of the total sugar concentration, while the filter paper method recovered $87 \%-72 \%$, and the stainless steel mesh screen contained $90 \%-71 \%$ of the total sugars available (Figure 2.3). There was no significant difference between methods of filtration based on the percentage of glucose found in total quantity of sugars available $(p=0.368)$, however there was a significant difference in the percentage of glucose found between urea concentrations $(\mathrm{p}=0.0003)$. 

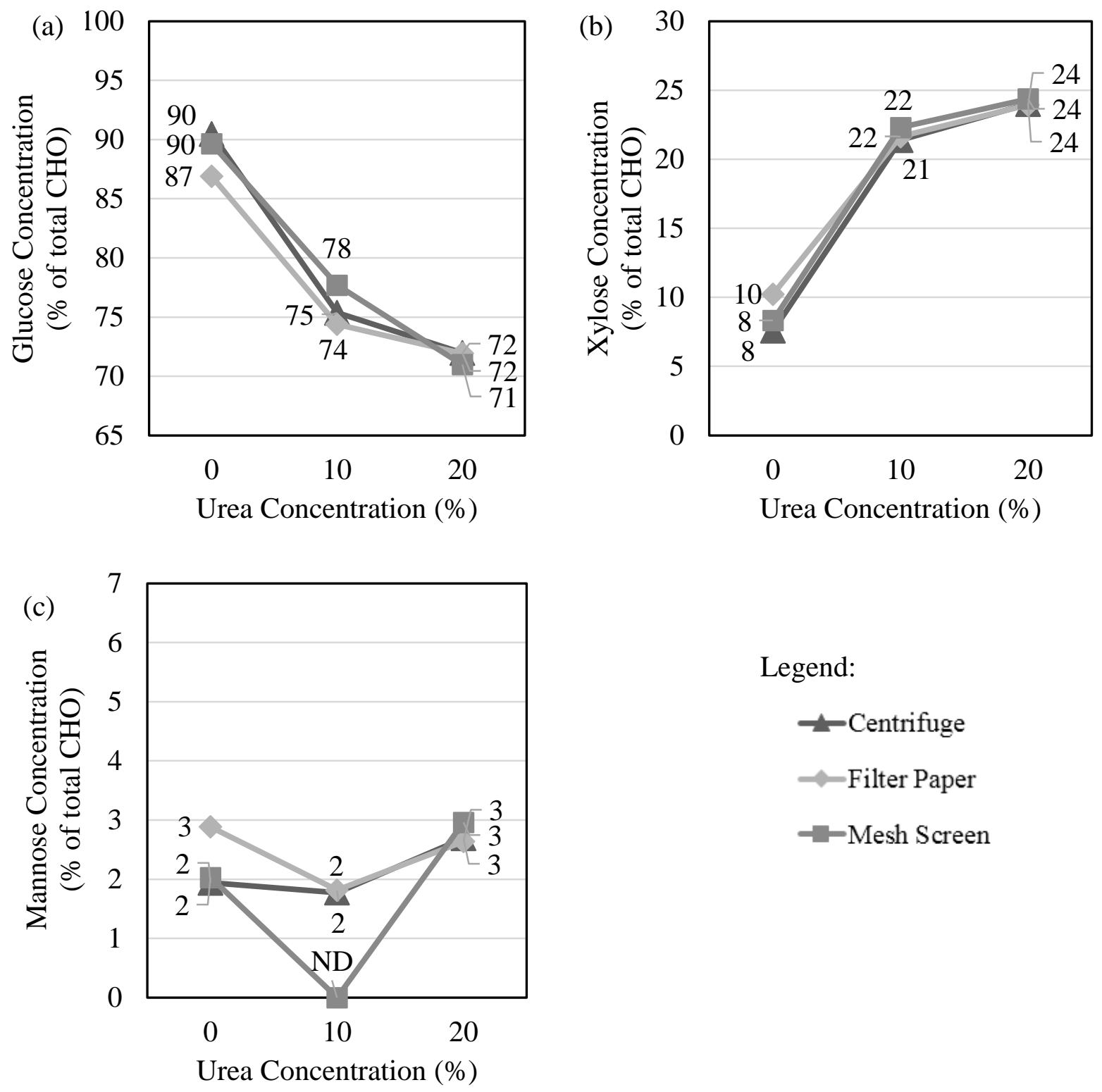

Legend:

$\leftarrow$ Centrifuge

$\sim$ Filter Paper

- Mesh Screen

Figure 2.3 Major sugar concentrations: (a) glucose, (b) xylose, (c) mannose; represented as a percentage of total tested sugars available, based on filtration method and urea concentration. Data labels indicate percent at each urea level. 


\subsection{CONCLUSIONS}

Urea pretreatment of woody biomass affects the ability to separate the resultant solid and liquid pretreatment fractions. As urea concentration increases, it becomes more and more difficult to separate the dissolved sugars in the liquid fraction from the solid particulate matter. Proper filtration is essential for maximum recovery, regardless of whether the solid or liquid portions are desired. Increasing concentrations of urea in the pretreatment is effective at disrupting the structure of the woody biomass and breaking the complex molecules and crystalline structure, but does not efficiently hydrolyze the sugar into monomer form. The aqueous ammonia in the liquid causes the cellulosic fibers in the filter paper to swell, thus restricting the pore opening and preventing successful filtration. Consequently, as the urea concentration increases, the quantity of sugar recovered in the liquid fraction decreases.

Centrifugation allowed the greatest quantity of glucose $(1.92 \mathrm{mg} / \mathrm{mL})$ to be recovered from the liquid filtrate at a $0 \%$ urea concentration, while the least quantity of glucose $(0.62$ $\mathrm{mg} / \mathrm{mL}$ ) to be recovered at a $20 \%$ urea concentration. This most likely occurs because of the slurry layer that prevents all liquid to be decanted from the solid. This slurry layer does not allow for all liquid to be decanted, thus causes some of the hydrolyzed sugars to precipitate back into the solid material when the red oak biomass is dried. This is evident when looking at the complete sugar analysis on the solid material provided by the Forest Products Laboratory; the grams of glucose found per gram of biomass at $0 \%$ urea concentration was $0.729 \mathrm{~g} / \mathrm{g}$ and 0.557 $\mathrm{g} / \mathrm{g}$ at a $20 \%$ urea level. These concentrations are greater that those found using either filter paper or the stainless steel mesh screen filtration methods. At the baseline urea concentration $(0 \%)$, glucose comprised $87 \%-90 \%$ of the total sugars, xylose was $8 \%-10 \%$, and mannose was $2 \%-3 \%$ of the total sugars. As the urea concentration increased, the glucose concentration 
decreased to $71 \%-72 \%$ of the total sugars found, while xylose increased to $24 \%$ of the total sugars, and mannose was consistent at 2\%-3\% of the total sugars available.

\section{REFERENCES}

Agbor VB, Cicek N, Sparling R, Berlin A, Levin DB. 2011. Biomass pretreatment: Fundamentals toward application. Biotechnology advances 29:675-685.

Alvira P, Tomas-Pejo E, Ballesteros M, Negro MJ. 2010. Pretreatment technologies for an efficient bioethanol production process based on enzymatic hydrolysis: A review. Bioresource Technology 101:4851-4861.

Barry AJ, Peterson FC, King AJ. 1936. x-Ray Studies of Reactions of Cellulose in NonAqueous Systems. I. Interaction of Cellulose and Liquid Ammonia1. Journal of the American Chemical Society 58:333-337.

Boegger. 2016. Stainless Steel Woven Wire Mesh http://www.ssmesh.org/stainless-steel-wiremesh/stainless-steel-woven-wire-mesh.html (Type of Medium).

Brodeur G, Yau E, Badal K, Collier J, Ramachandran K, Ramakrishnan S. 2011. Chemical and physicochemical pretreatment of lignocellulosic biomass: a review. Enzyme research 2011.

Caymon_Chemical_Company. 2015. Glucose Colorimetric Assay Kit. In: Item No. 10009582

Galletti AMR, Antonetti C. 2012. 5 Biomass pretreatment: separation of cellulose, hemicellulose, and lignin-existing technologies and perspectives. Biorefinery: From Biomass to Chemicals and Fuels. 
Grushecky ST, Wang J, McGill DW. 2007. Influence of site characteristics and costs of extraction and trucking on logging residue utilization in southern West Virginia. Forest Products Journal 57:63.

Huang H-J, Ramaswamy S, Tschirner UW, Ramarao BV. 2008. A review of separation technologies in current and future biorefineries. Separation and Purification Technology 62:1-21.

Jin, W., Singh, K. and Zondlo, J., 2013. Pyrolysis kinetics of physical components of wood and wood-polymers using isoconversion method.Agriculture, 3(1), pp.12-32.

King E, Garner R. 1947. The colorimetric determination of glucose. Journal of Clinical Pathology 1:30.

Kumar P, Barrett DM, Delwiche MJ, Stroeve P. 2009. Methods for Pretreatment of Lignocellulosic Biomass for Efficient Hydrolysis and Biofuel Production. Industrial \& Engineering Chemistry Research 48:3713-3729.

Miller GL. 1959. Use of dinitrosalicylic acid reagent for determination of reducing sugar. Analytical chemistry 31:426-428.

Mittal A, Katahira R, Himmel ME, Johnson DK. 2011. Effects of alkaline or liquid-ammonia treatment on crystalline cellulose: changes in crystalline structure and effects on enzymatic digestibility. Biotechnol Biofuels 4:41.

Mosier N, et al. 2005. Features of promising technologies for pretreatment of lignocellulosic biomass. Bioresource Technology 96:673-686.

Rushton A, Ward AS, Holdich RG. 2008. Solid-liquid filtration and separation technology: John Wiley \& Sons. 
Sahu JN, Mahalik K, Patwardhan AV, Meikap BC. 2008. Equilibrium and Kinetic Studies on the Hydrolysis of Urea for Ammonia Generation in a Semibatch Reactor. Industrial \& Engineering Chemistry Research 47:4689-4696/

Sigma-Aldrich. 2016. Whatman qualitative filter paper, Grade 113, creped http://www.sigmaaldrich.com/catalog/product/aldrich/z240915?lang=en\&region=US 2015) (Type of Medium).

Sluiter A, et al. 2012. Determination of structural carbohydrates and lignin in biomass. Laboratory analytical procedure.

Wang NS. 2005. Experiment no. 4A, Glucose assay by dinitrosalicylic colorimetric method: Retrieved 14/5-2005 from the University of Maryland, Department of Chemical Engineering 


\section{AnAlysis OF UREA AS AN AdDitive to THE Hot-WATER EXTRACTION OF RED OAK BIOMASS}




\section{AbSTRACT}

Among many characteristics, an effective pretreatment of woody biomass should be able to overcome the lignocellulosic recalcitrance, produce high yields of sugars, and be cost effective. To this end, urea is a promising additive to a hot water extraction of woody biomass because when one molecule of urea is hydrolyzed, two molecules of ammonia are produced. This characteristic, when applied in a hot water treatment of woody biomass, can react with lignin and decrystallize cellulose. Pretreated red oak biomass was tested and analyzed for sugar content according to the National Renewable Energy Laboratory (NREL) Analytical Procedures to determine the structural carbohydrates and lignin. Glucose is used as an indicator for total sugar content, and response surface modelling was employed to optimize the urea concentration for maximum sugar yield with consideration of temperature, holding time, and urea concentration. Temperature and holding time were determined to be insignificant in the recovery of glucose, and urea concentration was the major significant factor in maximizing the quantity of glucose recovered. Of the factors analyzed, the optimal extraction factors were determined to be: temperature at $170^{\circ} \mathrm{C}$, holding time of 60 minutes, and a urea concentration of $13.27 \%(\mathrm{w} / \mathrm{w})$. These conditions produced a glucose yield of 1.05 grams of glucose per gram of biomass.

\subsection{INTRODUCTION}

Woody biomass is one of the most recalcitrant forms of lignocellulosic materials for conversion to value-added biofuels or bioproducts due to the lignin matrix surrounding the hemicellulose and cellulose. This resistance to degradation can be reduced through mechanical pretreatment followed by chemical pretreatment for the extraction of sugars. Mechanical pretreatment reduces the size of the woody biomass material so that a greater surface area is 
available for chemicals to react with the biomass components: cellulose, hemicellulose, and lignin. For chemical pretreatments, there are four major categories of extraction: acidic, alkaline, liquid hot water, and Organosolv.

Dilute acid-pretreatment is one of the most promising approaches because of its low cost and high hemicellulose yield of up to $90 \%$, but is corrosive to the equipment and tends to ferment the sugars into other byproducts instead (Mok and Antal Jr, 1992). Liquid hot water extraction can completely recover hemicellulose from hardwoods and herbaceous materials without significant degradation of pentoses (Huang et al., 2008; Mok and Antal Jr, 1992), but only dissolves about half of the total woody biomass (Kumar et al., 2009). The Organosolv process can remove the lignin, leaving behind cellulose and hemicellulose, but for this to occur the solid material must first be washed with an organic solvent (Pan et al., 2006). These solvents are typically expensive and volatile, thus inhibiting their use and safety (Zhao et al., 2009).

Ammonia Fiber Explosion (AFEX) treatment also yields optimal hydrolysis rates for pretreated lignocellulosic materials with the ammonia reacting primarily with the lignin and the decrystallization of cellulose (Mosier et al., 2005), but the price of ammonia and ammonia recovery significantly increases the pretreatment costs. Alkaline pretreatments are more effective on hardwoods, herbaceous crops and agricultural residues with lignin contents lower than softwoods (Hu and Ragauskas, 2012). The AFEX process produces lignin aggregation with no significant loss of hemicellulose, but provides a significant effect on cell wall structure (Langan et al., 2014).

Using urea as an alkaline pretreatment is a potential substitute for ammonia in the pretreatment of wood/biomass. The basic chemistry involved in the breakdown of urea uses excess water to promote the hydrolysis reaction, thereby breaking down urea to produce 
ammonium carbamate, which continues to break down to produce carbon dioxide and ammonia as the final products. The published information on the hydrolysis of urea for the production of ammonia is limited and patented (Brooks et al., 2005; Hofmann and Rusch, 2001; Jacob and Stiermann, 2006; Jones, 1998; Lagana, 1999; Sahu et al., 2008). However, no information has been found on the use of urea to extract sugars from woody biomass, with the urea converting to ammonia in the process line. Once the urea has been broken into its ammonia/carbon dioxide components, the pretreatment of the woody biomass should proceed like any other ammonia pretreatment, i.e. ammonia fiber explosion (AFEX) or ammonia recycle percolation (ARP). Although there are many differences among the pretreatment methods (Table 3.1), the overall goal of each method is to disrupt the recalcitrant structure to separate the cellulose, hemicellulose and lignin. Each method does this in a slightly different manner. Some, like the AFEX pretreatment, disrupt the structure but leave the compounds in a solid form that is less rigidly bound, while others like the Organosolv pretreatment completely dissolve out the hemicellulose, then separate the cellulose and lignin into distinct streams. 
Table 3.1. Comparison of major pretreatment methods.

\begin{tabular}{|c|c|c|c|c|}
\hline & Urea $^{1}$ & Acid $^{2}$ & AFEX $^{3}$ & Organosolv $^{4}$ \\
\hline Cost of chemicals ${ }^{5}$ & $\$ 375 /$ ton (urea) & $\begin{array}{l}\$ 318 / \text { ton (sulfuric } \\
\text { acid) }\end{array}$ & \$700/ton (ammonia) & $\begin{array}{l}\$ 333 / \text { ton }\left(\mathrm{H}_{2} \mathrm{SO}_{4}+\right. \\
\text { ethanol) }\end{array}$ \\
\hline \multicolumn{5}{|c|}{ Yield } \\
\hline Glucose yield & Up to $30 \%$ & $11-13 \%$ & $25 \%$ & $13 \%$ \\
\hline Xylose yield & Unknown & $70-85 \%$ & $90 \%$ & $72 \%$ \\
\hline Minor sugar yield & Unknown & $20 \%$ & $20 \%$ & $12 \%$ \\
\hline \multicolumn{5}{|c|}{ Reaction Conditions } \\
\hline Temperature & $\begin{array}{l}\text { Low temperature } \\
\quad\left(<200^{\circ} \mathrm{C}\right)\end{array}$ & $\begin{array}{l}\text { Low temperature } \\
\quad\left(<200^{\circ} \mathrm{C}\right)\end{array}$ & $\begin{array}{l}\text { Low temperature } \\
\quad\left(<200^{\circ} \mathrm{C}\right)\end{array}$ & $\begin{array}{l}\text { High temperature } \\
\left(>200^{\circ} \mathrm{C}\right)\end{array}$ \\
\hline Reaction time & Minutes to hours & Minutes to hours & Minutes & Minutes to hours \\
\hline $\begin{array}{l}\text { Chemical recovery } \\
\text { required }\end{array}$ & No & $\begin{array}{l}\text { Yes and No (Yes } \\
\text { only when using } \\
\text { concentrated acid) }\end{array}$ & Yes & Yes \\
\hline \multicolumn{5}{|c|}{ Other } \\
\hline Health Hazards & Non-toxic & Toxic, corrosive & $\begin{array}{c}\text { Toxic, volatile, } \\
\text { corrosive, explosion } \\
\text { hazard }\end{array}$ & $\begin{array}{l}\text { Corrosive, } \\
\text { fire/explosion } \\
\text { hazard }\end{array}$ \\
\hline $\begin{array}{l}\text { Inhibitory } \\
\text { compounds } \\
\text { produced }\end{array}$ & Unknown & Yes & No & Yes \\
\hline \multirow[t]{2}{*}{ Chemical Storage } & Transported in bulk & $\begin{array}{l}\text { Stored in non- } \\
\text { corrosive containers }\end{array}$ & $\begin{array}{l}\text { Compressed } \\
\text { cylinder }\end{array}$ & $\begin{array}{l}\text { Stored in non- } \\
\text { corrosive containers }\end{array}$ \\
\hline & $\begin{array}{l}\text { Long-term storage } \\
\text { capabilities }\end{array}$ & Must be neutralized & & \\
\hline Key advantages & $\begin{array}{l}\text { Safer to use with } \\
\text { less environmental } \\
\text { impacts }\end{array}$ & $\begin{array}{c}\text { Dilute acid } \\
\text { hydrolysis is less } \\
\text { expensive }\end{array}$ & $\begin{array}{l}\text { Increases accessible } \\
\text { surface area, even if } \\
\text { initial sugar } \\
\text { recovery is low }\end{array}$ & $\begin{array}{l}\text { Produces distinct } \\
\text { fractions for each } \\
\text { lignocellulosic } \\
\text { component }\end{array}$ \\
\hline Key disadvantages & $\begin{array}{l}\text { Urea to ammonia } \\
\text { conversion known, } \\
\text { but use as a } \\
\text { pretreatment has not } \\
\text { been widely } \\
\text { researched }\end{array}$ & $\begin{array}{l}\text { Concentrated acid } \\
\text { has a slow rate of } \\
\text { reaction }\end{array}$ & $\begin{array}{l}\text { Cost of ammonia is } \\
\text { extremely high }\end{array}$ & $\begin{array}{l}\text { Solvents must be } \\
\text { recovered and are } \\
\text { inhibitory for } \\
\text { downstream } \\
\text { processes }\end{array}$ \\
\hline
\end{tabular}

1- (Sahu et al., 2008)

2- (Thygesen et al., 2005)

3- (Balan et al., 2009)

4- (Pan et al., 2006)

5- (Knorr, 2015) 
The production of ammonia from urea occurs in two steps: first urea and water react to form ammonium carbamate, which is a mildly exothermic reaction. Second, the ammonium carbamate is broken down into ammonia and carbon dioxide, which is a strongly endothermic reaction in which the release of ammonia and carbon dioxide quickly stops once the heat source is withdrawn (Mahalik et al., 2010). Looking at the kinetics of urea decomposition into ammonia, based on a study by Sahu et al. (2008), the hydrolysis of urea to ammonia behaves as a first order reaction with respect to urea, and the rate equation can be written as:

$$
-r_{A}=k C_{A}
$$

Where $r_{A}$ is the rate of the reaction, $k$ is the forward rate constant, and $C_{A}$ is the concentration of the reactant (Sahu et al., 2008). The temperature dependency of the forward rate constant can then be written as:

$$
k=A e^{-E / R T}
$$

Where $A$ is the frequency factor and $E$ is the activation energy (Sahu et al., 2008). The research performed by Sahu et al. (2008) studied the effects of temperature, initial urea concentration and time on the conversion of urea to ammonia. The major results are listed below for easy reference:

Temperature $\left(110-180^{\circ} \mathrm{C}\right)$ : As temperature increased, the equilibrium conversion of urea increased

Initial Urea Conc. (10-30\%): As initial urea concentration increased, equilibrium conversion of urea decreased. Also, as the temperature was increased at each level of initial urea concentration, the equilibrium concentration decreased

Time (10-60 min): As time increased, the equilibrium conversion of urea increased. 
Equilibrium conversion increases with increasing temperature and reaches a maximum value of $17.07 \%$ for an initial urea concentration of $10 \mathrm{wt} \%$ and a temperature of $180^{\circ} \mathrm{C}$ and a reaction time of 50 minutes. This information was used as the basis for an optimization experiment to determine the optimal urea concentration necessary to recover the maximum quantity of sugars extracted from the woody biomass (Sahu et al., 2008).

When ammonia is used in a pretreatment process, it is found that the ammonia molecules penetrate the cellulose structure and cause a solid state transition from cellulose I to cellulose III, which contains an enhanced sensitivity to hydrolysis (Langan et al., 2014). Alkaline pretreatment efficiencies, such as ammonia pretreatments, are mainly affected by reaction temperature, pretreatment time, and alkali loading (Hu and Ragauskas, 2012). The objectives of the following study were to (1) optimize the temperature, holding time, and urea concentration necessary for the extraction of the maximum quantity of glucose possible; and (2) quantify the amount of glucose capable of being hydrolyzed after pretreatment has occurred.

\subsection{MATERIALS AND METHODS}

\subsubsection{Materials}

The optimization of urea concentration for the extraction of sugars was carried out using red oak biomass (Quercus rubra), obtained from the West Virginia University Forest near Morgantown, West Virginia. Red oak is a commonly logged species in the Appalachian region, thus constitutes most of the slash left in the forest after harvesting, which gives it the greatest potential for use as an alternative feedstock for energy or bioproducts. The material was chipped and air dried to a constant weight. The chips were then further reduced in size using a power 
cutting mill (Model: Pulverisette 25, Fritsch GmbH, Germany) with a $1 \mathrm{~mm}$ screen. The ground biomass was sieved and particles $\geq 0.25 \mathrm{~mm}$ were used for testing, while particles $\leq 0.25 \mathrm{~mm}$ were discarded as waste. The smaller particles were discarded to ensure sufficient wetting of the material occurred.

\subsubsection{Experimental Design and Analysis}

To determine the optimal urea concentration at which the greatest quantities of sugars were extracted, a Box-Behnken design was used to obtain initial pretreatment conditions. The factors tested were reactor temperature, holding time, and urea concentration. Each treatment factor was varied individually to determine the optimum loading for each condition. Three levels of each factor were examined: temperature at $160^{\circ} \mathrm{C}, 170^{\circ} \mathrm{C}$, and $180^{\circ} \mathrm{C}$; holding time at 40 minutes, 60 minutes and 80 minutes; and urea concentration at 0\%, 10\%, and 20\%. A Response

Surface Model (RSM) was then applied to the initial treatment conditions to optimize the number of samples required for further testing to determine the optimal sugar yield from the pretreatment. The response surface model contains all possible variables and interactions. The true model was determined based on the experimental results. A description of the possible factors and their interactions is found in Equation 3.3.

$$
\begin{aligned}
& y=\mu+S P_{i}+T_{j}+H_{k}+C_{l}+(T * H)_{i j}+(T * C)_{j l}+(H * C)_{k l}+(T * H * C)_{j k l}+\varepsilon_{i j k l} \\
& \mathrm{y}=\text { sugar concentration } \\
& \mathrm{SP}=\text { species } \\
& \mathrm{T}=\text { temperature }
\end{aligned}
$$


$\mathrm{H}=$ holding time

$\mathrm{C}=$ urea concentration

$\mathrm{T} * \mathrm{H}=$ temperature/holding time interaction

$\mathrm{T} * \mathrm{C}=$ temperature/urea concentration interaction

$\mathrm{H}^{*} \mathrm{C}=$ holding time/urea concentration interaction

$\mathrm{T}^{*} \mathrm{H}^{*} \mathrm{C}=$ temperature/holding time/urea concentration interaction

$\varepsilon=$ error

$\mathrm{i}=$ red oak

$\mathrm{j}=160^{\circ} \mathrm{C}, 170^{\circ} \mathrm{C}, 180^{\circ} \mathrm{C}$

$\mathrm{k}=40$ minutes, 60 minutes, 80 minutes

$1=0 \%, 10 \%, 20 \%$

A response surface regression analysis with backwards elimination of terms was

performed using MiniTab software to determine the significant factors affecting total sugar yield, based on the glucose content as a representation of total sugar content of the pretreated material.

\subsubsection{Pretreatment}

A urea extraction was performed in a Parr batch reactor using deionized water, ground red oak biomass and urea in a $1 \mathrm{~L}$ vessel. Deionized water and biomass were added in a 7/1 ratio to ensure sufficient wetting of the biomass. Urea concentration was measured on a weight-byweight basis. Temperature, time and urea concentration were varied as the independent variables and the initial testing conditions can be found in Table 3.2. Stirring speed was set between 160$170 \mathrm{rpm}$. 
Table 3.2. Initial pretreatment conditions.

\begin{tabular}{ccc}
\hline Time $(\min )$ & Temperature $\left({ }^{\circ} \mathrm{C}\right)$ & Urea Concentration $(\%)$ \\
\hline 40 & 160 & 10 \\
40 & 180 & 10 \\
80 & 160 & 10 \\
80 & 180 & 10 \\
60 & 160 & 0 \\
60 & 160 & 20 \\
60 & 180 & 0 \\
60 & 180 & 20 \\
40 & 170 & 0 \\
80 & 170 & 0 \\
40 & 170 & 20 \\
80 & 170 & 20 \\
60 & 170 & 10 \\
60 & 170 & 10 \\
60 & 170 & 10 \\
\hline
\end{tabular}

After the glucose concentration at each of these levels is determined, the information is input into MiniTab software and a backwards regression of terms was applied to determine significant factors. This software also provided an equation to determine the mathematical optimum for each factor tested. Sample points surrounding these optimum conditions were also tested to ensure that the mathematical optimum was in fact the true maximum as opposed to a local maximum.

\subsubsection{Filtration}

After the pretreatment, the resultant slurry from the Parr batch reactor was then filtered through a $72 \mu \mathrm{m}$ stainless steel mesh screen. The stainless steel mesh screen was found to be an effective separation method based on the study described in Chapter 2. The extracted mixture of 
water, urea and wood was poured over the $72 \mu \mathrm{m}$ mesh screen and a vacuum pump was used to pull the liquid through the screen and separate it from the solid fraction. The solids remaining on the mesh screen were then washed with $175 \mathrm{~mL}$ of deionized water. Once the solids were washed, the liquid extract plus $175 \mathrm{~mL}$ rinse were combined and weighed. Excess deionized water was used to capture all solid particles onto the mesh screen.

\subsubsection{Characterization of biomass}

The red oak biomass used in the present study was characterized using proximate and ultimate analyses. The proximate analysis (moisture, volatile matter, fixed carbon, and ash) summarized in Table 3.3, was performed using a thermogravimetric analyzer (Model: LECO TGA 701, LECO Corporation, St. Joseph, MI. USA). Samples were run in triplicates to ensure accuracy. The ultimate (elemental) analysis was performed using CHNS analysis (Model: Series

II CHNS/O Analyzer 2400, PerkinElmer, Waltham, MA. USA), and summarized in Table 3.4.

Table 3.3. Proximate analysis (moisture, ash, volatile, and fixed carbon (\% d.b.) of urea pretreated red oak biomass (mean \pm standard deviation).

\begin{tabular}{ccccc}
\hline & Moisture (\%) & Ash (\%) & Volatile (\%) & Fixed Carbon (\%) \\
\hline Red Oak & $6.16 \pm 0.06$ & $0.245 \pm 0.01$ & $81.71 \pm 0.05$ & $18.06 \pm 0.06$ \\
\hline
\end{tabular}

Table 3.4. Elemental analysis (carbon, hydrogen, nitrogen, and sulfur content) of red oak biomass (mean \pm standard deviation).

\begin{tabular}{lcccc}
\hline & Carbon $(\%)$ & Hydrogen $(\%)$ & Nitrogen $(\%)$ & Sulfur $(\%)$ \\
\hline Red Oak & $46.80 \pm 0.22$ & $5.88 \pm 0.13$ & $0.17 \pm 0.08$ & $0.17 \pm 0.02$ \\
\hline
\end{tabular}




\subsubsection{Sugar Quantification}

Theoretically, the majority of the sugar is found in the solid fraction because although the urea will disrupt the crystalline structure of cellulose, it does not completely hydrolyze the sugar. The solid fraction was subjected to a two-step acid hydrolysis, using NREL (National Renewable Energy Laboratory) Laboratory Analytical Procedures (LAP) "Determination of Structural Carbohydrates and Lignin in Biomass" (Sluiter et al., 2012). This procedure hydrolyzes polymeric carbohydrates into soluble monomeric forms. The hydrolyzate was tested for reducing sugars by a Nelson-Somogyi assay. This assay determines the reducing sugar content based on the absorbance at 540nm of a colored complex. Standard curves were developed to calculate the concentration of unknown sugars in each extraction. Glucose is used as an indicator for total sugar concentration because it is the major sugar hydrolyzed in wood, since cellulose which is comprised of glucose monomeric units (Barr et al., 2014). To quantify sugar concentrations, glucose was used as an indicator of total sugars available in wood. This is because glucose comprises about $70-90 \%$ of the total sugars found in wood, and is the monomer most desired for conversion into fuels such as bioethanol (Balat, 2011). Although other sugars can produce alternate bioproducts, glucose is found in both the cellulose and hemicellulose components of wood. The glucose standard curve was created based on known concentrations of D-glucose subjected to the Nelson-Somogyi assay. Glucose concentrations were tested in triplicates to ensure accurate readings and the averages were regressed with the linear equation being used in the unknown sample concentration calculations.

Serial dilutions were performed to bring the absorbance readings into the acceptable range of 0 to 1, according to Beer's Law (King and Garner, 1947). Absorbance values were determined with an ultraviolet (UV) spectrometer. The corrected absorbance was determined by 
subtracting the absorbance found in the blank (deionized water) from the absorbance of the unknown solutions. Unknown glucose concentrations were calculated using Equation 3.4.

Glucose $\left(\frac{g}{L}\right)=($ slope $*$ corrected absorbance $+y$ intercept $) *$ dilution

Where the slope and the y-intercept were determined from the best-fit line calculated from the glucose standard curve, the corrected absorbance was calculated by subtracting the blank absorbance from the unknown absorbance, and the dilution is the number of times the unknown must be diluted to read an absorbance between 0 and 1 .

\subsection{RESULTS AND DISCUSSION}

\subsubsection{Sugar quantification}

Glucose was quantified using a Nelson-Somogyi method for the determination of reducing sugars. The Nelson-Somogyi method is a more ideal method as compared to the dinitrosalicylic acid assay (DNS) because the compounds used in the DNS assay have a tendency to precipitate out of solution when treating materials with a $\mathrm{pH}$ lower than 7 . The NelsonSomogyi method allows for materials with lower $\mathrm{pH}$ values $(\mathrm{pH}<7)$, which is extremely beneficial when analyzing sugars after isolation with the National Renewable Energy Laboratory procedure for the determination of structural carbohydrates, since this procedure uses a two-step acid hydrolysis to fractionate the biomass. This method is applicable for a variety of sugars that are capable of being reduced, and standard curves can be developed based on sugar type. A

glucose standard curve was calculated using known concentrations of d-glucose subjected to the 
Nelson-Somogyi method with the absorbance read at $540 \mathrm{~nm}$. Plotting the concentration vs. absorbance allowed to generate a linear regression model (Figure 3.1).

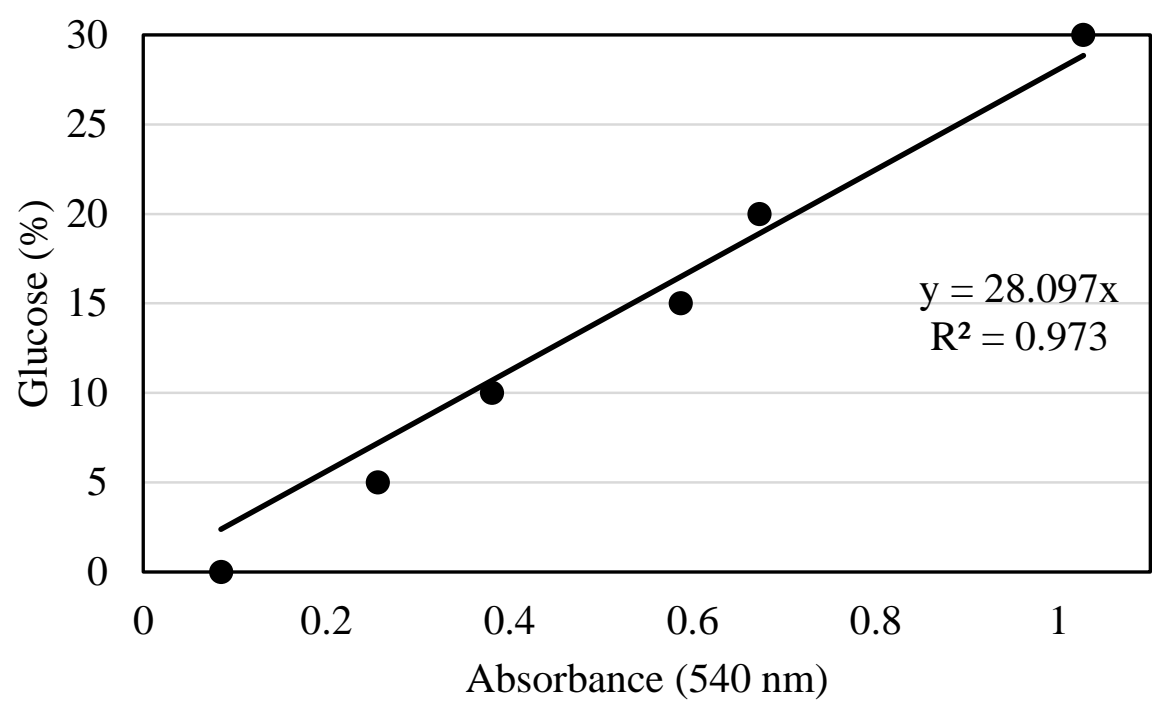

Figure 3.1. Glucose Standard Curve, representing percent glucose concentrations vs absorbance recorded at $540 \mathrm{~nm}$.

Glucose concentrations of each of the initial set of testing conditions were calculated using the absorbance read from the solution of each set of treatments, and the equation from the best fit line in Figure 3.1. The unknown concentrations were calculated in percent glucose form from the glucose standard curve, then converted to grams of glucose per gram of biomass $(\mathrm{g} / \mathrm{g}$ ) based on the known amounts of material and percentage glucose extracted. These results are reported in Table 3.5 . 
Table 3.5. Glucose concentrations (grams of glucose per gram of wood) of initial testing conditions (mean \pm standard deviation).

\begin{tabular}{cccc}
\hline $\begin{array}{c}\text { Time } \\
(\mathrm{min})\end{array}$ & $\begin{array}{c}\text { Temperature } \\
\left({ }^{\circ} \mathrm{C}\right)\end{array}$ & $\begin{array}{c}\text { Urea Concentration } \\
(\%)\end{array}$ & $\begin{array}{c}\text { Glucose Concentration } \\
(\mathrm{g} / \mathrm{g})\end{array}$ \\
\hline 40 & 160 & 10 & $0.8 \pm 0.22$ \\
40 & 180 & 10 & $0.7 \pm 0.03$ \\
80 & 160 & 10 & $0.4 \pm 0.26$ \\
80 & 180 & 10 & $0.4 \pm 0.04$ \\
60 & 160 & 0 & $0.2 \pm 0.02$ \\
60 & 160 & 20 & $0.4 \pm 0.01$ \\
60 & 180 & 0 & $0.3 \pm 0.03$ \\
60 & 180 & 20 & $0.4 \pm 0.02$ \\
40 & 170 & 0 & $0.2 \pm 0.01$ \\
80 & 170 & 0 & $0.3 \pm 0.02$ \\
40 & 170 & 20 & $0.6 \pm 0.00$ \\
80 & 170 & 20 & $0.7 \pm 0.02$ \\
60 & 170 & 10 & $0.7 \pm 0.00$ \\
60 & 170 & 10 & $0.6 \pm 0.03$ \\
60 & 170 & 10 & $0.6 \pm 0.07$ \\
\hline
\end{tabular}

\subsubsection{Optimization of Urea Concentrations}

MiniTab 17 Software was used to analyze the raw data from the glucose concentrations in $\mathrm{g} / \mathrm{g}$. A response surface regression with a backward stepwise elimination of terms, using a full quadratic of available terms, was performed to analyze the factors tested and their interactions: temperature, holding time, and urea concentration. The significance of each factor was evaluated in the model. It was determined that both the reactor temperature and the holding time were insignificant in the maximization of sugar recovery, while the urea concentration is significant in the model (Equation 3.5). Square terms were included in the analysis of factors, which allowed for a maximum to be reached, as shown in Figure 3.2, as opposed to a linear equation in which no theoretical maximum could ever occur. 


$$
[\operatorname{Glucose}(g / g)]=0.2458+0.0586 *[\text { Urea }]-0.002209 *[\text { Urea }]^{2}
$$

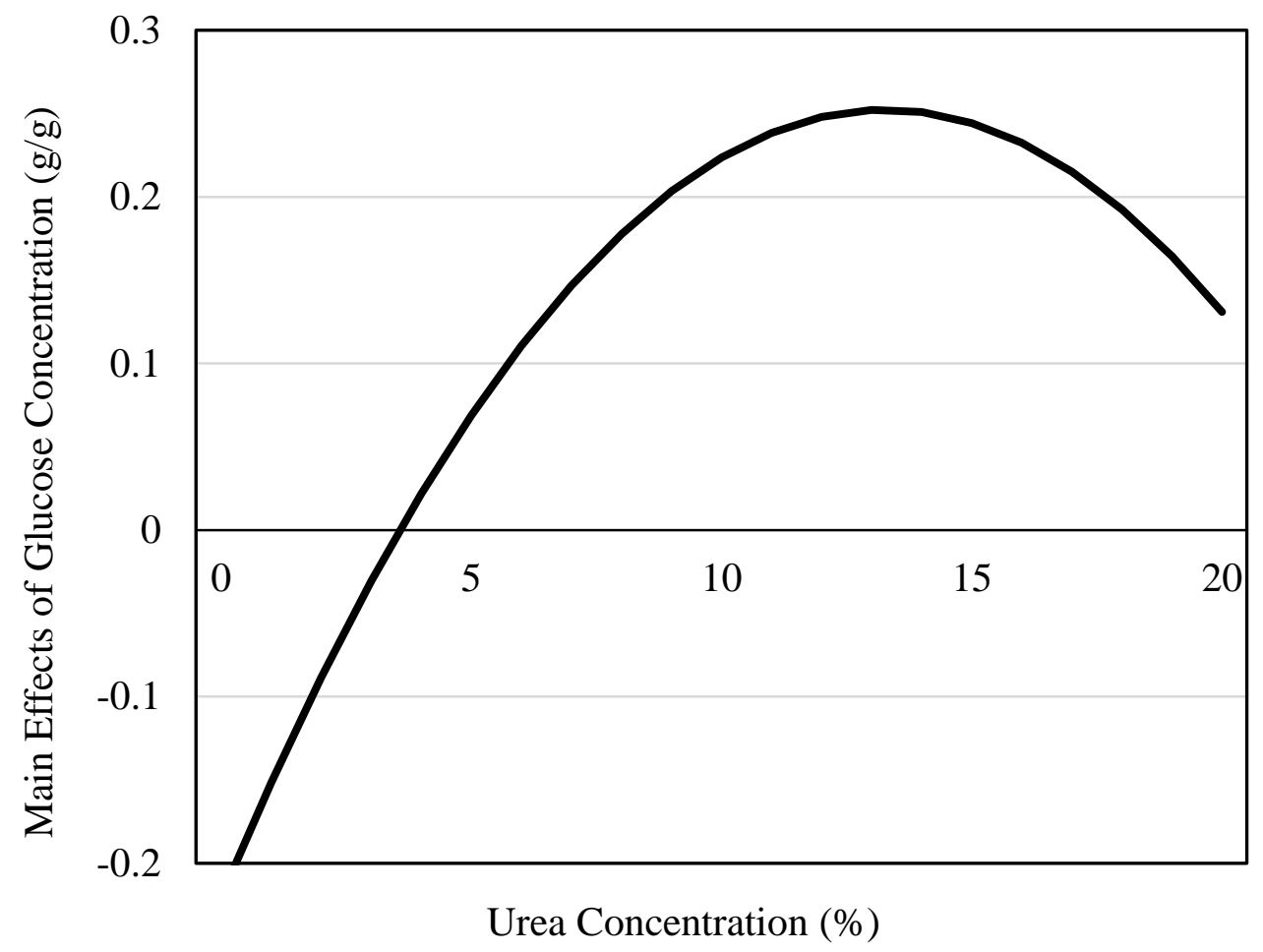

Figure 3.2. Plot of the theoretical glucose concentration (grams glucose per gram biomass) vs. urea concentration, as determined by Equation 3.5.

Using equation 3.5, the theoretical glucose peaked at a calculated urea concentration of 13.27\%. This theoretical optimum concentration was used to determine the further concentrations to be tested to experimentally confirm the maximum concentration of glucose that can be recovered (Table 3.6). Based on the MiniTab analysis, temperature and holding time played an insignificant factor in the quantity of glucose determined. Therefore, in the ranges experimentally tested, temperature and holding time were set at the midpoints of the 
experimental ranges, since it was determined that varying them did not significantly affect the glucose capable of being extracted from the woody biomass using the urea pretreatment. Temperature was set at $170^{\circ} \mathrm{C}$ and holding time was left at 60 minutes. The midpoint values were used instead of the low values also due to the research performed by Sahu et al., 2008. Sahu et al.'s research, previously described in sections 2.1 and 3.1, state that the conditions selected were ideal for the conversion of urea to ammonia. The experiments confirmed that a 13.27\% urea concentration produced $1.1 \mathrm{~g}$ glucose/g biomass (Table 3.6) using the NelsonSomogyi assay for reducing sugars and the UV Spectrophotometer at $540 \mathrm{~nm}$.

Table 3.6. Amount of recovered glucose (gram glucose per gram biomass) based on urea concentration (mean \pm standard deviation).

\begin{tabular}{cc}
\hline Urea Concentration $(\%)$ & Glucose $(\mathrm{g} / \mathrm{g})$ \\
\hline 0 & $0.3 \pm 0.02$ \\
10 & $0.6 \pm 0.05$ \\
13 & $1.0 \pm 0.12$ \\
13.27 & $1.1 \pm 0.08$ \\
13.5 & $0.9 \pm 0.03$ \\
20 & $0.6 \pm 0.17$ \\
\hline
\end{tabular}

There was no significant difference determined between the glucose concentration found when extracted with $13 \%, 13.27 \%$, and $13.5 \%$ urea concentrations $(\mathrm{p}=0.153)$. Although $13.27 \%$ did experimentally determine the greatest quantity of glucose capable of being recovered, thus confirming the theoretical maximum, a range of concentrations can be used without significantly affecting the glucose concentration. Glucose concentrations determined at $10 \%$ urea and $20 \%$ urea were not significantly different $(\mathrm{p}=0.629)$. 


\subsection{CONCLUSIONS}

Urea as an additive to the hot water extraction process is capable of pretreating woody biomass for the extraction of glucose. Understanding the optimal urea concentration necessary for extraction of glucose from red oak biomass has potential for applications of this procedure to be applied to other lignocellulosic materials for pretreatment purposes. Temperature and holding time were insignificant parameters in the recovery of glucose from urea-treated biomass, while urea concentration was the most important factor analyzed. The midpoint in the range of each insignificant factor was used because although each factor was determined insignificant in this experiment, the previous study by Sahu et al., 2008, determined these were the optimum conditions for the conversion of urea to ammonia. Through experiments, together with the response surface modelling, the optimal yield of glucose production was achieved producing 1.1 g glucose/g biomass under the conditions: temperature $\left(170^{\circ} \mathrm{C}\right)$, holding time $(60 \mathrm{~min})$, and urea concentration $(13.27 \% \mathrm{w} / \mathrm{w})$. The theoretical maximum concentration coincided with the experimental maximum, and was confirmed by experimental testing of concentrations surrounding the $13.27 \%$ urea extraction point. There was no significant difference found in the quantity of glucose recovered between 13\%, 13.27\%, and 13.5\% urea concentrations ( $\mathrm{p}=0.153)$, thus the quantity of urea necessary does not have to be exact to two decimal places. 


\section{REFERENCES}

Balan V, et al. 2009. Enzymatic digestibility and pretreatment degradation products of AFEXtreated hardwoods (Populus nigra). Biotechnology Progress 25:365-375.

Balat M. 2011. Production of bioethanol from lignocellulosic materials via the biochemical pathway: a review. Energy conversion and management 52:858-875.

Barr C, Hanson BL, Click K, Perrotta G, Schall C. 2014. Influence of ionic-liquid incubation temperature on changes in cellulose structure, biomass composition, and enzymatic digestibility. Cellulose 21:973-982.

Brooks B, Jessup WA, MacArthur BW. 2005. Method of quantitatively producing ammonia from urea: Google Patents

Hofmann L, Rusch K. 2001. Process for converting urea into ammonia: Google Patents

Hu F, Ragauskas A. 2012. Pretreatment and lignocellulosic chemistry. Bioenerg. Res. 5:10431066.

Huang H-J, Ramaswamy S, Tschirner UW, Ramarao BV. 2008. A review of separation technologies in current and future biorefineries. Separation and Purification Technology 62:1-21.

Jacob E, Stiermann E. 2006. Device and method for producing ammonia from solid urea pellets: Google Patents

Jones DG. 1998. Method for converting urea to ammonia: Google Patents

King E, Garner R. 1947. The colorimetric determination of glucose. Journal of Clinical Pathology 1:30. 
Knorr B. 2015. Weekly Fertilizer Review http://farmfutures.com/story-weekly-fertilizerreview-0-30765 (accessed April 22, 2015) (Type of Medium).

Kumar P, Barrett DM, Delwiche MJ, Stroeve P. 2009. Methods for Pretreatment of Lignocellulosic Biomass for Efficient Hydrolysis and Biofuel Production. Industrial \& Engineering Chemistry Research 48:3713-3729.

Lagana V. 1999. Combustion flue gas conditioning: Google Patents

Langan P, et al. 2014. Common processes drive the thermochemical pretreatment of lignocellulosic biomass. Green Chemistry 16:63-68.

Mok WSL, Antal Jr MJ. 1992. Uncatalyzed solvolysis of whole biomass hemicellulose by hot compressed liquid water. Industrial \& Engineering Chemistry Research 31:1157-1161.

Mosier N, et al. 2005. Features of promising technologies for pretreatment of lignocellulosic biomass. Bioresource Technology 96:673-686.

Pan X, et al. 2006. Bioconversion of hybrid poplar to ethanol and co-products using an organosolv fractionation process: optimization of process yields. Biotechnology and bioengineering 94:851-861.

Sahu JN, Mahalik K, Patwardhan AV, Meikap BC. 2008. Equilibrium and Kinetic Studies on the Hydrolysis of Urea for Ammonia Generation in a Semibatch Reactor. Industrial \& Engineering Chemistry Research 47:4689-4696.

Sluiter A, et al. 2012. Determination of structural carbohydrates and lignin in biomass. Laboratory analytical procedure.

Thygesen A, Oddershede J, Lilholt H, Thomsen AB, Ståhl K. 2005. On the determination of crystallinity and cellulose content in plant fibres. Cellulose 12:563-576. 
Zhao X, Cheng K, Liu D. 2009. Organosolv pretreatment of lignocellulosic biomass for enzymatic hydrolysis. Applied Microbiology and Biotechnology 82:815-827. 


\section{Urea Catalyzed Hot-Water Pretreatment of HYBRID WiLlow BIOMASS}




\section{AbSTRACT}

Hybrid willow is a short rotation wood crop (SWRC) that has the potential to be used for the extraction of sugars for biofuels or bioproducts. In the extraction of sugars from woody biomass feedstock, the pretreatment process is the most critical and costly step. Chemical pretreatments can partially destroy this recalcitrance of biomass and make it accessible for further conversion agents. A $2 \times 4$ factorial design was applied to analyze the use of urea as a chemical additive to a hot-water extraction process for the recovery of sugars from two cultivars of hybrid shrub willow: Belleville SV1 and Belleville Owasco. A reaction temperature of $170^{\circ} \mathrm{C}$ with a holding time of 60 minutes and varying urea concentration level were employed. There is no significant difference in the amount of sugar extracted between $12-15 \%$ urea concentrations, with hybrid shrub willow cultivar SV1 producing on average $0.42 \mathrm{~g}$ total sugar/g biomass, with glucose providing $93 \%$ of the total sugars. Cultivar Owasco produced on average $0.39 \mathrm{~g}$ total sugar/g biomass, with $91 \%$ of the total sugars were accounted for by glucose. There was also no significant difference in the quantity of total lignin determined in cultivars SV1 (37.9\%) and Owasco (44.7\%).

\subsection{INTRODUCTION}

Shrub willow hybrids are one of the most popular energy crops in the northeastern United States. It can grow quickly and in the poor soils of abandoned mine lands with a yield of 10-15 dry tons per hectare (ha). Shrub willow hybrids also have high pest and disease resistance, an increased wood density, and high biomass yield (Serapiglia et al., 2012), while containing the highest net energy output and lowest overall greenhouse gas emissions when compared to other perennial bioenergy feedstocks (Ehret et al., 2015). These traits make it possible for the willow 
to grow on low quality sites, and sites not conducive to agricultural crops. These traits also allow the willow to have the potential to be an efficient biomass crop with a short rotation and high yield. In order to utilize lignocellulosic materials, such as hybrid willow, as a feedstock for bioproducts, intensive labor and high capital costs for processing are required (Himmel et al., 2007; Limayem and Ricke, 2012). Pretreatment is considered the most costly operation and a major constraint toward achieving high yield with low costs (Limayem and Ricke, 2012), thus more efficient pretreatment methods must be developed to lower the overall cost of using biomass as a feedstock for bioenergy.

During the pretreatment of lignocellulosic biomass with hot water, the most significant reaction that occurs on plant material is a large amount of hemicellulose is removed, resulting in an enriched cellulose and lignin content in the pretreated residues. Due to the effective removal of the hemicellulose, the ability to extract glucose from the remaining sugars increases significantly. In a hot compressed water pretreatment, the acetic acid is released from O-acetyl groups in the polysaccharides, therefore lowering the $\mathrm{pH}$ of the extract. In other words, the hot water treatment can be considered an acid pretreatment of biomass (Rogalinski et al., 2008; Xiao et al., 2011). At extremely high temperatures, there is a greater tendency for the extracted sugars to degrade further into products such as hydroxymethyl furfural (HMF) or even further into levulinic acid (Rogalinski et al., 2008). The hemicelluloses are then dissolved as oligomers and further hydrolyzed to monomer sugars and sugar degradation products. The lignin is depolymerized and partially solubilized as well, but complete delignification is not possible (Xiao et al., 2011). During hot water treatment of hardwood chips, spherical droplets are formed on the surface of the material, which is thought to be hydrophobic lignin that has melted and repolymerized during pretreatment to minimize the exposed surface area in contact with the 
solution (Ko et al., 2015). Xiao et al. (2011) also analyzed the impacts of a compressed hot water pretreatment on the structure of woody biomass. They showed that the glucose produced in the water soluble fraction increased with increasing temperature until $140^{\circ} \mathrm{C}$. By the time the temperature reached $160^{\circ} \mathrm{C}$, the production of glucose actually began to decrease. Similarly, the xylose production increased with increasing temperature until $160^{\circ} \mathrm{C}$, then the production began to decrease afterwards with increasing temperature due to degradation of the xylose molecules. The quantity of levulinic acid formed was considered negligible, but the hydroxymethyl furfural (HMF) yield was always $<0.09 \mathrm{~g} / \mathrm{L}$. An XRD analysis (x-ray diffraction) indicated that there was little change in the cellulosic crystalline structures between pretreated and non-pretreated biomass, however the crystallinity index significantly increased (Xiao et al., 2011). This is thought to be caused by the pretreatment conditions solubilizing the hemicelluloses and lignin together, along with the non-crystalline cellulose (Yu and $\mathrm{Wu}, 2011)$.

When extremely low concentrations, approximately $0.07 \%$ of sulfuric acid, is added to a compressed hot water treatment, it does not lead to better results when compared to pure water (Rogalinski et al., 2008). The advantage to using the extremely low sulfuric acid is that the $\mathrm{pH}$ of the system can be significantly decreased resulting in faster reaction rates, but concentration is kept low enough that additional safety concerns can be avoided. When looking at the yield of this type of reaction, it was found that only the yield of undesired degradation products increased, namely furfural and HMF (Rogalinski et al., 2008). In a dilute acid hydrolysis, the maximum glucose yield capable of being converted from cellulose on a commercial scale was $50 \%$ (Yu et al., 2008). Higher yields are possible for shorter reaction times, but the process efficiency becomes low due to glucose degradation (Yu et al., 2008). During a dilute acid hydrolysis, the sugars obtained from the lignocellulosic biomass may be further degraded to 
other products, typically furfural. The five carbon sugars (from hemicellulose) typically degrade much faster than the six carbon sugars (from cellulose). One method for decreasing sugar degradation in the liquid phase is through the implementation of a two-stage process where the five carbon sugars are recovered first, followed by a second stage to recover the six carbon sugars (Karimi et al., 2006). During the use of concentrated sulfuric acid, the sulfuric acid is used to disrupt the hydrogen bonds between cellulose chains, converting it to a completely amorphous state. In comparison to dilute acid, the concentrated acid leads to very little sugar degradation, and results in up to $100 \%$ sugar yield (Yu et al., 2008).

A study by Timung et al. (2015) optimized temperature, holding time, and weight percent of both hot water and acid pretreatments on bamboo and sugar cane bagasse using response surface methodology. This study determined that the highest reducing sugar yield possible for the sugar cane bagasse was $23.49 \mathrm{~g} / \mathrm{L}$ for the acid treatment $\left(100^{\circ} \mathrm{C}, 10 \%\right.$ biomass loading, and 20 minutes), and $26.51 \mathrm{~g} / \mathrm{L}$ for the hot water treatment $\left(150^{\circ} \mathrm{C}, 10 \%\right.$ biomass loading, and 20 minutes). For the bamboo biomass, $15.6 \mathrm{~g} / \mathrm{L}$ reducing sugars were determined using acid pretreatment $\left(100^{\circ} \mathrm{C}, 10 \%\right.$ biomass loading, and 20 minutes), while the greatest amount reducing sugars, $17.98 \mathrm{~g} / \mathrm{L}$, from the hot water pretreatment were determined using the conditions: $167^{\circ} \mathrm{C}$, $7.5 \%$ biomass loading, and 15 minutes. It was found that irrespective of the biomass type, a hot water pretreatment produced more sugars than an acid pretreatment process, and that a higher temperature, the $\mathrm{pH}$ of the water was drastically reduced (Timung et al., 2015).

In comparison to a hot water treatment and an acidic treatment, the products produced by an alkaline treatment such as urea, vary again. The chemistry involved in the breakdown of urea uses excess water to promote the hydrolysis reaction, thereby breaking down urea to produce 
ammonium carbamate (Eq. 4.1), which continues to break down to produce carbon dioxide and ammonia (Eq. 4.2).

$$
\begin{array}{r}
\mathrm{NH}_{2} \mathrm{COHN}_{2}+\mathrm{H}_{2} \mathrm{O} \rightarrow \mathrm{NH}_{2} \mathrm{COONH}_{4} \\
\mathrm{NH}_{2} \mathrm{COONH}_{4} \rightarrow 2 \mathrm{NH}_{3}+\mathrm{CO}_{2}
\end{array}
$$

Further explanations of the kinetics and equilibrium have been explained in sections 2.1 and 3.1. Qualitatively, urea or ammonia pretreatment should affect lignocellulosic biomass in the same way. Urea is hydrolyzed into ammonia and carbon dioxide, and the ammonia then acts on the biomass. When ammonia is used to pretreat lignocellulosic biomass, it removes the lignin by cleaving the $\mathrm{C}-\mathrm{O}-\mathrm{C}$ bonds in lignin and other ether and ester bonds in the lignin carbohydrate matrix. This results in delignification of the biomass and a release of the cellulose and hemicellulose (Salvi et al., 2010). If the desired end product of pretreatment is sugar extracted from the biomass, ammonia pretreatment requires a secondary hydrolysis step because the majority of the sugars remain in the solid form instead of solubilizing into the liquid phase. The majority of sugars are still in solid polysaccharide form after this treatment while the lignin has been dissolved (Salvi et al., 2010; Sun and Cheng, 2002). Toxic inhibitors to microbes are not produced in the liquid phase either (Kumar et al., 2009; Salvi et al., 2010), which is beneficial for downstream conversion or fermentation.

When comparing acid and alkaline promoters on a liquid hot water pretreatment of rice straw, the addition of acid showed that there was an increasing trend of inhibitory sugar degradation by-products formed, which only increased with temperature and time (Imman et al., 2014). Also, when the desired end product was sugar, an alkali catalyzed reaction generated the 
least amount of solubilized glucose as well as the least sugar by-product in the liquid fraction (Imman et al., 2014). This allowed the majority of the glucose to stay in solid form after pretreatment, thus allowing a more efficient hydrolysis and recovery for the determination of sugars.

The research performed in the present study analyzes the ability of urea to be added to the hot water extraction process for the pretreatment of willow biomass. This study determined how sugar and lignin yields differ between hybrid willow cultivars, and what modifications allow for a greater sugar recovery. The specific objectives of this study were to (1) pretreat two cultivars of hybrid willow biomass using urea catalyzed hot water; (2) quantify the amount of lignin remaining in the treated willow biomass; and (3) quantify the amount of sugar recovered from treated willow biomass to evaluate the pretreatment efficacy

\subsection{MATERIALS AND METHODS}

\subsubsection{Materials}

Two hybrid willow cultivars (Salix spp.) were tested for the recovery of sugars after a urea pretreatment: Belleville SV1 Rep 1 and Bellville Owasco Rep 2. Shrub willow hybrid samples, in chip form, were provided by Cornell University and the New York State Agricultural Experiment Station. The chips from each cultivar were mechanically reduced in size using a power cutting mill (Model: Pulverisette 25, Fritsch GmbH, Germany) equipped with a $1 \mathrm{~mm}$ screen. Moisture content was conditioned to $6 \%$. 


\subsubsection{Experimental Design and Analysis}

To analyze the efficiency of sugar extraction from a urea pretreatment, a factorial design analyzing cultivar (2) x urea concentration (4) (Table 4.1) was used where the cultivar factor contains two levels (Owasco and SV1), while the urea concentration factor contains four levels $(12 \%, 13 \%, 13.27 \%$, and $15 \%)$. Urea concentrations chosen were those surrounding the optimal urea concentration determined in Chapter 3 for red oak biomass. Since the glucose determined in Chapter 3 was insignificantly different in a range surrounding the mathematical optimum, a small range of urea concentrations were used for hybrid willow biomass as well for the extraction of sugars.

Table 4.1. Testing conditions for shrub willow hybrids.

\begin{tabular}{lc}
\hline Cultivar & Urea Concentration (\%) \\
\hline Belleville SV1 Rep 1 & 12 \\
Belleville SV1 Rep 1 & 13 \\
Belleville SV1 Rep 1 & 13.27 \\
Belleville SV1 Rep 1 & 15 \\
Belleville Owasco Rep 2 & 12 \\
Belleville Owasco Rep 2 & 13 \\
Belleville Owasco Rep 2 & 13.27 \\
Belleville Owasco Rep 2 & 15 \\
\hline
\end{tabular}

The general linear model describing this factorial design is displayed in Equation 4.3.

$y_{i j k}=\mu+C_{i}+U_{j}+(C * U)_{i j}+\epsilon_{i j k}$

Where: $\mu=$ overall mean

$$
\mathrm{C}=\text { cultivar }
$$




$$
\begin{aligned}
& U=\text { urea concentration } \\
& \varepsilon=\text { error } \\
& i=1,2 \\
& j=1,2,3,4 \\
& k=1,2, \ldots n
\end{aligned}
$$

The urea concentrations used were chosen by dispersing levels around the ideal concentration found for red oak biomass, as found in Chapter 3. The factors taken into consideration in the optimization conditions determined for red oak biomass included temperature, holding time, and urea concentration. Temperature $\left(170^{\circ} \mathrm{C}\right)$ and holding time $(60$ minutes) were held constant since they were determined to be insignificant in the recovery of glucose, while urea concentration was a significant contributing factor in the recovery of glucose. The significant differences were tested at alpha 0.05 level.

\subsubsection{Pretreatment}

A Parr batch reactor was used to pretreat the material under a specified temperature $\left(170^{\circ} \mathrm{C}\right)$, holding time $(60 \mathrm{~min})$, and urea concentration levels, with a stirring speed set between 160-170 rpm. Deionized water and willow wood particles were combined in the $1 \mathrm{~L}$ vessel in a 7:1 water to wood weight ratio; this was used to ensure sufficient wetting of the material could occur. Urea concentration was measured on a weight-by-weight basis. After the 60-minute holding time, the reactor was cooled and the material was then sent through a filtration process. 
Filtration used a stainless steel mesh screen with a pore size of $72 \mu \mathrm{m}$ and a vacuum pump. The extracted mixture was poured over the stainless steel mesh screen and $175 \mathrm{~mL}$ of water was used to rinse the slurry. The liquid filtrate was captured in a flask and sampled before excess deionized water was used to recover the remaining solids from the reaction vessel. Once the solids were recovered, the material was placed in an oven at $103^{\circ} \mathrm{C}$ until a constant weight was achieved.

\subsubsection{Lignin and Carbohydrate Extraction}

After filtration, the solid material separated from the previous extraction was subjected to a National Renewable Energy Laboratory Analytical Procedure (NREL-LAP) for the determination of structural carbohydrates and lignin in biomass (Sluiter et al., 2012). This procedure performs an acid hydrolysis on the solid material to fractionate the acid soluble and acid insoluble material. The insoluble material may contain ash and protein, while the soluble fraction contains acid soluble lignin and hydrolyzed monomeric carbohydrates. Acid soluble lignin was measured through UV-Vis spectroscopy at $240 \mathrm{~nm}$, while the hydrolyzed monomeric carbohydrates were sent to Penn State for further analysis with high performance liquid chromatography (HPLC).

\subsubsection{Characterization of Biomass}

The two hybrid shrub willow cultivars used in this research, SV1 and Owasco have previously been classified with the quantities of cellulose, hemicellulose and lignin by Serapiglia et al., 2013 (Table 4.2). This testing was performed using thermogravimetric analysis of three replicates as a proportion of total dry biomass. 
Table 4.2. Approximate percent concentrations of cellulose, hemicellulose, and lignin of hybrid willow cultivars SV1 and Owasco (Serapiglia et al., 2013). Numbers in parentheses are the least significant differences from Tukey’s studentized range test (Serapiglia et al., 2013)

\begin{tabular}{lccc}
\hline & $\begin{array}{c}\text { Cellulose } \\
(\text { LSD }=2.7)\end{array}$ & $\begin{array}{c}\text { Hemicellulose } \\
(\mathrm{LSD}=2.1)\end{array}$ & $\begin{array}{c}\text { Lignin } \\
(\mathrm{LSD}=1.9)\end{array}$ \\
\hline Belleville Owasco & $43.5 \%$ & $32.5 \%$ & $21.5 \%$ \\
Belleville SV1 & $45 \%$ & $32 \%$ & $21.5 \%$ \\
\hline
\end{tabular}

This biomass was further characterized using proximate analysis to provide moisture, volatile matter, fixed carbon, and ash contents. The proximate analysis (moisture, volatile matter, fixed carbon, and ash) summarized in Table 4.3, was performed using a thermogravimetric analyzer (Model: LECO TGA 701, LECO Corporation, St. Joseph, MI. USA). Samples were run in triplicates to ensure accuracy.

Table 4.3. Proximate analysis (moisture, ash, volatile, and fixed carbon (\% d.b.) of urea pretreated red oak biomass.

\begin{tabular}{lcccc}
\hline & Moisture $(\%)$ & Ash $(\%)$ & Volatile $(\%)$ & Fixed Carbon $(\%)$ \\
\hline Belleville Owasco & 8.23 & 2.06 & 79.56 & 18.37 \\
Belleville SV1 & 6.32 & 1.60 & 81.44 & 16.96 \\
\hline
\end{tabular}




\subsection{RESULTS AND DISCUSSION}

\subsubsection{Acid Soluble Lignin}

There was no significant difference found in the quantity of acid soluble lignin (ASL) found among urea concentrations $(\mathrm{p}=0.657)$ or between cultivars $(\mathrm{p}=0.493)$. Regardless of the percentage urea used to treat the hybrid willow biomass, on average there was a total of $7.2 \%$ ASL found in cultivar SV1, while Owasco contained 6.0\% ASL (Table 4.4).

Table 4.4. Percent acid soluble lignin (ASL) in willow biomass at varying urea extraction concentrations (mean \pm standard deviation).

\begin{tabular}{lccccc}
\hline Urea concentration & $12 \%$ & $13 \%$ & $13.27 \%$ & $15 \%$ & Average \\
\hline SV1 & $6.3 \pm 2.17$ & $4.9 \pm 1.17$ & $9.9 \pm 2.56$ & $8.0 \pm 0.18$ & $7.3 \mathrm{~A}$ \\
Owasco & $3.1 \pm 1.34$ & $9.4 \pm 0.16$ & $5.9 \pm 3.98$ & $5.7 \pm 1.95$ & $6.0 \mathrm{~A}$ \\
\hline Average & $4.7 \mathrm{~A}$ & $7.1 \mathrm{~A}$ & $7.9 \mathrm{~A}$ & $6.9 \mathrm{~A}$ & \\
\hline
\end{tabular}

*Averages with the same letter are statistically not significantly different from each other.

When using sulfuric acid to depolymerize cellulose and hemicellulose as part of the NREL-LAP, the hydrolysis of the dissolved polysaccharides causes a fraction of the lignin to dissolve in the filtrate as well. Because lignin contains oxygen-containing functional groups, it is sensitive to acidic media and undergoes considerable changes (Yasuda et al., 2001). Hardwood and softwood species contain significantly different quantities of acid soluble lignin (ASL), and the report by Yasuda (2001) determined that beech wood, when soaked in water bath at $100^{\circ} \mathrm{C}$ for 60 minutes, contained 3.4\% ASL, while red pine, a softwood species, contained 0.5\% ASL. The ASL yield has been determined to almost completely dissolve within 30 minutes of 
hydrolysis when treated with $72 \%$ sulfuric acid (Yasuda et al., 2001). The hydrolysis procedures provided by NREL (Sluiter et al., 2012) use $72 \%$ acid for 60 minutes, thus ensuring all ASL has been dissolved. Since there is no significant difference between ASL measured among urea concentrations or cultivars, it implies that the urea pretreatment might not affect the quantity of ASL produced, nor was ASL affected by the cultivar of willow used either.

\subsubsection{Acid Insoluble Lignin}

When analyzing two cultivars of hybrid shrub willow, it was noticed that no significant difference in the quantity of acid insoluble lignin (AIL) existed between cultivars $(\mathrm{p}=0.169)$ nor did the urea extraction concentrations have any effect on the quantity of AIL $(p=0.942)$ (Table 4.5). Since there was no significant difference in the quantity of AIL calculated between all urea concentrations, the solid material of cultivar SV1, which underwent the acid hydrolysis, contained 30\% AIL while the cultivar Owasco material contained 38\% AIL. The quantity of AIL measured based on urea concentration ranged from $32 \%$ to $37 \%$, with no significant differences among each concentration or cultivar.

Table 4.5. Percent acid insoluble lignin (AIL) in willow biomass at varying urea concentrations.

\begin{tabular}{lccccc}
\hline Urea Concentration & $12 \%$ & $13 \%$ & $13.27 \%$ & $15 \%$ & Average \\
\hline SV1 & $23.8 \pm 5.53$ & $36.1 \pm 2.52$ & $29.8 \pm 9.13$ & $33.0 \pm 0.46$ & $30.7 \mathrm{~A}$ \\
Owasco & $49.5 \pm 4.73$ & $28.8 \pm 0.39$ & $35.3 \pm 6.48$ & $40.9 \pm 5.91$ & $38.6 \mathrm{~A}$ \\
\hline Average & $36.6 \mathrm{~A}$ & $32.5 \mathrm{~A}$ & $32.6 \mathrm{~A}$ & $37.0 \mathrm{~A}$ & \\
\hline
\end{tabular}

*Averages with the same letter are statistically not significantly different from each other 
When an acid hydrolysis is performed on woody biomass to hydrolyze the polymeric carbohydrates, a small fraction of solid material remains and is considered lignin (Effland, 1977). This acid insoluble lignin is theoretically the majority of the lignin contained within the sample. The removal of acid insoluble lignin is a driving factor when carbohydrate linkages are broken to hydrolyze poly- and monomeric sugars. Since this type of lignin is insoluble, if the bonds are not broken between the lignin and cellulose and hemicellulose components, it is possible for the lignin to prevent the carbohydrates from hydrolyzing into useful sugars (ASTM, 2007; Tappi, 2002). The ultimate goal of many hydrolysis procedures are to extract and recover the maximum quantity of sugars possible, and lignin has the possibility to hinder or prevent the recovery of these sugar monomers.

The two cultivars of hybrid willow analyzed showed no significant difference in the quantity of AIL measured. Since there is also no effect of urea pretreatment concentration on the quantity of AIL calculated, it can be determined that the acid hydrolysis procedure is capable of removing all lignin available in the hybrid willow biomass.

\subsubsection{Total Lignin}

The total lignin found in this study was not significantly different between cultivars $(\mathrm{p}=$ 0.324) nor among urea concentrations $(\mathrm{p}=0.933)$ used during pretreatment (Table 4.6). The average quantity of lignin found in cultivar SV1 was $37.9 \%$, while the average quantity of lignin in Owasco was $44.7 \%$. 
Table 4.6. Total lignin (\%) found in willow biomass at varying urea concentrations.

\begin{tabular}{lccccc}
\hline Urea Concentration & $12 \%$ & $13 \%$ & $13.27 \%$ & $15 \%$ & Average \\
\hline SV1 & $30.1 \pm 3.36$ & $40.9 \pm 3.70$ & $39.7 \pm 6.57$ & $41.0 \pm 0.64$ & $37.9 \mathrm{~A}$ \\
Owasco & $52.6 \pm 3.38$ & $38.2 \pm 0.55$ & $41.2 \pm 2.50$ & $46.7 \pm 3.96$ & $44.7 \mathrm{~A}$ \\
\hline Average & $41.3 \mathrm{~A}$ & $39.6 \mathrm{~A}$ & $40.5 \mathrm{~A}$ & $43.8 \mathrm{~A}$ & \\
\hline
\end{tabular}

*Averages with the same letter are statistically not significantly different from each other.

Urea pretreatment concentration was not a significant factor affecting the quantity of lignin determined within each cultivar of shrub willow because the procedure used in this research allowed the willow biomass to soak in $72 \%$ sulfuric acid for 60 minutes, then placed in an autoclave at $121^{\circ} \mathrm{C}$ for another 60 minutes at $4 \%$ sulfuric acid. It has been previously determined that after 30 minutes of allowing the material to soak in sulfuric acid, sufficient hydrolysis of the insoluble polysaccharides occurs (Yasuda et al., 2001). The 60-minute soak allows all polysaccharides to be hydrolyzed with sufficient swelling and destruction of the microfibril structure of cellulose. Klason lignin is defined in this procedure as the wood or pulp insoluble in 72\% sulfuric acid (Tappi, 2002), and because this Klason lignin has sufficient time for hydrolysis, all polysaccharides are removed, and pure lignin is the only constituent remaining in the solid. The amount of total lignin is comprised of the acid insoluble lignin combined with the acid soluble lignin (Figure 4.1). 


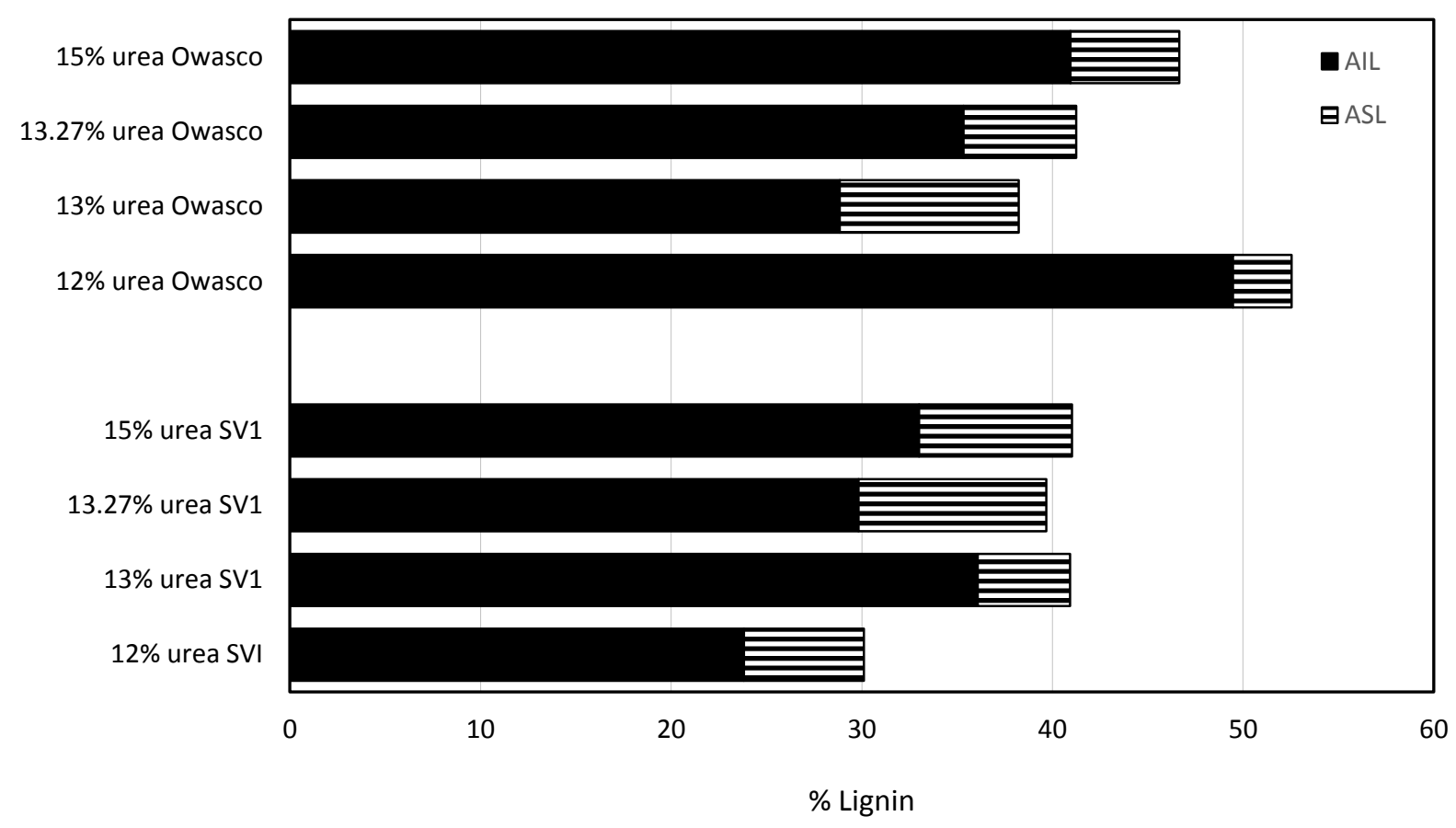

Figure 4.1. Total lignin available in cultivars of shrub willow according to urea pretreatment concentrations.

The quantities of lignin have the capability of being skewed high due to extractives and ash found in the wood. When extractives and ash are not removed prior to lignin quantification, it is possible for these two components to be calculated into the lignin amount. Ash content in wood is generally very low, less than $1 \%$. Extractive contents can range from $4-10 \%$ of the woody biomass (Serapiglia et al., 2009). 


\subsubsection{Carbohydrate Analysis}

Sugar samples isolated from the Determination of Structural Carbohydrates and Lignin procedure were set to Penn State for a complete sugar analysis using HPLC (Table 4.7). The sugars quantified included both 6-carbon (glucose, mannose, galactose), which used an anhydro correction factor of 0.90 , and 5-carbon (xylose, arabinose) with an anhydro correction factor of 0.88. Quantities reported from Penn State were determined in $\mathrm{mg} / \mathrm{L}$ and converted to a $\mathrm{g}$ sugar/g biomass basis based on the equations found in the NREL procedure. Quantities of galactose, arabinose, and mannose were insignificant in the total amount of $\mathrm{CHO}$ available. There was no significant difference in the quantity of glucose obtained between cultivars $(p=0.495)$, nor between urea concentrations $(\mathrm{p}=0.391)$. Glucose comprised the greatest amount of the total sugars available, ranging from $84 \%-97 \%$ of the total sugars in cultivar SV1, and $83 \%-94 \%$ of the

total sugars available in cultivar Owasco. Xylose, the second most abundant sugar found in this analysis, comprised only $1 \%-12 \%$ of the total sugars in cultivar SV1. The xylose in cultivar Owasco represented $4 \%-14 \%$ of the total sugars available. The remaining three sugars, galactose, arabinose, and mannose represented $>2 \%$ combined. 
Table 4.7. Sugar concentrations (g sugar/g biomass) determined by HPLC. Sugars separated using "Determination of Structural Carbohydrates and Lignin" procedure, and converted from $\mathrm{mg} / \mathrm{L}$ to gram sugar/gram biomass.

\begin{tabular}{llcccccc}
\hline \multirow{2}{*}{ Willow ID } & $\begin{array}{l}\text { Urea } \\
\text { Concentration }\end{array}$ & $\begin{array}{c}\text { glucose } \\
(\mathrm{g} / \mathrm{g})\end{array}$ & $\begin{array}{c}\text { xylose } \\
(\mathrm{g} / \mathrm{g})\end{array}$ & $\begin{array}{c}\text { galactose } \\
(\mathrm{g} / \mathrm{g})\end{array}$ & $\begin{array}{c}\text { arabinose } \\
(\mathrm{g} / \mathrm{g})\end{array}$ & $\begin{array}{c}\text { mannose } \\
(\mathrm{g} / \mathrm{g})\end{array}$ & $\begin{array}{c}\text { Total } \\
(\mathrm{g} / \mathrm{g})\end{array}$ \\
\hline \multirow{3}{*}{$\mathrm{SV} 1$} & $12 \%$ & 0.35 & 0.05 & 0.01 & 0.00 & 0.01 & 0.42 \\
& $13 \%$ & 0.41 & 0.02 & 0.00 & 0.00 & 0.01 & 0.44 \\
& $13.27 \%$ & 0.37 & 0.00 & 0.00 & $\mathrm{ND}$ & 0.01 & 0.38 \\
& $15 \%$ & 0.43 & 0.01 & 0.00 & $\mathrm{ND}$ & 0.01 & 0.45 \\
\hline Owasco & $12 \%$ & 0.21 & 0.01 & 0.00 & $\mathrm{ND}$ & 0.00 & 0.22 \\
& $13 \%$ & 0.48 & 0.08 & 0.00 & 0.00 & 0.01 & 0.58 \\
& $13.27 \%$ & 0.41 & 0.03 & 0.00 & 0.00 & 0.01 & 0.45 \\
& $15 \%$ & 0.28 & 0.01 & 0.00 & 0.00 & 0.00 & 0.30 \\
\hline
\end{tabular}

The results from the current urea pretreatment study indicated that on average across all urea extraction conditions, the total sugar yield per gram of biomass of cultivar SV1 is $0.42 \mathrm{~g} / \mathrm{g}$, while the Owasco cultivar yielded $0.39 \mathrm{~g}$ sugar/g biomass. The study by Serapiglia et al. (2013) analyzed each of these specific cultivars of willow, but used hot water to pretreat the willow biomass. Those results determined that cultivar SV1 was capable of yielding approximately $0.62 \mathrm{~g} / \mathrm{g}$ of glucose released while cultivar Owasco yielded approximately $0.58 \mathrm{~g} / \mathrm{g}$ of glucose after treatment. The hot water pretreatment improved the accessibility of the cell walls to enzymatic digestion, thus leading to 3-5 times greater sugar yields compared to untreated biomass. Serapiglia et al. stated that the majority of the sugar released was glucose, but "neither total sugar yield nor glucose yield was correlated with biomass composition or wood density, indicating that the total sugar content in the biomass is not the primary contributing factor for sugar availability" (Serapiglia et al., 2013). The results from the study performed Serapiglia et al. are consistently and evenly greater than those found in this study. This could be due to the 
efficiency of the urea pretreatment, indicating a pure hot water treatment performs better for the extraction of glucose. A second possibility would be that degradation of sugars occurred from the point of extraction to the HPLC analysis, since samples were transported to another facility for sugar analysis. To remove this uncertainty, it would be beneficial to both extract and test fresh sugars at the same facility as opposed to storing for future analysis.

The previous study in Chapter 3 on the optimization of temperature, holding time, and urea concentration on red oak biomass indicated that $13.27 \%$ urea concentration was the optimal level of urea to be added to the hot water extraction process when the biomass was treated at $170^{\circ} \mathrm{C}$ and held for 60 minutes. However, a range of urea concentrations were statistically insignificant when maximizing glucose yield. Using these conditions for the extraction of sugars from shrub willow hybrids appears to maximize the quantity of glucose as well.

\subsection{CONCLUSIONS}

When biomass was pretreated at $170^{\circ} \mathrm{C}$ and soaked for 60 minutes, it was found that a urea concentration range between $12-15 \%$ was the most suited for the extraction of glucose for recovery. On average, this urea concentration was capable of yielding $0.39 \mathrm{~g}$ glucose/g biomass, representing $93 \%$ of the total sugars available from cultivar SV1, while Owasco was capable of producing $0.34 \mathrm{~g}$ glucose/g biomass, representing $91 \%$ of the total sugars available. Coinciding with the glucose extractions, the solid residue from the pretreatment of SV1 only contained about $38 \%$ lignin while Owasco contained about $45 \%$ lignin. The total lignin for SV1 comprised of $30.6 \%$ AIL and 7.2\% ASL. The total lignin in cultivar Owasco was comprised of $38.6 \%$ AIL and $6.0 \%$ ASL. It was found that the quantity of urea used for pretreatment did not significantly affect the quantity of lignin separated in the biomass material. The maximum quantity of lignin 
was measured due to the sulfuric acid hydrolysis, not the urea pretreatment. The urea

pretreatment is effective due to the fact that the urea can disrupt and partially hydrolyze the carbohydrate matrices, while the lignin is still intact. This allows for a greater sugar extraction and recovery in the solid material after pretreatment. This is an ideal quality for a pretreatment technique so that sugar is not removed from the solid treated material, thus requiring recovery from both solid and liquid fractions from hydrolysis.

\section{REFERENCES}

ASTM. 2007. Standard Test Method for Acid-Insoluble Lignin in Wood West Conshohocken, PA: ASTM International

Effland MJ. 1977. Modified procedure to determine acid-insoluble lignin in wood and pulp. Journal Name: Tappi; (United States); Journal Volume: 60:10:Medium: X; Size: Pages: 143-144.

Ehret M, Bühle L, Graß R, Lamersdorf N, Wachendorf M. 2015. Bioenergy provision by an alley cropping system of grassland and shrub willow hybrids: biomass, fuel characteristics and net energy yields. Agroforestry Systems 89:365-381.

FPL. 2000. Wood handbook: wood as an engineering material--Laboratory FP, ed.: United States Government Printing. 5.

Himmel ME, et al. 2007. Biomass recalcitrance: engineering plants and enzymes for biofuels production. science 315:804-807.

Imman S, Arnthong J, Burapatana V, Champreda V, Laosiripojana N. 2014. Effects of acid and alkali promoters on compressed liquid hot water pretreatment of rice straw. Bioresource Technology 171:29-36. 
Karimi K, Kheradmandinia S, Taherzadeh MJ. 2006. Conversion of rice straw to sugars by dilute-acid hydrolysis. Biomass and Bioenergy 30:247-253.

King E, Garner R. 1947. The colorimetric determination of glucose. Journal of Clinical Pathology 1:30.

Ko JK, Kim Y, Ximenes E, Ladisch MR. 2015. Effect of liquid hot water pretreatment severity on properties of hardwood lignin and enzymatic hydrolysis of cellulose. Biotechnology and bioengineering 112:252-262.

Kumar P, Barrett DM, Delwiche MJ, Stroeve P. 2009. Methods for Pretreatment of Lignocellulosic Biomass for Efficient Hydrolysis and Biofuel Production. Industrial \& Engineering Chemistry Research 48:3713-3729.

Limayem A, Ricke SC. 2012. Lignocellulosic biomass for bioethanol production: current perspectives, potential issues and future prospects. Progress in Energy and Combustion Science 38:449-467.

Rogalinski T, Ingram T, Brunner G. 2008. Hydrolysis of lignocellulosic biomass in water under elevated temperatures and pressures. The Journal of Supercritical Fluids 47:54-63.

Salvi D, Aita G, Robert D, Bazan V. 2010. Dilute Ammonia Pretreatment of Sorghum and Its Effectiveness on Enzyme Hydrolysis and Ethanol Fermentation. Applied biochemistry and biotechnology 161:67-74.

Serapiglia M, Cameron K, Stipanovic A, Smart L. 2009. Analysis of Biomass Composition Using High-Resolution Thermogravimetric Analysis and Percent Bark Content for the Selection of Shrub Willow Bioenergy Crop Varieties. Bioenerg. Res. 2:1-9. 
Serapiglia MJ, Cameron KD, Stipanovic AJ, Abrahamson LP, Volk TA, Smart LB. 2012. Yield and woody biomass traits of novel shrub willow hybrids at two contrasting sites. Bioenerg. Res. 6:533-546.

Serapiglia MJ, et al. 2013. Enzymatic saccharification of shrub willow genotypes with differing biomass composition for biofuel production. Frontiers in plant science 4 .

Sluiter A, et al. 2012. Determination of structural carbohydrates and lignin in biomass. Laboratory analytical procedure.

Sun Y, Cheng J. 2002. Hydrolysis of lignocellulosic materials for ethanol production: a review. Bioresource Technology 83:1-11.

Tappi. 2002. Acid-insoluble lignin in wood and pulp. In: T222 om-02: Tappi Standard

Timung R, Mohan M, Chilukoti B, Sasmal S, Banerjee T, Goud VV. 2015. Optimization of dilute acid and hot water pretreatment of different lignocellulosic biomass: A comparative study. Biomass and Bioenergy 81:9-18.

Xiao L-P, Sun Z-J, Shi Z-J, Xu F, Sun R-C. 2011. Impact of hot compressed water pretreatment on the structural changes of woody biomass for bioethanol production. BioResources 6:1576-1598.

Yasuda S, Fukushima K, Kakehi A. 2001. Formation and chemical structures of acid-soluble lignin I: sulfuric acid treatment time and acid-soluble lignin content of hardwood. J Wood Sci 47:69-72.

Yu Y, Lou X, Wu H. 2008. Some recent advances in hydrolysis of biomass in hot-compressed water and its comparisons with other hydrolysis methods $\uparrow$. Energy \& Fuels 22:46-60.

Yu Y, Wu H. 2011. Effect of ball milling on the hydrolysis of microcrystalline cellulose in hotcompressed water. AIChE Journal 57:793-800. 


\section{A Comparative Analysis of Pelletization Effects ON LIGNOCELLULOSIC SUGAR EXTRACTION FROM WOODY BIOMASS}




\section{AbSTRACT}

Densified biomass, such as pellets, could be an ideal feedstock for the production of biofuels and bioproducts due to their advantages of long-term storage, resistance to degradation, and transportation. This study compared and tested whether pelletized biomass could produce the same quantity and quality sugars as non-pelletized biomass using two cultivars of hybrid willow biomass: Belleville SV1 and Bellville Owasco. Biomass was pretreated with hot water and urea, filtered, and analyzed for sugar content. The National Renewable Energy Laboratory, Laboratory Analytical Procedure (LAP) for the determination of structural carbohydrates and lignin was performed on the solid fraction, and the extracted sugars were quantified. The results of this study showed that no significant difference in the sugar yield existed between pelletized and non-pelletized biomass in cultivar SV1. However, there was a significant difference in the quantity of glucose extracted between cultivars SV1 and Owasco. Pelleted cultivar SV1 yielded the greatest quantity of glucose per gram of bimoass, $0.49 \mathrm{~g} / \mathrm{g}$, followed by non-pelleted SV1 containing $0.48 \mathrm{~g} / \mathrm{g}$. Pelleted cultivar Owasco contained a minimal $0.16 \mathrm{~g} / \mathrm{g}$, with the nonpelleted Owasco containing $0.38 \mathrm{~g} / \mathrm{g}$. A basic cost analysis determined approximately $\$ 14.3$ million per year is required for the use of wood pellets with no material being lost due to degradation by the weather, while $\$ 7.02$ million per year is required for wood chips with $\$ 15,500$ lost per year.

\section{$5.1 \quad$ INTRODUCTION}

Industrial sugars are important bio-based precursors for a variety of chemicals, especially when produced at competitive costs. As woody biomass becomes more widely used as an alternative energy source, even with increases in market value due to increased demand, the 
harvesting and collection costs may be a limiting factor in the true availability of a woody biomass feedstock (Hartley, 2014). The use of wood pellets instead of initially harvesting the biomass from the forest eliminates the need for a secondary facility to deal with the harvesting, collection, and transportation costs. It does not eliminate the effects of those cost variations downstream, but usually those variations are seen more indirectly and are absorbed into the entire process. Although wood pellet use can be expensive, the ability to use wood pellets as a feedstock in a sugar production facility might be beneficial because it can increase the energy density available, as well as being a mild form of "chemical" pretreatment. When material is pelletized, the lignin is softened to act as a binder in the pellet, eliminating the need for extra material, such as a resin or adhesive, to be included. Pelletized material also has the benefits of improved transportation, material handling, and storage (Hartley, 2014; Samson et al., 2000).

Densification is greatly impacted by a variety of processing parameters and raw material properties. The key process parameters and material properties identified for the pelletization of biomass include: particle size, moisture content, species, temperature, die length and diameter, and die rotation speed (Samson et al., 2000; Stelte, 2015).

The typical target value for the particle size of raw biomass is $4 \mathrm{~mm}$ when the target pellet size for residential heating fuel is 6-8mm in diameter (Mani et al., 2006; Nielsen et al., 2009; Obernberger and Thek, 2010). This size of pellet is the common diameter for use in a smallscale furnace, but variations can occur. For example, large power stations that have been converted from coal to pellets require a smaller particle size, because the pellets are crushed at the plant before injection into the boiler where the biomass will be burned. A larger particle size has the chance of incomplete combustion, resulting in stack emissions and charcoal in the bottom ash (Obernberger and Thek, 2010). Generally, finer particles cause the pellets to have a higher 
durability and can accept more moisture as compared to larger particles (Kaliyan and Morey, 2008). However, the finer grinding consumes more energy in the production process and thus leads to an increase in the production costs. A balance is necessary between required particle size and energy input to optimize the pellet production.

Moisture content also plays a significant role in processing the raw biomass. The higher the moisture content, the more difficult it is to grind the material since the wet biomass has a tendency to clog screens and holes as well as requiring a greater energy input. Once the material is processed to a smaller size, it is then easier to dry or condition to a set uniform moisture content (Obernberger and Thek, 2010). Water can also act as both a binding agent and a lubricant in the pellet process, and several studies have shown that the strength and durability of densified products increased with an increasing moisture content (Kaliyan and Morey, 2008). Again, a balance must also be found between moisture content and the ability to pelletize raw biomass, because it has been shown that as moisture content increases, the pellet density decreases. Potentially, too much moisture can prevent the particles from binding together to form the pellet since water cannot be compressed, while too little, again, allows the pellet to fall apart.

Species is the third factor that plays an important role in the ability to pelletize biomass. Logistically, the process steps for a raw material such as a short rotation woody crop must start before the raw material reaches the pellet facility. If the biomass is coming from a short rotation woody crop, the raw material is generally delivered as wood chips, thus requiring a coarse grinding before actual processing of pellets can occur. If raw biomass such as logs, chips from whole tree chipping, or residues are to be used, the chipping/grinding processes must again occur before the material reaches the pellet facility. The biomass is in need of a coarse grinding before 
the pelletization process can begin. The most frequently used material for pellet production include wood shavings, sawdust and wood dust which do not require the same mechanical treatments. Differences between hardwoods and softwoods must also be taken into account. Softwoods are considered to contain greater amounts of extractives than hardwoods, including resin compounds, fatty acids, waxes and sterols that could possibly act as a lubricant in the press channel, thus reducing the amount of friction and pelletizing pressure necessary to form softwood pellets. Also, the high extractive content might reduce the temperature dependency of the pelleting pressure as well (Stelte et al., 2011). As the extractive content increases in either hardwood or softwood biomass, the extractives could provide strength and stability to the pellet. For example, perhaps dirty chips were used so that there is bark in the biomass mixture; at temperatures above $180^{\circ} \mathrm{C}$ the extractives and lignin in the bark begin to polymerize, exhibiting a strong adhesive nature (Chow and Pickles, 1971).

Temperature is a significant factor in the production of wood pellets because it can be affected by a variety of sources: the pelletizer temperature, conditioning temperature as well as friction and moisture content (Stelte et al., 2011). As the temperature increases, drying of the biomass occurs, thus reducing the moisture content of the biomass being pressed. Increased moisture decreases the stiffness of the wood, thereby reducing the stiffness of the wood pellet as well (Gerhards, 1982). Friction can be minimized by increasing the temperature and moisture content because higher temperatures have the potential for extractives to polymerize, allowing the waxes, fatty acids, and other extractives to lubricate the pellet press; similarly a higher moisture content allows the water to act as a mobile layer between the pellet and the channel walls (Chow and Pickles, 1971; Nielsen et al., 2009). 
The press ratio, defined as the diameter of the die holes to the channel length, sets the length and width of the pellet that will be extruded from the pellet press (Figure 5.1).

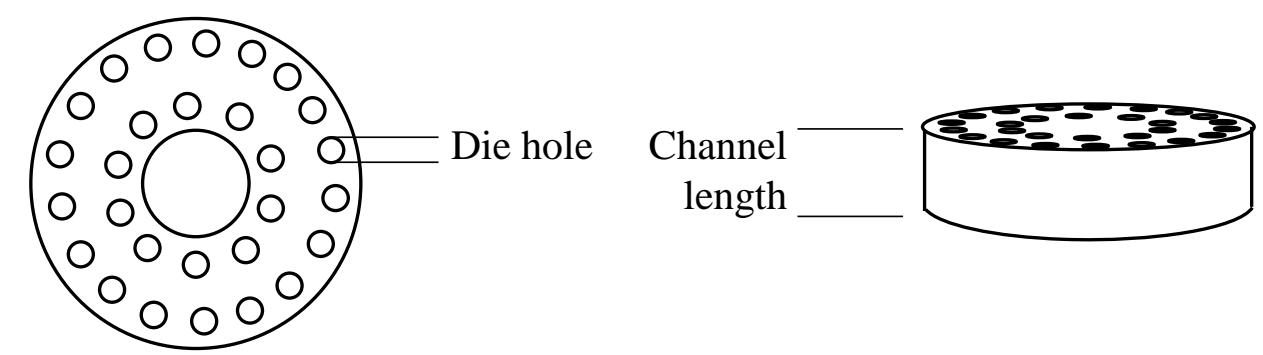

Figure 5.1. Diagram of a flat die for a pellet mill with top and side views. Die hole and length labelled for the press ratio.

For woody biomass, the optimal press ratio is between 1:3 and 1:5 (Obernberger and Thek, 2010). When investigating the processing parameters involved with the pelletization process, the press ratio combined with a specific type of raw material, determines the amount of friction generated in the press channels. The amount of friction is then directly related to both the force required to press the sawdust into the channels, as well as the temperature (Nielsen et al., 2009). A method of altering the press ratio is by altering the length of the die. A longer channel provides greater surface area, which in turn results in an increase of friction and temperature. Pellets that do not have a lot of binding strength require longer compression channels because the stiffness of the pellets increases with the channel length (Obernberger and Thek, 2010). Particle size is a key factor here. If the particle size is too large for the opening, the particles will block the openings, thus clogging the pellet press and limiting the quantity of quality pellets from being made. However, if the particles are extremely small in comparison to the opening, the pellets will become very dense with a greater quantity of biomass pressed into 
the space, again requiring more energy to compact the material (Kaliyan and Morey, 2008). The research performed by Stelte et al. in 2011 showed that there was a significant drop-off in the pressure required to make the pellets around a $10 \%$ moisture content in beech (another hardwood species), thus increasing the initial moisture content allows for some drying due to the friction in the press while still keeping the pressure required to make the pellets low.

Die rotation speed is the parameter influencing the densification of manufactured pellets. A slower rotational speed allows the amount of force applied to the sawdust entering the channels to be applied at an individual point for a longer period of time. The faster the rotational speed, the less time the material is being pressed at any given moment. The die rotation speed, the speed at which the raw material is forced into the channel, has been shown to be correlated to the pellet quality; when the rotation speed decreases, the pellet quality increases (Stelte, 2015). The slower rotation results in the material being compressed for longer periods of time, thus acquiring a longer retention time in the die. This then leads back into the discussion on friction and increasing temperature has the ability to soften the biomass and improve the flow of polymers to improve the internal adhesion of the particles in the wood pellet (Stelte et al., 2011).

Currently, pelletized biomass is commonly used in industrial or residential settings for home heating or co-firing with coal in power plants. When investigating the potential to use wood pellets as a feedstock for the extraction of sugars to be further refined into bioenergy products, it is necessary to determine what type of pellet is required. If the target is to extract as many sugars as possible from a pellet for comparison to non-pelletized, ground biomass, the pellets should retain higher quantities of cellulose and hemicellulose. This means that during the process of making the pellets, no sugars are degraded or lost through heating or chemical reactions. The processing factors that should have the greatest impact on the potential 
degradation of sugars are temperature, followed by particle size, pellet diameter, and to a lesser extent, species.

It was hypothesized that the pelletized material can produce similar quantities and qualities of sugar as ground, non-pelletized biomass. If this occurs, then the need for mechanical pretreatments at sugar facilities could be reduced or eliminated. Pelletized biomass, instead of ground, non-pelletized material, can be used as an initial feedstock for the extraction of sugars for future conversion. Therefore, the objectives of this study were to: (1) pretreat and analyze both pelletized and non-pelletized biomass using a urea pretreatment, and (2) compare and evaluate the two treated types of biomass in terms of sugar yield and lignin content.

\subsection{MATERIALS AND METHODS}

\subsubsection{Materials}

Two cultivars of shrub willow hybrid (Salix spp.) biomass were used: Belleville SV1 Rep 1 and Bellville Owasco Rep 2, obtained in northern New York by Cornell University. Shrub willow biomass characterized by rapid juvenile growth is being domesticated for use as a bioenergy crop in short rotation coppice systems (Serapiglia et al., 2012). The willow, obtained as chips, was further reduced in size using a power cutting mill (Model: Pulverisette 25, Fritsch $\mathrm{GmbH}$, Germany) with a $1 \mathrm{~mm}$ screen. Ground material was conditioned to $12 \%$ moisture content using an environmental chamber.

\subsubsection{Pelletization}

The pellets were made using Kahl pelletizer (Model: 14-175, Amandus Kahl GmbH, Germany). Once proper moisture content had been achieved, the ground material was fed into 
the pelleting piston press with a press ratio of 1 to 5 for the formation of pellets. Table 5.1 describes the production parameters used in this study to make pellets for the extraction of sugars.

Table 5.1. Production parameters to make pellets for the extraction of sugars.

\begin{tabular}{ll}
\hline Parameters & Values \\
\hline Particle size & $\leq 2 \mathrm{~mm}$ \\
Moisture Content & $12 \%$ \\
Species & Hybrid willow, two cultivars \\
Pellet length \& diameter & $6 \mathrm{~mm}$ diameter, $20 \mathrm{~mm}$ length \\
\hline
\end{tabular}

Particle size of willow biomass was $\leq 2 \mathrm{~mm}$ in this study. Allowing all sizes less than the $2 \mathrm{~mm}$ allows for an optimum pellet quality because the smaller particles will fill in the gaps between the larger particles with inter-particle bonding (Kaliyan and Morey, 2008). The smaller size particle will also be beneficial when the pellets are pretreated for the removal of sugars. The smaller size allows for greater surface area to be exposed for chemical, thermochemical, or enzymatic hydrolysis treatments.

The die length and diameter have been set to $6 \mathrm{~mm}$ in diameter. Pellet length was set to approximately $20 \mathrm{~mm}$. Pellets are cut to length by the cutting knife, which rotates at a given speed to allowing pellets to reach a specific length before being cut, dependent on diameter of the pellet die and press. This is a standard size commonly used in mills currently, so less modifications would be necessary if using pellets for the extraction of sugars.

The wood was conditioned to $12 \%$ moisture content in an environmental chamber to ensure that sufficient moisture is available to help plasticize the amorphous regions in the wood without denaturing the sugars. With sufficient water present in the wood, the hydrogen bonds 
between wood polymers are substituted with the hydrogen bonds to water instead (Stelte et al., 2011). This level of moisture content would also ensure that the hemicellulose sugars were not severely damaged by the temperatures necessary for pelletization.

\subsubsection{Experimental Design and Analysis}

To determine the effects of densification on the extraction of sugars, both pelletized and ground, non-pelletized biomass materials were pretreated with three urea concentrations. A $2 \times 2 \times 3$ mixed level factorial design was used to examine if significant differences of sugar yields exist among species (willow cultivars SV1 and Owasco), pelletization treatment (pelletized and non-pelletized), and urea concentration (three levels) (Table 5.2). A generalized linear model (Equation 5.1) was used to test the significances of sugar yields among the above mentioned factors and their interactions at $\alpha=0.05$ level.

$$
y_{i j k l}=\mu+C_{i}+P_{j}+U_{k}+(C * U)_{i j}+(C * P)_{i k}+(U * P)_{j k}+\varepsilon_{i j k}
$$

$$
\begin{aligned}
& \text { Where: } \mathrm{y}=\text { sugar yield } \\
& \begin{aligned}
\mu & =\text { overall mean } \\
\mathrm{C} & =\text { cultivar } \\
\mathrm{P} & =\text { pelletized/non pelletized } \\
\mathrm{U} & =\text { urea concentration } \\
\varepsilon & =\text { error } \\
\mathrm{i} & =1,2
\end{aligned}
\end{aligned}
$$




$$
\begin{aligned}
& \mathrm{j}=1,2 \\
& \mathrm{k}=1,2,3 \\
& \mathrm{l}=1,2, \ldots \mathrm{n}
\end{aligned}
$$

The urea concentrations were chosen using a low and a high level, surrounding the concentration determined to extract the greatest quantity of sugars from ground biomass. Pretreatment temperature was set at $170^{\circ} \mathrm{C}$ with a holding time of 60 minutes. These conditions were held constant since they were determined to be insignificant in the recovery of glucose, while urea concentration was the significant contributing factor in glucose recovery. The significant differences were tested at a 0.05 alpha level.

Table 5.2. Urea concentration for willow cultivars.

\begin{tabular}{lcc}
\hline Cultivar & Pelletized & Urea Concentration (\%) \\
\hline Belleville SV1 Rep 1 & No & 0 \\
Belleville SV1 Rep 1 & Yes & 0 \\
Belleville SV1 Rep 1 & No & 13.27 \\
Belleville SV1 Rep 1 & Yes & 13.27 \\
Belleville SV1 Rep 1 & No & 15 \\
Belleville SV1 Rep 1 & Yes & 15 \\
Belleville Owasco Rep 2 & No & 0 \\
Belleville Owasco Rep 2 & Yes & 0 \\
Belleville Owasco Rep 2 & No & 13.27 \\
Belleville Owasco Rep 2 & Yes & 13.27 \\
Belleville Owasco Rep 2 & No & 15 \\
Belleville Owasco Rep 2 & Yes & 15 \\
\hline
\end{tabular}




\subsubsection{Pretreatment}

A urea extraction was performed in a Parr batch reactor using deionized water, willow biomass and urea in a $1 \mathrm{~L}$ vessel. Deionized water and biomass were added in a 7/1 ratio in weight to ensure sufficient wetting of the biomass. Urea concentration is measured on a weightby-weight basis of urea to wood. Willow biomass was either added in non-pelletized or pelletized form. After pretreatment, the resultant slurry from the Parr batch reactor was then filtered through a $72 \mu \mathrm{m}$ stainless steel mesh screen. The extracted mixture of water, urea and wood was poured over the $72 \mu \mathrm{m}$ mesh screen and a vacuum pump was used to pull the liquid through the screen and separate it from the solid fraction. The solids remaining on the mesh screen were then washed with $175 \mathrm{~mL}$ of deionized water. Once the solids were washed, the liquid extract plus $175 \mathrm{~mL}$ rinse were weighed. Excess deionized water was used to capture all solid particles onto the mesh screen.

\subsubsection{Lignin and carbohydrate quantification}

The NREL (National Renewable Energy Laboratory) Laboratory Analytical Procedures (LAP) were used to determine the structural carbohydrates and lignin in biomass (Sluiter et al., 2012). In this process, $300.0+/-10.0 \mathrm{mg}$ of the solid particulate recovered from the extraction in section 5.2.4 was combined in a pressure tube with $3.00 \mathrm{~mL}$ of $72 \%$ sulfuric acid. This mixture was incubated for 60 minutes in a $30^{\circ} \mathrm{C}$ water bath, with the mixture stirred every 10 minutes. Upon completion of the 60-minute hydrolysis, the mixture was diluted with $84 \mathrm{~mL}$ water to reach a $4 \%$ sulfuric acid concentration. The mixture was then autoclaved at $121^{\circ} \mathrm{C}$ for one hour, then allowed to cool to near room temperature. The autoclaved hydrolysis solution was then vacuum filtered through a weighing crucible with the filtrate captured and a sample of the liquid 
extract saved for acid soluble lignin and carbohydrate analyses. The remaining solids in the autoclaved flask were then recovered using excess deionized water to capture all remaining material. The filtering crucibles were then oven dried at $103^{\circ} \mathrm{C}$ until a constant weight was achieved and the weight was recorded. The sample was then placed in a muffle furnace at $575^{\circ} \mathrm{C}$ for 24 hours to determine acid insoluble lignin content. The aliquot of hydrolysis liquor, saved previously, was measured at $240 \mathrm{~nm}$ for acid soluble lignin content. A portion of the hydrolysis liquor was also subjected to the Somogyi-Nelson procedure for the estimation of glucose with the absorbance read at $540 \mathrm{~nm}$.

A glucose standard curve was developed based on known concentrations of D-glucose subjected to the Nelson-Somogyi assay for use as an indicator of the total sugar content extracted by the NREL-LAP. Glucose concentrations were tested in triplicates to ensure accurate readings. A linear regression model was developed to estimate the unknown sample concentrations. This linear equation was then multiplied by a dilution factor, as determined by the number of dilutions necessary to bring the absorbance reading to between 0 and 1 , according to Beer's Law (King and Garner, 1947). Corrected absorbance values were determined by subtracting the absorbance found in the deionized water blank filled with deionized water from the absorbance of the unknown solutions (Caymon_Chemical_Company, 2015).

\subsubsection{Characterization of biomass}

This biomass was characterized using proximate analysis to provide moisture, volatile matter, fixed carbon, and ash contents of both the raw material as well as the pelletized material. The proximate analysis (moisture, volatile matter, fixed carbon, and ash) summarized in Table 
5.3, was performed using a thermogravimetric analyzer (Model: LECO TGA 701, LECO Corporation, St. Joseph, MI. USA).

Table 5.3. Proximate analysis (moisture, ash, volatile, and fixed carbon (\% d.b.) of urea pretreated hybrid willow biomass, both pelleted and non-pelleted.

\begin{tabular}{lcccc}
\hline & Ash (\%) & Fixed Carbon (\%) & Moisture (\%) & Volatile (\%) \\
\hline SV1 Ground & 1.60 & 16.96 & 6.32 & 81.44 \\
SV1 Pellet & 1.19 & 18.29 & 6.88 & 80.52 \\
Owasco Ground & 2.06 & 18.37 & 8.23 & 79.56 \\
Owasco Pellet & 2.24 & 18.47 & 7.08 & 79.28 \\
\hline
\end{tabular}

Pellet density was also analyzed to determine whether the pellets manufactured for this study are consistent with those produced in industry. Industrial pellets were made from pure hybrid poplar material and obtained from the Greene Team Pellet Fuel Company (Carmichaels, PA). These pellets were tested as a standard for pellet density and compared to the pellets manufactured for this study. Density was tested using a liquid displacement method (Rabier et al., 2006), with Belleville SV1 measuring a density of $1.3 \mathrm{~g} / \mathrm{cm}^{3}$, Belleville Owasco at $1.2 \mathrm{~g} / \mathrm{cm}^{3}$, and commercial pellets from Greene Team at $1.1 \mathrm{~g} / \mathrm{cm}^{3}$.

\subsection{RESULTS AND DISCUSSION}

\subsubsection{Sugar Quantification}

From the determination of structural carbohydrates and lignin procedure (Sluiter et al., 2012), the structural carbohydrates were isolated as described in section 5.2.5. The hydrolysis liquor was filtered and sent to Penn State University for high performance liquid 
chromatography (HPLC) analysis of both 5-carbon (xylose, galactose, and arabinose) and 6carbon (glucose, mannose) (Table 5.4).

Table 5.4. HPLC analysis of sugars performed by Penn State University. Values obtained were reported in $\mathrm{mg} / \mathrm{L}$ and converted to grams sugar per gram biomass using equations found in NREL-LAP (Sluiter et al., 2012).

\begin{tabular}{ccccccccc}
\hline Cultivar & $\begin{array}{c}\text { Material } \\
\text { Type }\end{array}$ & $\begin{array}{c}\text { Urea } \\
\text { Conc. }\end{array}$ & $\begin{array}{c}\text { glucose } \\
(\mathrm{g} / \mathrm{g})\end{array}$ & $\begin{array}{c}\text { xylose } \\
(\mathrm{g} / \mathrm{g})\end{array}$ & $\begin{array}{c}\text { galactose } \\
(\mathrm{g} / \mathrm{g})\end{array}$ & $\begin{array}{c}\text { arabinose } \\
(\mathrm{g} / \mathrm{g})\end{array}$ & $\begin{array}{c}\text { mannose } \\
(\mathrm{g} / \mathrm{g})\end{array}$ & $\begin{array}{c}\text { Total } \\
(\mathrm{g} / \mathrm{g})\end{array}$ \\
\hline SV1 & ground & $0 \%$ & 0.58 & 0.04 & 0.00 & NA & 0.01 & 0.63 \\
SV1 & ground & $13.27 \%$ & 0.36 & 0.00 & 0.00 & NA & 0.01 & 0.38 \\
SV1 & ground & $15 \%$ & 0.42 & 0.01 & 0.00 & NA & 0.01 & 0.44 \\
SV1 & pellet & $0 \%$ & 0.53 & 0.01 & 0.00 & NA & 0.01 & 0.54 \\
SV1 & pellet & $13.27 \%$ & 0.39 & 0.00 & 0.00 & NA & 0.01 & 0.40 \\
SV1 & pellet & $15 \%$ & 0.42 & 0.00 & 0.00 & NA & 0.01 & 0.43 \\
Owasco & ground & $0 \%$ & 0.12 & 0.00 & NA & NA & 0.00 & 0.12 \\
Owasco & ground & $13.27 \%$ & 0.40 & 0.03 & 0.00 & 0.00 & 0.01 & 0.44 \\
Owasco & ground & $15 \%$ & 0.27 & 0.01 & 0.00 & 0.00 & 0.00 & 0.29 \\
Owasco & pellet & $0 \%$ & 0.41 & 0.01 & NA & NA & 0.00 & 0.42 \\
Owasco & pellet & $13.27 \%$ & 0.12 & 0.01 & 0.00 & NA & 0.00 & 0.13 \\
Owasco & pellet & $15 \%$ & 0.21 & 0.01 & 0.00 & NA & 0.00 & 0.22 \\
\hline
\end{tabular}

Glucose comprised between $91 \%-98 \%$ of the total sugars available in both cultivars, so glucose can be used as an indicator of total sugars found in hybrid willow biomass, regardless of cultivar. Overall, there was a significant difference in the amount of glucose determined between the material types $(\mathrm{p}=0.008)$, but there was no significant difference in the glucose recovered based on urea concentration $(\mathrm{p}=0.253)$. Further investigation is required to determine if some or all of the material types produced significantly different glucose concentrations. Looking at the amount of glucose determined from the ground material of both cultivars SV1 and Owasco, there was no significant difference from each other based on urea concentration ( $\mathrm{p}$ 
$=0.363)$ nor cultivar $(\mathrm{p}=0.292)$. However, once the willow biomass has been pelleted, significant differences in glucose concentrations were found between cultivars $(p=0.038)$, but not between urea concentrations $(\mathrm{p}=0.661)$. Across all urea concentrations, pelleted SV1 produced $0.46 \mathrm{~g}$ glucose /g biomass, while pelleted Owasco produced $0.16 \mathrm{~g}$ glucose/g biomass.

When looking individually at cultivar SV1, there was no significant difference found between pelleted and non-pelleted glucose concentrations $(\mathrm{p}=0.717)$, but there was a significant difference in the amount of glucose extracted based on urea concentration $(\mathrm{p}=0.044)$. Cultivar Owasco had a significant difference in glucose recovered in two out of the three urea concentrations. At a $0 \%$ and a $13.27 \%$ urea concentration, there was a significant difference in the quantity of glucose recovered $(p=0.008)$, but at the $15 \%$ urea level, there was no significant difference $(\mathrm{p}=0.958)$. On average, pelleted Owasco recovered only $0.16 \mathrm{~g}$ glucose/g biomass, while ground Owasco recovered $0.38 \mathrm{~g}$ glucose $/ \mathrm{g}$ biomass.

Cultivar SV1 consistently provided a greater glucose recovery than Owasco, regardless of urea extraction concentration. Pelleted and non-pelleted SV1 samples are capable of being used interchangeably for the recovery of glucose, however non-pelleted Owasco recovers a significantly greater quantity of glucose as compared to pelleted Owasco. It is noted however that the variation provided by the pelleted material is smaller than that found with the nonpelleted, indicating that the extraction of sugars from pelleted material is more uniform (Figure 5.2). 


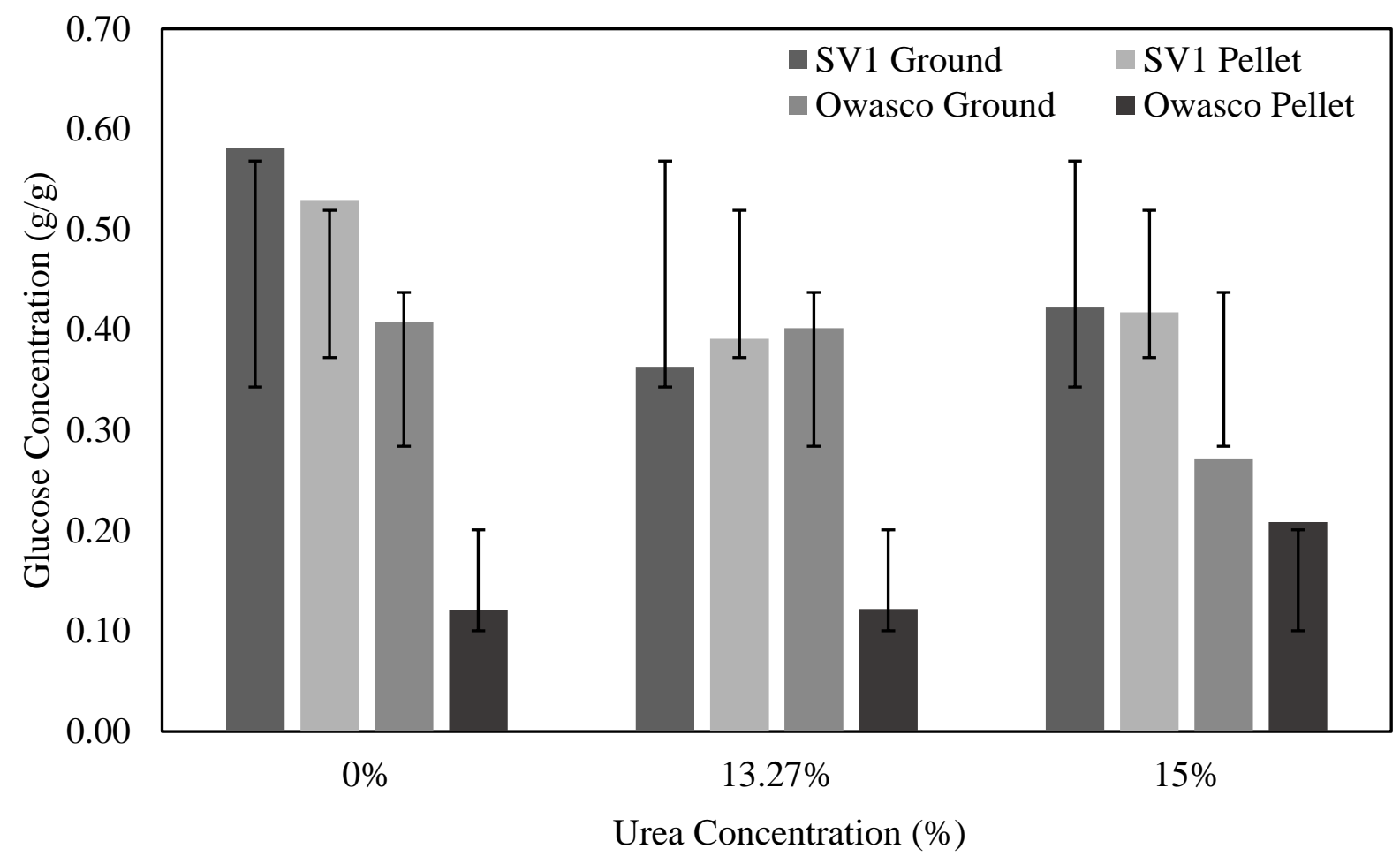

Figure 5.2. Glucose concentrations (g glucose/g biomass) recovered from willow biomass, based on urea concentration, cultivar, and material type (mean \pm standard deviation).

Serapiglia et al. (2013) performed testing on the same hybrid willow cultivars and showed that the quantity of cellulose found in cultivar SV1 was greater than that of Owasco. Moreover, they determined that the quantity of total sugars found in cultivar SV1 was consistently greater than those found in the Owasco cultivar. Since cellulose is comprised of many glucose monomers linked together through $\beta 1-4$ glycosidic bonds (Zhang et al., 2006), it stands to reason that a greater quantity of glucose has the potential of being recovered. The more efficient a pretreatment method is, the greater the quantity of glucose. The results from this 
study show that the quantity of glucose recovered from SV1 is greater than that from cultivar Owasco, thus confirming the use of glucose as an indicator of total sugars.

\subsubsection{Lignin Quantification}

Pelletized material did not contain any significantly different concentrations of acid soluble lignin (ASL) compared to its non-pelletized form at any level of urea concentration (Table 5.4). However, a significantly different quantity of lignin existed between cultivars SV1 and Owasco pellets $(\mathrm{p}=0.027)$. Pelleted cultivar SV1 contained on average $5.32 \%$ ASL across all urea concentrations, while pelleted cultivar Owasco only had 2.82\% ASL. There is no pattern in the quantity of acid soluble lignin found in shrub willow among urea concentrations for each cultivar nor between pelletized and non-pelletized material. This indicates that the majority of the ASL that exists in the willow cultivars is accounted for.

For the acid insoluble lignin (AIL) contents, there was no significant difference between pelletized and non-pelletized materials among any urea concentrations (p-values: $0 \%=0.966$, $13.27 \%=0.354,15 \%=0.674)($ Table 5.4). However, the AIL did differ significantly between cultivars $(\mathrm{p}=0.019)$. The pelletized cultivar SV1 contained 34.2\% AIL while the pelletized Owasco had 50.5\% AIL. Non-pelletized SV1 contained 30.6\% AIL and non-pelletized Owasco contained $43.6 \%$ AIL. 
Table 5.5. Means and significance levels of percent acid soluble lignin (ASL) and acid insoluble lignin (AIL) between pelletized and non-pelletized hybrid willow cultivars by urea concentrations.

\begin{tabular}{|c|c|c|c|c|c|c|c|c|c|}
\hline & \multicolumn{3}{|c|}{ ASL } & \multicolumn{3}{|c|}{ AIL } & \multicolumn{3}{|c|}{ Total Lignin } \\
\hline & $0 \%$ urea & $13.27 \%$ urea & $15 \%$ urea & $0 \%$ urea & $13.27 \%$ urea & $15 \%$ urea & $0 \%$ urea & $13.27 \%$ urea & $15 \%$ urea \\
\hline Owasco Pellet & $2.62 \mathrm{~A}$ & $3.52 \mathrm{~A}$ & $2.33 \mathrm{~A}$ & $48.1 \mathrm{~A}$ & $49.8 \mathrm{~A}$ & $53.7 \mathrm{~A}$ & $50.7 \mathrm{~A}$ & $53.3 \mathrm{~A}$ & $56.1 \mathrm{~A}$ \\
\hline Owasco Ground & $2.56 \mathrm{~A} / \mathrm{C}$ & $5.90 \mathrm{~A} / \mathrm{C}$ & $5.71 \mathrm{~A} / \mathrm{C}$ & $54.6 \mathrm{~A} / \mathrm{B}$ & $35.3 \mathrm{~A} / \mathrm{B}$ & $40.9 \mathrm{~A} / \mathrm{B}$ & $57.2 \mathrm{~A} / \mathrm{B}$ & $41.2 \mathrm{~A} / \mathrm{B}$ & $46.7 \mathrm{~A} / \mathrm{B}$ \\
\hline SV1 Pellet & $4.84 \mathrm{~B} / \mathrm{C}$ & $5.47 \mathrm{~B} / \mathrm{C}$ & $5.65 \mathrm{~B} / \mathrm{C}$ & $35.0 \mathrm{~B}$ & $34.7 \mathrm{~B}$ & $33.0 \mathrm{~B}$ & $39.8 \mathrm{~B}$ & $40.3 \mathrm{~B}$ & $38.4 \mathrm{~B}$ \\
\hline SV1 Ground & $5.74 \mathrm{~B}$ & $9.86 \mathrm{~B}$ & $8.02 \mathrm{~B}$ & $29.8 \mathrm{~B}$ & $29.8 \mathrm{~B}$ & $33.0 \mathrm{~B}$ & $35.5 \mathrm{~B}$ & $39.7 \mathrm{~B}$ & $41.0 \mathrm{~B}$ \\
\hline
\end{tabular}

*Means with the same letter in column are not significantly different at 0.05 level using the analysis of variance test. 
These results are supported by the determination that SV1 contained a greater quantity of cellulose (Serapiglia et al., 2013). SV1 contains a greater quantity of cellulose than Owasco, thus it stands to reason that either its hemicellulose or lignin percent should be lower. Interestingly, there was no significant difference for the AIL of the non-pelletized biomass between SV1 and Owasco (p-value $=0.170)$. However the difference in AIL in pelletized biomass could be due to the fact that during pelletization, the lignin can be softened and its structure disrupted, thus affecting the quantity of AIL capable of being measured after pelletization has occurred. Although each cultivar underwent the same pelletization process, the effects of temperature and pressure can create different effects genetically modified genotypes.

Acid soluble lignin and acid insoluble lignin together comprise the total lignin content available in the biomass sample. The Owasco cultivar consistently had a greater lignin content than the SV1 cultivar. Total lignin was not significantly different between non-pelletized and pelletized Owasco $(\mathrm{p}=0.480)$, and did not significantly change among urea concentrations either $(\mathrm{p}$-value $=0.688)($ Figure 5.3). Similarly, for the SV1 cultivar no significant difference in total lignin existed between pelletized and non-pelletized material $(\mathrm{p}=0.738)$; nor among urea concentrations $(\mathrm{p}=0.646)$. However, a significant difference in the total lignin content did exist between pelletized Owasco and SV1 $(\mathrm{p}=0.020)$. On average, among all urea concentrations, SV1 pellets contained 39.5\% lignin while Owasco pellets contained 53.4\% lignin. 


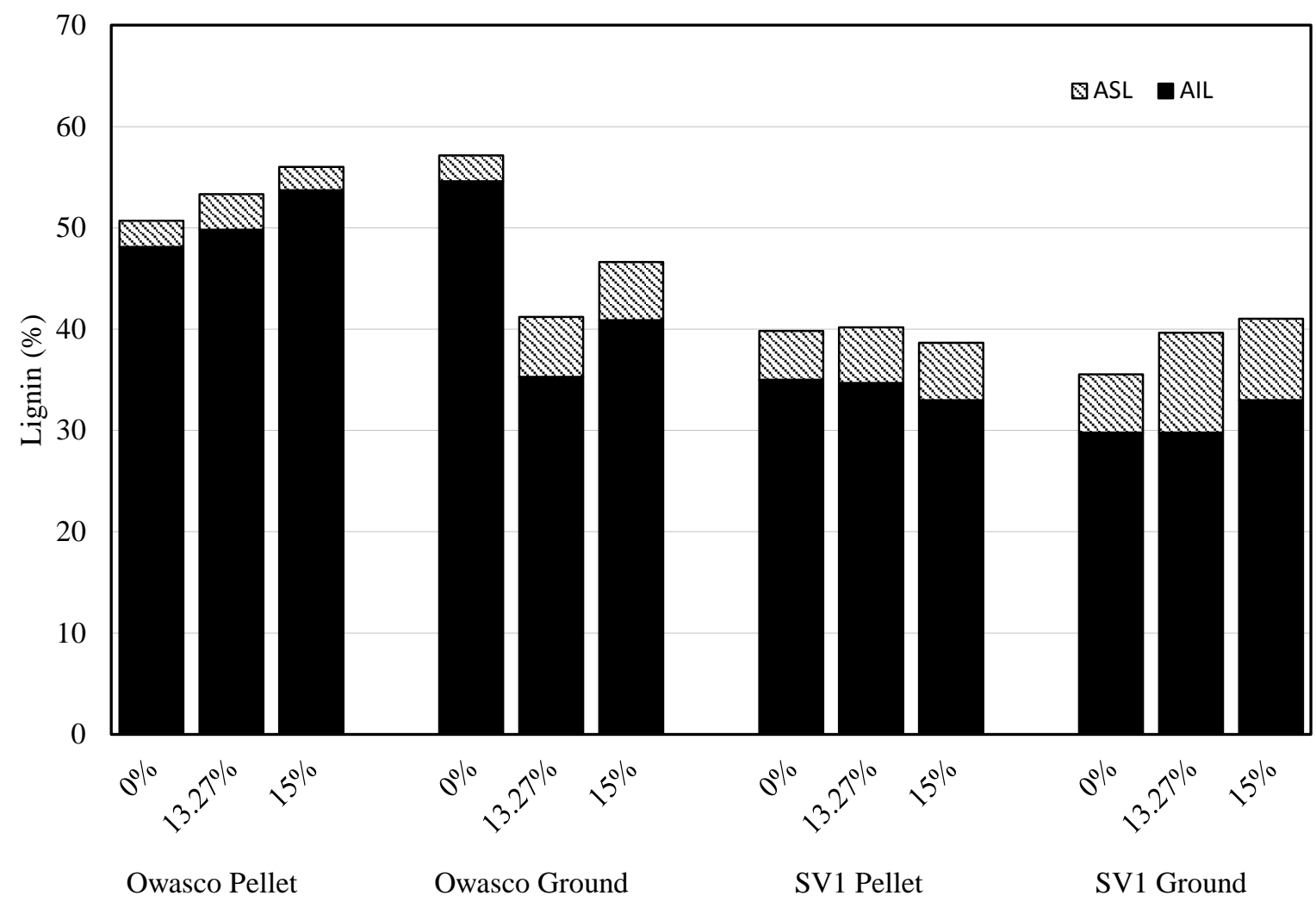

Figure 5.3. Total lignin as a composite of acid insoluble lignin (AIL) and acid soluble lignin (ASL) by species (Owasco, SV1), treatment (pellet, ground) and urea concentration (0\%, $13.27 \%, 15 \%)$.

\subsubsection{Cost Comparisons}

A basic cost analysis of pelletized vs. non-pelletized biomass is necessary to justify if the pelletized biomass is an economical feedstock for lignocellulosic sugar production. The major cost factors of interest include: feedstock cost (chipped or pelleted), transportation, drying, grinding and storage. This analysis does not include profit made from any final products, it is purely expenses. These process steps comprise the beginning of the supply chain from the initial 
procurement of material until pretreatment is ready to be performed. The pretreatment process and beyond are not included in this cost comparison, since facilities and other material costs will stay the same between pellets and wood chips.

Feedstock cost of willow wood chips are reported on a dry ton basis. Pellet cost is reported on an aggregated survey of wood pellet dealers and includes both hardwood and mixed blend pellets. Transportation was assumed to be 50 miles and would cover the distance from the dealer to the processing facilities. There are three types of storage available for biomass: open air, covered storage, or silo storage. For both pellets and chips the storage type is reported as covered storage. Pellets cannot be stored in open air due to their inability to withstand precipitation and silo storage has a much higher fixed cost associated with it (Hartley, 2014), thus covered storage is used as a base cost. The values listed in Table 5.5 are the maximum capacities a covered building can store, based on feedstock type. The percent material loss per month is the amount of material that is lost to degradation due to natural factors and is rendered unusable. Finally, drying and grinding must occur on the willow wood chips to process the material into particles for use in the pretreatment process. Since wood pellets are the direct feedstock, no extra processing is required thus resulting in no cost for these process steps. 
Table 5.6. Cost comparisons of wood pellets and willow wood chips in terms of major logistical processes. A transportation distance of 50 miles is assumed.

\begin{tabular}{|c|c|c|}
\hline & Pellets & Willow Chips \\
\hline Feedstock Cost & $\$ 257 /$ ton $^{\mathrm{d}}$ & $\$ 55 /$ ton $^{\mathrm{c}}$ \\
\hline Transportation & $\$ 5.90 /$ ton $^{\mathrm{a}}$ & $\$ 7.75 /$ ton $^{\mathrm{a}}$ \\
\hline Storage & $\begin{array}{c}10323 \text { tons @ 0\% material } \\
\text { loss } / \text { month }^{\mathrm{a}}\end{array}$ & $\begin{array}{c}5556 \text { tons @ } 0.5 \% \text { material } \\
\text { loss } / \text { month }^{\mathrm{a}}\end{array}$ \\
\hline Drying & N/A & $\$ 62.21 /$ ton $^{\mathrm{b}}$ \\
\hline Grinding & N/A & $\$ 3.49 /$ ton $^{\mathrm{b}}$ \\
\hline \multicolumn{3}{|c|}{ * The price/cost was reported in $€ /$ tonne and was converted to $\$ /$ ton. Conversion rates for money } \\
\hline \multicolumn{3}{|c|}{ were calculated based on the exchange rate at the time of publication. } \\
\hline \multicolumn{3}{|l|}{ a(Hartley, 2014) } \\
\hline \multicolumn{3}{|c|}{ b(Obernberger and Thek, 2010) } \\
\hline \multicolumn{3}{|l|}{ c(Eisenbies, 2015) } \\
\hline d (EEA, 2015) & & \\
\hline
\end{tabular}

Almost twice as many pellets can be stored in one location compared to wood chips, which reduces the space necessary to store the material. Wood chips are subjected to weathering and degradation, losing approximately $0.5 \%$ material per month, while pellets do not encounter this material loss when using covered storage (Hartley, 2014). The average length of time wood chips spend in storage is approximately 6 months on a first-in first-out basis (Hartley, 2014). This results in 165 tons of wood chips degrading in a six month time span while pellets do not lose any material. The total cost of one ton of willow chips stored for six months is $\$ 132 /$ ton, while the total cost of one ton of pellets stored for six months is $\$ 263 /$ ton. If the covered building used for storage is completely filled, the cost of the building and the storage of the 
pellets for six months is $\$ 2.7$ million, but can hold 10343 tons of material. The cost associated with wood chips, stored for six months, is only $\$ 718,000$. Assuming a small bioenergy production facility requires 49,500 dry Mg per year (54,564.4 dry tons per year), using pellets requires $\$ 14.3$ million while the use of wood chips is $\$ 7.02$ million. However, between the two scenarios, no material was lost during storage for the wood pellets thus no capital lost. The use of wood pellets has a material loss of $0.5 \%$ per month, therefore losing $\$ 15,500$ per year in degraded material. This can significantly impact the overall cost in the long run when material is stored on site.

\subsection{CONCLUSIONS}

Biomass pelletization is not a significant factor affecting the lignocellulosic sugar extraction. When comparing densified material in the form of wood pellets to its alternate form, ground, non-pelleted particles, the quantity of glucose capable of being recovered based on urea concentration is not significantly different $(\mathrm{p}=0.253)$. Pelletized Owasco contained $162 \mathrm{mg}$ glucose/g biomass, while non-pelletized Owasco had $380 \mathrm{mg}$ glucose/g biomass. Pelletized SV1 contained $485 \mathrm{mg}$ glucose/g biomass and non-pelletized had $481 \mathrm{mg}$ glucose/g biomass. These concentrations were an average across all urea concentrations, since urea concentration was not a significant factor in the extraction of glucose. There is no significant difference between pelleted and non-pelleted SV1 biomass $(\mathrm{p}=0.717)$. There is a difference between pelleted and nonpelleted Owasco biomass $(\mathrm{p}=0.008)$. Greater quantities of glucose were capable of being extracted from pelleted cultivar SV1 than pelleted cultivar Owasco on average across all urea concentrations. 
SV1 contained a lower percentage of total lignin when compared to Owasco, $39.1 \%$ to $50.9 \%$ respectively. SV1 contained $32.5 \%$ and $6.6 \%$ AIL and ASL respectively, while Owasco contained $47.1 \%$ and $3.7 \%$ AIL and ASL respectively. The most significant difference in total lignin quantity was found when comparing both pelletized cultivars. Owasco pellets contained $53.4 \%$ total lignin across all urea concentrations, while SV1 only contained 39.5\% total lignin. There was no significant difference in the quantity of lignin extracted using different urea concentrations $(\mathrm{p}=0.808)$.

There appears to be a significant different in initial costs associated with using pellets as opposed to wood chips for the production of bioproducts. The use of pellets requires a much higher initial capital investment, but a more in-depth analysis should be performed to confirm or reject the feasibility of using wood pellets for the production of sugars. Using wood chips causes $\$ 15,500 /$ year to be lost in material degradation which is saved during the use of pellets. This degradation could cause the consistent long term use of pellets on a first in first out basis to eventually be more economical than wood chips.

\section{REFERENCES}

Agbor VB, Cicek N, Sparling R, Berlin A, Levin DB. 2011. Biomass pretreatment: Fundamentals toward application. Biotechnology advances 29:675-685.

Alvira P, Tomas-Pejo E, Ballesteros M, Negro MJ. 2010. Pretreatment technologies for an efficient bioethanol production process based on enzymatic hydrolysis: A review. Bioresource Technology 101:4851-4861. 
ASTM. 2007. Standard Test Method for Acid-Insoluble Lignin in Wood West Conshohocken, PA: ASTM International

Balan V, et al. 2009. Enzymatic digestibility and pretreatment degradation products of AFEXtreated hardwoods (Populus nigra). Biotechnology Progress 25:365-375.

Balat M. 2011. Production of bioethanol from lignocellulosic materials via the biochemical pathway: a review. Energy conversion and management 52:858-875.

Barr C, Hanson BL, Click K, Perrotta G, Schall C. 2014. Influence of ionic-liquid incubation temperature on changes in cellulose structure, biomass composition, and enzymatic digestibility. Cellulose 21:973-982.

Barry AJ, Peterson FC, King AJ. 1936. x-Ray Studies of Reactions of Cellulose in NonAqueous Systems. I. Interaction of Cellulose and Liquid Ammonia1. Journal of the American Chemical Society 58:333-337.

Bridgwater T. 2006. Biomass for energy. Journal of the Science of Food and Agriculture $86: 1755-1768$.

Brodeur G, Yau E, Badal K, Collier J, Ramachandran K, Ramakrishnan S. 2011. Chemical and physicochemical pretreatment of lignocellulosic biomass: a review. Enzyme research 2011.

Brooks B, Jessup WA, MacArthur BW. 2005. Method of quantitatively producing ammonia from urea: Google Patents

Caymon_Chemical_Company. 2015. Glucose Colorimetric Assay Kit. In: Item No. 10009582

Chow S-Z, Pickles K. 1971. Thermal softening and degradation of wood and bark. Wood and Fiber Science 3:166-178. 
EEA. 2015. Wood Pellet Price Survey http://www.mass.gov/eea/energy-utilities-cleantech/home-heating/wood/wood-dealers-and-prices.html (accessed September 18, 2015) (Type of Medium).

Effland MJ. 1977. Modified procedure to determine acid-insoluble lignin in wood and pulp. Journal Name: Tappi; (United States); Journal Volume: 60:10:Medium: X; Size: Pages: 143-144.

Ehret M, Bühle L, Graß R, Lamersdorf N, Wachendorf M. 2015. Bioenergy provision by an alley cropping system of grassland and shrub willow hybrids: biomass, fuel characteristics and net energy yields. Agroforestry Systems 89:365-381.

EIA. 2012. Annual Energy Outlook 2012 with Projections to 2035. In: Catalogue No. DOE/EIA-0383ER Washington D.C.

EIA. 2015. February 2015 Monthly Energy Review. Washington, DC.

Eisenbies M. 2015. Research Scientist, PhD. Woody Biomass/Forest Soils and Hydrology at SUNY College of Environmental Science and Forestry--personal email.

FPL. 2000. Wood handbook: wood as an engineering material--Laboratory FP, ed.: United States Government Printing. 5.

Galletti AMR, Antonetti C. 2012. 5 Biomass pretreatment: separation of cellulose, hemicellulose, and lignin-existing technologies and perspectives. Biorefinery: From Biomass to Chemicals and Fuels.

Gerhards CC. 1982. Effect of moisture content and temperature on the mechanical properties of wood: an analysis of immediate effects. Wood and fiber 14:4-36. 
Grushecky ST, Wang J, McGill DW. 2007. Influence of site characteristics and costs of extraction and trucking on logging residue utilization in southern West Virginia. Forest Products Journal 57:63.

Hartley DS. 2014. Modeling and Optimization of Woody Biomass harvest and Logistics in the Northeastern United States. In: Davis College of Agriculture, Natural Resources and Design Morgantown, WV: West Virginia University. 219

Hill J, Nelson E, Tilman D, Polasky S, Tiffany D. 2006. Environmental, economic, and energetic costs and benefits of biodiesel and ethanol biofuels. Proceedings of the National Academy of Sciences of the United States of America 103:11206-11210.

Himmel ME, et al. 2007. Biomass recalcitrance: engineering plants and enzymes for biofuels production. science 315:804-807.

Hofmann L, Rusch K. 2001. Process for converting urea into ammonia: Google Patents

Hu F, Ragauskas A. 2012. Pretreatment and lignocellulosic chemistry. Bioenerg. Res. 5:10431066.

Huang H-J, Ramaswamy S, Tschirner UW, Ramarao BV. 2008. A review of separation technologies in current and future biorefineries. Separation and Purification Technology 62:1-21.

Imman S, Arnthong J, Burapatana V, Champreda V, Laosiripojana N. 2014. Effects of acid and alkali promoters on compressed liquid hot water pretreatment of rice straw. Bioresource Technology 171:29-36.

Jacob E, Stiermann E. 2006. Device and method for producing ammonia from solid urea pellets: Google Patents

Jones DG. 1998. Method for converting urea to ammonia: Google Patents 
Kaliyan N, Morey RV. 2008. Densification of Biomass: Mechanisms, Models, and Experiments on Briquetting and Pelleting of Biomass: VDM Publishing.

Karimi K, Kheradmandinia S, Taherzadeh MJ. 2006. Conversion of rice straw to sugars by dilute-acid hydrolysis. Biomass and Bioenergy 30:247-253.

King E, Garner R. 1947. The colorimetric determination of glucose. Journal of Clinical Pathology 1:30.

Knorr B. 2015. Weekly Fertilizer Review http://farmfutures.com/story-weekly-fertilizerreview-0-30765 (accessed April 22, 2015) (Type of Medium).

Ko JK, Kim Y, Ximenes E, Ladisch MR. 2015. Effect of liquid hot water pretreatment severity on properties of hardwood lignin and enzymatic hydrolysis of cellulose. Biotechnology and bioengineering 112:252-262.

Kumar P, Barrett DM, Delwiche MJ, Stroeve P. 2009. Methods for Pretreatment of Lignocellulosic Biomass for Efficient Hydrolysis and Biofuel Production. Industrial \& Engineering Chemistry Research 48:3713-3729.

Lagana V. 1999. Combustion flue gas conditioning: Google Patents

Langan P, et al. 2014. Common processes drive the thermochemical pretreatment of lignocellulosic biomass. Green Chemistry 16:63-68.

Limayem A, Ricke SC. 2012. Lignocellulosic biomass for bioethanol production: current perspectives, potential issues and future prospects. Progress in Energy and Combustion Science 38:449-467.

Mani S, Tabil LG, Sokhansanj S. 2006. Effects of compressive force, particle size and moisture content on mechanical properties of biomass pellets from grasses. Biomass and Bioenergy 30:648-654. 
Miller GL. 1959. Use of dinitrosalicylic acid reagent for determination of reducing sugar. Analytical chemistry 31:426-428.

Mittal A, Katahira R, Himmel ME, Johnson DK. 2011. Effects of alkaline or liquid-ammonia treatment on crystalline cellulose: changes in crystalline structure and effects on enzymatic digestibility. Biotechnol Biofuels 4:41.

Mok WSL, Antal Jr MJ. 1992. Uncatalyzed solvolysis of whole biomass hemicellulose by hot compressed liquid water. Industrial \& Engineering Chemistry Research 31:1157-1161.

Mosier N, et al. 2005. Features of promising technologies for pretreatment of lignocellulosic biomass. Bioresource Technology 96:673-686.

Nielsen NPK, Poulsen T, Felby C. 2009. Importance of Temperature, Moisture Content, and Species for the Conversion Process of Wood Residues into Fuel Pellets. Wood and Fiber Science 41:414-425.

Obernberger I, Thek G. 2010. The pellet handbook. Earthscan Ltd.

Pan X, et al. 2006. Bioconversion of hybrid poplar to ethanol and co-products using an organosolv fractionation process: optimization of process yields. Biotechnology and bioengineering 94:851-861.

Rabier, F., Temmerman, M., Böhm, T., Hartmann, H., Jensen, P.D., Rathbauer, J., Carrasco, J. and Fernández, M., 2006. Particle density determination of pellets and briquettes. Biomass and Bioenergy, 30(11), pp.954-963.

Rogalinski T, Ingram T, Brunner G. 2008. Hydrolysis of lignocellulosic biomass in water under elevated temperatures and pressures. The Journal of Supercritical Fluids 47:54-63.

Rushton A, Ward AS, Holdich RG. 2008. Solid-liquid filtration and separation technology: John Wiley \& Sons. 
Sahu JN, Mahalik K, Patwardhan AV, Meikap BC. 2008. Equilibrium and Kinetic Studies on the Hydrolysis of Urea for Ammonia Generation in a Semibatch Reactor. Industrial \& Engineering Chemistry Research 47:4689-4696.

Salvi D, Aita G, Robert D, Bazan V. 2010. Dilute Ammonia Pretreatment of Sorghum and Its Effectiveness on Enzyme Hydrolysis and Ethanol Fermentation. Applied biochemistry and biotechnology 161:67-74.

Samson R, Duxbury P, Drisdelle M, Lapointe C. 2000. Assessment of pelletized biofuels. Publication at: http://www. reap-canada. com/Reports/pelletaug2000. html.

Serapiglia M, Cameron K, Stipanovic A, Smart L. 2009. Analysis of Biomass Composition Using High-Resolution Thermogravimetric Analysis and Percent Bark Content for the Selection of Shrub Willow Bioenergy Crop Varieties. Bioenerg. Res. 2:1-9.

Serapiglia MJ, Cameron KD, Stipanovic AJ, Abrahamson LP, Volk TA, Smart LB. 2012. Yield and woody biomass traits of novel shrub willow hybrids at two contrasting sites. Bioenerg. Res. 6:533-546.

Serapiglia MJ, et al. 2013. Enzymatic saccharification of shrub willow genotypes with differing biomass composition for biofuel production. Frontiers in plant science 4 .

Sissine F. 2007. Energy Independence and Security Act of 2007: a summary of major provisions: DTIC Document

Sluiter A, et al. 2012. Determination of structural carbohydrates and lignin in biomass. Laboratory analytical procedure.

Stelte W. 2015. Optimization of product specific processing parameters for the production of fuel pellets from torrefied biomass. 
Stelte W, Holm JK, Sanadi AR, Barsberg S, Ahrenfeldt J, Henriksen UB. 2011. Fuel pellets from biomass: The importance of the pelletizing pressure and its dependency on the processing conditions. Fuel 90:3285-3290.

Sun Y, Cheng J. 2002. Hydrolysis of lignocellulosic materials for ethanol production: a review. Bioresource Technology 83:1-11.

Tappi. 2002. Acid-insoluble lignin in wood and pulp. In: T222 om-02: Tappi Standard

Thygesen A, Oddershede J, Lilholt H, Thomsen AB, Ståhl K. 2005. On the determination of crystallinity and cellulose content in plant fibres. Cellulose 12:563-576.

Timung R, Mohan M, Chilukoti B, Sasmal S, Banerjee T, Goud VV. 2015. Optimization of dilute acid and hot water pretreatment of different lignocellulosic biomass: A comparative study. Biomass and Bioenergy 81:9-18.

Wang NS. 2005. Experiment no. 4A, Glucose assay by dinitrosalicylic colorimetric method: Retrieved 14/5-2005 from the University of Maryland, Department of Chemical Engineering

Xiao L-P, Sun Z-J, Shi Z-J, Xu F, Sun R-C. 2011. Impact of hot compressed water pretreatment on the structural changes of woody biomass for bioethanol production. BioResources 6:1576-1598.

Yasuda S, Fukushima K, Kakehi A. 2001. Formation and chemical structures of acid-soluble lignin I: sulfuric acid treatment time and acid-soluble lignin content of hardwood. J Wood Sci 47:69-72.

Yu Y, Lou X, Wu H. 2008. Some recent advances in hydrolysis of biomass in hot-compressed water and its comparisons with other hydrolysis methods $\dagger$. Energy \& Fuels 22:46-60. 
Yu Y, Wu H. 2011. Effect of ball milling on the hydrolysis of microcrystalline cellulose in hotcompressed water. AIChE Journal 57:793-800.

Zhang Y-HP, Himmel ME, Mielenz JR. 2006. Outlook for cellulase improvement: screening and selection strategies. Biotechnology advances 24:452-481.

Zhao X, Cheng K, Liu D. 2009. Organosolv pretreatment of lignocellulosic biomass for enzymatic hydrolysis. Applied Microbiology and Biotechnology 82:815-827.

Zhu JY, Pan X, Zalesny RS, Jr. 2010. Pretreatment of woody biomass for biofuel production: energy efficiency, technologies, and recalcitrance. Applied microbiology and biotechnology 87:847-857.

Zhu JY, Pan XJ. 2010. Woody biomass pretreatment for cellulosic ethanol production: Technology and energy consumption evaluation. Bioresource Technology 101:49925002. 


\section{SUMMARY}

The research performed in this study applied urea as an additive to a hot water pretreatment for the extraction of sugars, analyzing the efficiencies of filtration, the effects of process parameters, species, and densification. Based on the results from the urea pretreatments and the analysis of glucose, the following conclusions can be drawn:

(1) The filtration method necessary for recovering the greatest quantity of glucose from woody biomass is insignificant at low levels of urea $(<10 \% \mathrm{w} / \mathrm{w})$. When greater urea concentrations are reached $(>10 \% \mathrm{w} / \mathrm{w})$, the method of filtration significantly affects the ability to recover glucose separated during the initial pretreatment. A centrifuge proves to be the least effective method of filtration, followed by Whatman 113 filter paper, with the best filtration method determined to be a stainless steel mesh screen. The urea reacts with the cellulose in the Whatman filter paper, thus swelling the fibers and restricting the pores in which the liquid is to pass through. Centrifugation does not efficiently separate the solid and liquid fractions, leaving a slurry zone in which sugars can be lost when the liquid is decanted.

(2) When urea pretreatment conditions were optimized for the greatest extraction of sugars, temperature and holding time were determined to be insignificant factors. Urea concentration was the most significant factor and first and second order terms were used for optimization. The optimal conditions were found to be $170^{\circ} \mathrm{C}$, a holding time of 60 minutes, and a urea concentration at $13.27 \%(\mathrm{w} / \mathrm{w})$. These conditions allowed for the recovery of $1.1 \mathrm{~g}$ glucose $/ \mathrm{g}$ biomass. There was no significant difference in the quantity of glucose recovered between the $13 \%, 13.27 \%$, and $15 \%$ urea concentration levels, allowing for a range of urea concentrations to considered optimal. 
(3) The optimized conditions determined from red oak biomass were most suited for the extraction of glucose from hybrid willow biomass: temperature $170^{\circ} \mathrm{C}$, holding time 60 minutes and urea concentration $13.27 \%(\mathrm{w} / \mathrm{w})$. Two cultivars of hybrid willow were compared for sugar recovery (grams glucose per gram biomass) following a urea pretreatment with cultivar SV1 producing $0.39 \mathrm{~g} / \mathrm{g}$ while cultivar Owasco produced $0.34 \mathrm{~g} / \mathrm{g}$. There was also no significant difference in the quantity of glucose extracted from cultivar SV1 based on urea concentration (p $=0.391)$, nor based on cultivar $(\mathrm{p}=0.495)$. The total lignin in cultivar SV1 was $38 \%$, while cultivar Owasco contained $45 \%$ lignin. Glucose is extracted from the cellulose and hemicellulose fractions, so if a greater quantity of glucose was produced, there is less lignin available. The quantity of urea did not significantly affect the quantity of lignin extracted from either cultivar, although it did have a significant effect on the quantity of glucose.

(4) The pelletization of hybrid willow biomass was analyzed to determine the effects of densification on the ability to extract sugar from woody biomass. Ground, non-pelletized biomass was used as a baseline using two hybrid willow cultivars: SV1 and Owasco. The quantity of glucose capable of being recovered per gram biomass before and after pelletization is not significantly different based on urea concentration $(\mathrm{p}=0.253)$. Pelletized SV1 contained $0.49 \mathrm{~g} / \mathrm{g}$ while non-pelletized SV1 contained $0.48 \mathrm{~g} / \mathrm{g}$. Pelletized Owasco contained $162 \mathrm{mg} / \mathrm{g}$ and non-pelletized Owasco contained $0.38 \mathrm{~g} / \mathrm{g}$. Although there was no significant difference between pelletized/non-pelletized glucose recovery in cultivar SV1, there was a significant difference in the amount of glucose extracted between cultivars. SV1 consistently produced greater quantities of glucose than Owasco. The quantity of total lignin determined in Owasco pellets was $53 \%$, while SV1 contained $40 \%$. There was no significant difference in the quantity of lignin extracted based on urea concentration. 